\title{
AGR-2 Fuel Compact Pre-Irradiation Characterization Summary Report
}

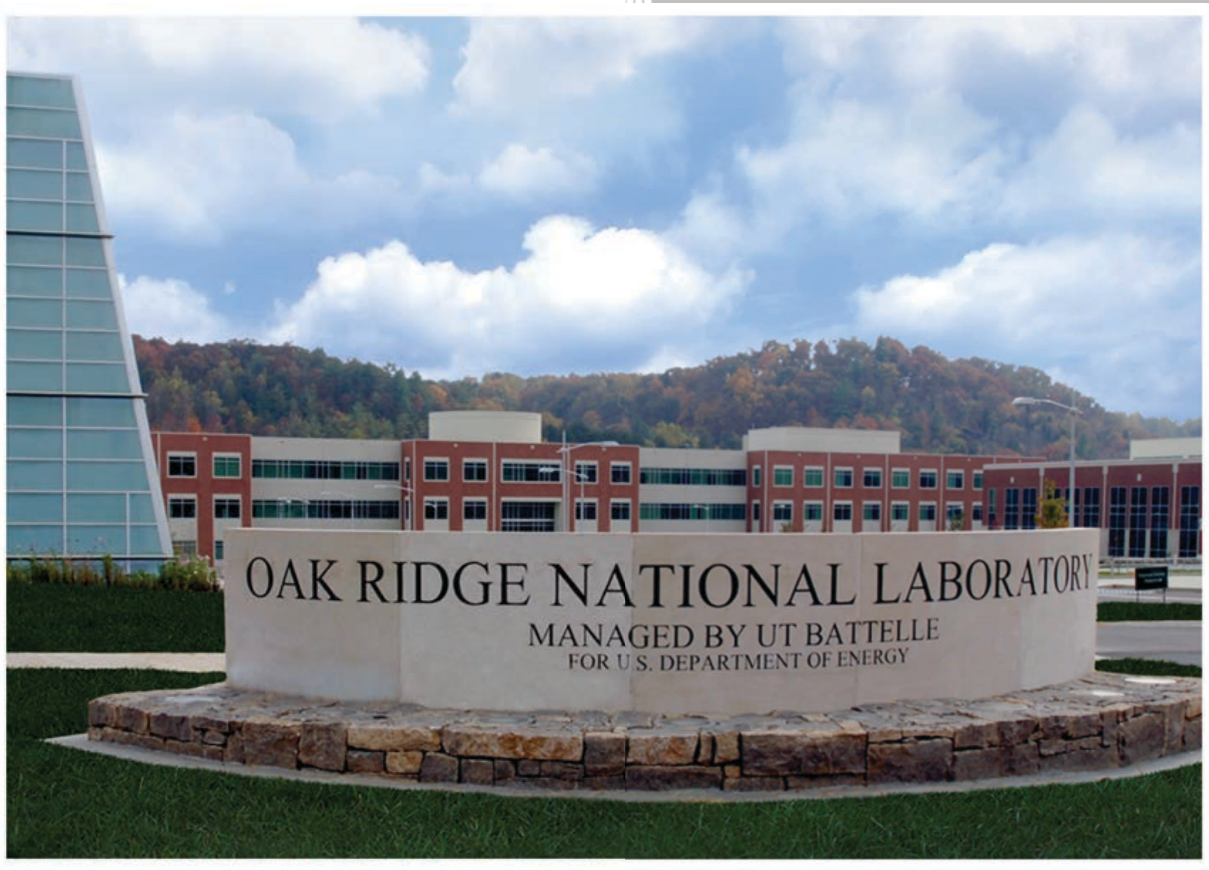

Approved for public release.

John D. Hunn

Traig W. Savage

G.W. Chinthaka Silva

Distribution is unlimited. 


\title{
DOCUMENT AVAILABILITY
}

Reports produced after January 1, 1996, are generally available free via US Department of Energy (DOE) SciTech Connect.

Website http://www.osti.gov/scitech/

Reports produced before January 1, 1996, may be purchased by members of the public from the following source:

\author{
National Technical Information Service \\ 5285 Port Royal Road \\ Springfield, VA 22161 \\ Telephone 703-605-6000 (1-800-553-6847) \\ TDD 703-487-4639 \\ Fax 703-605-6900 \\ E-mail info@ntis.gov \\ Website http://www.ntis.gov/help/ordermethods.aspx
}

Reports are available to DOE employees, DOE contractors, Energy Technology Data Exchange representatives, and International Nuclear Information System representatives from the following source:

Office of Scientific and Technical Information

PO Box 62

Oak Ridge, TN 37831

Telephone 865-576-8401

Fax 865-576-5728

E-mail reports@osti.gov

Website http://www.osti.gov/contact.html

This report was prepared as an account of work sponsored by an agency of the United States Government. Neither the United States Government nor any agency thereof, nor any of their employees, makes any warranty, express or implied, or assumes any legal liability or responsibility for the accuracy, completeness, or usefulness of any information, apparatus, product, or process disclosed, or represents that its use would not infringe privately owned rights. Reference herein to any specific commercial product, process, or service by trade name, trademark, manufacturer, or otherwise, does not necessarily constitute or imply its endorsement, recommendation, or favoring by the United States Government or any agency thereof. The views and opinions of authors expressed herein do not necessarily state or reflect those of the United States Government or any agency thereof. 


\title{
AGR-2 Fuel Compact \\ Pre-Irradiation Characterization Summary Report
}

\author{
John D. Hunn, Traig W. Savage, \\ and G.W. Chinthaka Silva
}

\section{Revision 1}

November 2010

\begin{abstract}
Work sponsored by
US DEPARTMENT OF ENERGY

Office of Nuclear Energy

under the
\end{abstract}

Advanced Gas Reactor Fuel Development and Qualification Program

Prepared by

OAK RIDGE NATIONAL LABORATORY

Oak Ridge, TN 37831-6283

managed by

UT-BATTELLE, LLC

for the

US DEPARTMENT OF ENERGY

under contract DE-AC05-000R22725 



\title{
AGR-2 Fuel Compact \\ Pre-Irradiation Characterization Summary Report
}

\author{
John D. Hunn, Traig W. Savage, and G.W. Chinthaka Silva
}

\section{Introduction}

This document is a summary of pre-irradiation characterization data for four of the compact lots used in the Department of Energy's Office of Nuclear Energy (DOE-NE) Advanced Gas Reactor Fuel Development and Qualification (AGR) program second irradiation test, AGR-2. Kernels and coated particles were produced by Babcock and Wilcox (B\&W) in Lynchburg Virginia. Compacts were fabricated and characterized at Oak Ridge National Laboratory (ORNL).

The AGR-2 compacts contained two types of fuel kernels. Uranium oxide $\left(\mathrm{UO}_{2}\right)$ fuel kernels with a nominal diameter of $500 \mu \mathrm{m}$ and mixed uranium oxide/uranium carbide (UCO) fuel kernels with a nominal diameter of $425 \mu \mathrm{m}$. The UCO kernels were identified as composite G73I-14-69307. The $\mathrm{UO}_{2}$ kernels were identified as composite G73AA-10-69308.

The fuel kernels were coated with a tristructural-isotropic (TRISO) coating in a $150 \mathrm{~mm}$ diameter fluidized bed chemical vapor deposition (CVD) coating furnace at B\&W. The TRISO-coated particles consisted of a spherical kernel coated with an approximately 50\% dense carbon buffer layer (100 $\mu \mathrm{m}$ nominal thickness), followed by a dense inner pyrocarbon layer ( $40 \mu \mathrm{m}$ nominal thickness), followed by a SiC layer (35 $\mu \mathrm{m}$ nominal thickness), followed by another dense outer pyrocarbon layer ( $40 \mu \mathrm{m}$ nominal thickness).

The TRISO-coated particles were shipped to ORNL to be fabricated into the final fuel form. Particles were overcoated in a resinated graphite powder and then these overcoated particles were pressed into cylindrical compacts. This report includes characterization data for four compact lots: AGR-2 UCO Variant fuel compact lot LEU06-OP1-Z, AGR-2 UCO Baseline fuel compact lot LEU07-0P1-Z, AGR-2 UCO Variant fuel compact lot LEU09-0P2-Z, and AGR-2 $\mathrm{B} \& \mathrm{~W} \mathrm{UO} 2$ fuel compact lot LEU11-OP2-Z.

LEU06-0P1-Z was a compact lot fabricated using particle sample LEU06. LEU06 came from B\&W coated particle lot G73J-14-93074A, which was an upgraded batch of TRISOcoated $425 \mu \mathrm{m}$ diameter, 14\% low enriched uranium oxide/uranium carbide kernels (LEUCO). LEU07-OP1-Z was a compact lot fabricated using particle sample LEU07. LEU07 came from B\&W coated particle lot G73J-14-93072A, which was an upgraded batch of TRISO-coated $425 \mu \mathrm{m}$ diameter, 14\% LEUCO. These two compact lots were fully characterized, but were not used in the AGR-2 irradiation test.

LEU09-0P2-Z was a compact lot fabricated using particle sample LEU09. LEU09 came from B\&W coated particle lot G73J-14-93073A, which was an upgraded batch of TRISOcoated $425 \mu \mathrm{m}$ diameter, 14\% LEUCO. LEU11-OP2-Z was a compact lot fabricated using particle sample LEU11. LEU11 came from B\&W coated particle lot G73H-10-93085B, which was an upgraded batch of TRISO-coated $500 \mu \mathrm{m}$ nominal diameter, 9.6\% low enriched uranium oxide kernels. These two compact lots were fully characterized and were used in the AGR-2 irradiation test. 
Previous data packages prepared for the AGR-2 fuel particles and compacts are listed in Table 1. The compact data packages provide the information for compact acceptance in accordance with the AGR-2 Fuel Specification (INL SPC-923). In addition to the characterization data, each of these reports also contains other records relevant to the fuel product acceptance. A history of the material flow and sample naming is included. The overcoating and compacting process is summarized, and a record of the materials used to make the matrix is provided. A Certificate of Conformance and any applicable Nonconformance Reports are also attached. The ORNL particle data packages provide only limited information on the coated particle batches, including PyC anisotropy, average particle weight, OPyC open porosity, and SiC soot inclusion defect fraction. The bulk of the kernel and coated particle acceptance testing was performed at B\&W and is not contained in these reports. Some additional particle data is included in the compact data packages, such as particle diameter, average particle weight, average particle volume, OPyC open porosity, and average uranium content.

This report summarizes the data available in detail in the reports listed in Table 1 . In addition, optical and x-ray imaging has been performed and those images are attached to this report as appendices. X-ray radiographs and optical images of the surfaces were obtained for 12 archive compacts from each compact lot. Optical images of lateral and longitudinal polished cross-sections were also obtained using randomly selected compacts from each archive set.

Table 1. ORNL data packages for AGR-2 fuel particles and compacts

\begin{tabular}{|l|l|l|}
\hline \multicolumn{2}{|l|}{ Particles } & \multicolumn{2}{|l|}{ Rample ID } & Report Number & Report Title \\
\hline 93071A & ORNL/TM-2008/132 & $\begin{array}{l}\text { Data Compilation for AGR-2 Baseline Coated } \\
\text { Particle Batch G73J-14-93071A }\end{array}$ \\
\hline LEU06 & ORNL/TM-2008/135 & $\begin{array}{l}\text { Data Compilation for AGR-2 UCO Variant Coated } \\
\text { Particle Batch G73J-14-93074A }\end{array}$ \\
\hline LEU09 & ORNL/TM-2008/134 & $\begin{array}{l}\text { Data Compilation for AGR-2 UCO Variant Coated } \\
\text { Particle Batch G73J-14-93073A }\end{array}$ \\
\hline LEU11 & ORNL/TM-2009/255 & $\begin{array}{l}\text { Data Compilation for AGR-2 UO Coated Particle } \\
\text { Batch G73H-10-93085B }\end{array}$ \\
\hline Compacts & \multicolumn{2}{|l|}{ Reporticle Batch G73J-14-93072A } \\
\hline Sample ID & Report Number & Report Title \\
\hline LEU06-OP1-Z & ORNL/TM-2009/304 & $\begin{array}{l}\text { Data Compilation for AGR-2 UCO Variant Compact } \\
\text { Lot LEU06-OP1-Z }\end{array}$ \\
\hline LEU07-OP1-Z & ORNL/TM-2009/305 & $\begin{array}{l}\text { Data Compilation for AGR-2 UCO Baseline } \\
\text { Compact Lot LEU07-OP1-Z }\end{array}$ \\
\hline LEU09-OP2-Z & ORNL/TM-2010/017 & $\begin{array}{l}\text { Data Compilation for AGR-2 UCO Variant Compact } \\
\text { Lot LEU09-OP2-Z }\end{array}$ \\
\hline LEU11-OP2-Z & ORNL/TM-2010/055 & $\begin{array}{l}\text { Data Compilation for AGR-2 B\&W UO Compact } \\
\text { Lot LEU11-OP2-Z }\end{array}$ \\
\hline
\end{tabular}




\section{Table of Contents}

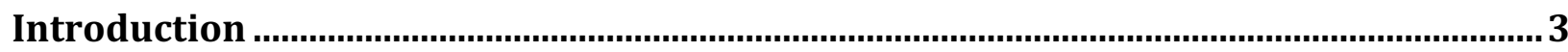

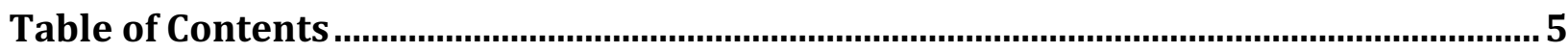

List of Tables

Summary Data Tables ....................................................................................................

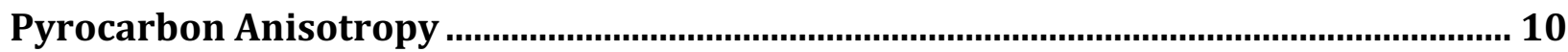

Compact Surface Appearance ....................................................................................... 11

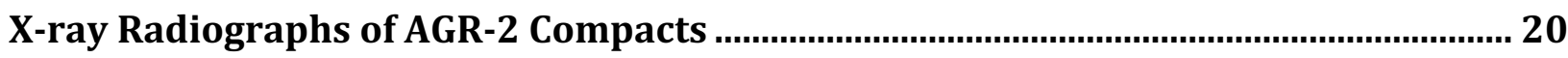

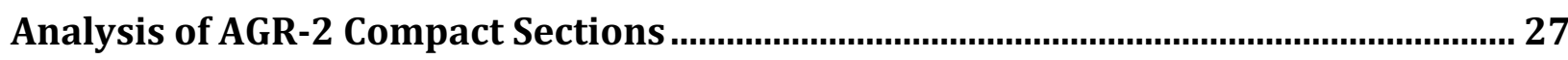

Appendix A - Stereoscope Images of AGR-2 Fuel Compacts .............................................. 33

Appendix B - X-ray Radiographs of AGR-2 Fuel Compacts.................................................. 54

Appendix C - Optical Images of AGR-2 Fuel Compact Sections ............................................65 


\section{List of Tables}

Table 1. ORNL data packages for AGR-2 fuel particles and compacts ..............................................

Table 2. Summary of key properties for AGR-2 fuel compacts ..........................................................

Table 3. Mean impurity levels in $\mu \mathrm{g} /$ compact for AGR-2 fuel compacts ........................................... 8

Table 4. Quick reference table for key attribute properties...............................................................

Table 5. Uranium not contained by $\mathrm{SiC}$ in compacts with intact $\mathrm{SiC}$...............................................

Table 6. Effect of heat-treatment on optical diattenuation of pyrocarbon layer ........................10

Table 7. AGR-2 archive compacts imaged by stereoscope..............................................................11

Table 8. AGR-2 archive compacts imaged by x-ray radiography ……………………………...... 20

Table 9. Properties of AGR-2 overcoating layer prior to compacting............................................ 26

Table 10. AGR-2 archive compacts sectioned and imaged with microscope................................27 


\section{Summary Data Tables}

Table 2 provides a summary of some of the AGR-2 fuel data extracted from the compact data packages. It gives the mean values and standard deviations of key variable properties of the compact lots and associated particle batches. Detailed data report forms associated with the summary data in Table 2 can be found in the associated data packages.

Table 2. Summary of key properties for AGR-2 fuel compacts

\begin{tabular}{|c|c|c|c|c|}
\hline Property & LEU06 & LEU07 & LEU09 & LEU11 \\
\hline Mean particle diameter $(\mu \mathrm{m})$ & $\begin{array}{c}874.7 \\
(22)\end{array}$ & $\begin{array}{c}861.8 \\
(24) \\
\end{array}$ & $\begin{array}{c}873.2 \\
(23)\end{array}$ & $\begin{array}{l}953.0 \\
(28) \\
\end{array}$ \\
\hline Mean particle volume $\left(\mathrm{cm}^{3}\right)$ & $3.46 \mathrm{E}-4$ & $3.29 \mathrm{E}-4$ & $3.43 E-4$ & $4.45 \mathrm{E}-4$ \\
\hline Mean particle weight (g) & $\begin{array}{l}1.036 \mathrm{E}-3 \\
(2 \mathrm{E}-6)\end{array}$ & $\begin{array}{c}1.004 \mathrm{E}-3 \\
(5 \mathrm{E}-6)\end{array}$ & $\begin{array}{c}1.032 \mathrm{E}-3 \\
(3 \mathrm{E}-6)\end{array}$ & $\begin{array}{c}1.462 \mathrm{E}-3 \\
(5 \mathrm{E}-6)\end{array}$ \\
\hline Mean uranium per particle ( $\mathrm{g} \mathrm{U}$ ) & $\begin{array}{c}3.95 \mathrm{E}-4 \\
(2 \mathrm{E}-6)\end{array}$ & $\begin{array}{l}3.93 \mathrm{E}-4 \\
(1 \mathrm{E}-6)\end{array}$ & $\begin{array}{c}3.96 \mathrm{E}-4 \\
(1 \mathrm{E}-6)\end{array}$ & $\begin{array}{c}6.39 \mathrm{E}-4 \\
(1 \mathrm{E}-6)\end{array}$ \\
\hline Average number of particles/compact & 3186 & 3177 & 3176 & 1543 \\
\hline Mean uranium per compact (g U) & $\begin{array}{c}1.256 \\
(0.002)\end{array}$ & $\begin{array}{c}1.251 \\
(0.005)\end{array}$ & $\begin{array}{c}1.257 \\
(0.003)\end{array}$ & $\begin{array}{c}0.993 \\
(0.006)\end{array}$ \\
\hline $\begin{array}{c}\text { \% packing fraction } \\
\text { (particle volume / compact volume) }\end{array}$ & $\begin{array}{l}37.08 \\
(0.15) \\
\end{array}$ & $\begin{array}{l}35.09 \\
(0.12) \\
\end{array}$ & $\begin{array}{l}36.81 \\
(0.05) \\
\end{array}$ & $\begin{array}{l}23.46 \\
(0.04) \\
\end{array}$ \\
\hline Mean compact diameter (mm) & $\begin{array}{c}12.29 \\
(0.011)\end{array}$ & $\begin{array}{c}12.32 \\
(0.007)\end{array}$ & $\begin{array}{c}12.29 \\
(0.004)\end{array}$ & $\begin{array}{c}12.27 \\
(0.008)\end{array}$ \\
\hline Mean compact length (mm) & $\begin{array}{l}25.18 \\
(0.09)\end{array}$ & $\begin{array}{l}25.19 \\
(0.07)\end{array}$ & $\begin{array}{l}25.14 \\
(0.02)\end{array}$ & $\begin{array}{l}25.13 \\
(0.02)\end{array}$ \\
\hline Mean compact mass (g) & $\begin{array}{c}6.254 \\
(0.011)\end{array}$ & $\begin{array}{c}6.346 \\
(0.008)\end{array}$ & $\begin{array}{c}6.295 \\
(0.012)\end{array}$ & $\begin{array}{c}6.100 \\
(0.017)\end{array}$ \\
\hline Mean compact matrix density $\left(\mathrm{g} / \mathrm{cm}^{3}\right)$ & $\begin{array}{c}1.56 \\
(0.012)\end{array}$ & $\begin{array}{c}1.61 \\
(0.008)\end{array}$ & $\begin{array}{c}1.59 \\
(0.005)\end{array}$ & $\begin{array}{c}1.68 \\
(0.008)\end{array}$ \\
\hline
\end{tabular}

Values in parentheses are standard deviations

Table 3 summarizes impurity data for the AGR-2 fuel compacts. This data was obtained by leach-burn-leach (LBL) followed by inductively coupled plasma mass spectrometry analysis of the nitric acid leach solutions. The table shows the possible range for the mean value of the measured impurities, where the upper limit is the as-reported mean and the lower limit is the possible minimum value calculated by accounting for the fact that the analytical mass spectrometer measurements reported as threshold values could have been as low as zero. This range reflects the uncertainty in the measured impurity values due to the mass spectrometry measurement thresholds. 
Table 3. Mean impurity levels in $\mu \mathrm{g} /$ compact for AGR-2 fuel compacts

\begin{tabular}{|c|c|c|c|c|}
\hline Impurity & LEU06 & LEU07 & LEU09 & LEU11 \\
\hline Iron & $1.43-4.86$ & $0.70-4.78$ & $0.51-4.04$ & $0.13-2.75$ \\
\hline Chromium & $0.30-0.64$ & $0.37-0.59$ & $0.46-0.61$ & $0.34-0.48$ \\
\hline Manganese & $0.31-0.84$ & $0.00-0.20$ & $0.000-0.136$ & $0.000-0.133$ \\
\hline Cobalt & $0.00-0.26$ & $0.00-0.16$ & $0.000-1.115$ & $0.000-0.113$ \\
\hline Nickel & $0.00-1.28$ & $0.02-0.84$ & $0.38-0.96$ & $0.02-0.59$ \\
\hline Calcium & $39.23-40.78$ & $30.35-36.05$ & $36.20-39.34$ & $34.29-35.16$ \\
\hline Aluminum & $31.37-31.48$ & $30.01-30.08$ & $29.60-29.60$ & 42.69 \\
\hline Titanium & $7.77-9.12$ & $2.17-3.05$ & $2.20-2.81$ & $2.76-3.31$ \\
\hline Vanadium & $20.06-20.37$ & $18.01-18.23$ & $16.94-17.09$ & $15.27-15.41$ \\
\hline
\end{tabular}

Table 4 is a summary of the measured defect fractions for AGR-2 fuel compacts. Listed in the table are the actual numbers of defects observed for the numbers of particles analyzed. In parentheses are the binomial distribution calculated upper limits of the $95 \%$ confidence interval on the various defect fractions. In other words, these values are the lowest tolerance limits for which the compact lot would be deemed acceptable at 95\% confidence, based on the particular sample that was measured. In many cases zero defects were observed. The defect fractions listed in the table for these cases are limited by the number of particles measured. The actual defect fraction could be much lower.

Table 4. Quick reference table for key attribute properties

\begin{tabular}{|c|c|c|c|c|}
\hline Defect Property & LEU06 & LEU07 & LEU09 & LEU11 \\
\hline \multirow{2}{*}{ Exposed kernel fraction } & $10 / 127448$ & $15 / 317690$ & $3 / 317625$ & $3 / 246840$ \\
& $(\leq 1.4 \mathrm{E}-4)$ & $(\leq 7.3 \mathrm{E}-5)$ & $(\leq 2.5 \mathrm{E}-5)$ & $(\leq 3.2 \mathrm{E}-5)$ \\
\hline \multirow{2}{*}{ Defective SiC coating fraction } & $0 / 127448$ & $0 / 190614$ & $0 / 254100$ & $0 / 123420$ \\
& $(\leq 2.4 \mathrm{E}-5)$ & $(\leq 1.6 \mathrm{E}-5)$ & $(\leq 1.2 \mathrm{E}-5)$ & $(\leq 2.5 \mathrm{E}-5)$ \\
\hline \multirow{2}{*}{ Defective IPyC coating fraction } & $0 / 63724$ & $443 / 63538$ & $0 / 63525$ & $1 / 61710$ \\
& $(\leq 4.8 \mathrm{E}-5)$ & $(\leq 7.6 \mathrm{E}-3)$ & $(\leq 4.8 \mathrm{E}-5)$ & $(\leq 7.7 \mathrm{E}-5)$ \\
\hline \multirow{2}{*}{ Defective OPyC coating fraction } & $0 / 3186$ & $0 / 3177$ & $0 / 3176$ & $0 / 1543$ \\
& $(\leq 9.4 \mathrm{E}-4)$ & $(\leq 9.5 \mathrm{E}-4)$ & $(\leq 9.5 \mathrm{E}-4)$ & $(\leq 2.0 \mathrm{E}-3)$ \\
\hline
\end{tabular}

Values in parentheses are $95 \%$ confidence limits.

Exposed kernel defects are those kernels that are not protected by any coating layer, which can be due to fracture of the TRISO coating during particle handling operations or coating damage during compacting. The fraction of exposed kernels is determined from the dissolved uranium in the pre-burn leach solutions during deconsolidation-LBL analysis. Particles with $\mathrm{SiC}$ coating defects are particles whose kernels become exposed only after removal of exposed carbon during the burn step of the LBL analysis. This can indicate porous or cracked $\mathrm{SiC}$ layers that may not retain fission products during reactor operation. The fraction of particles with $\mathrm{SiC}$ coating defects is determined from the dissolved uranium in the post-burn leach solutions. Particles with defective IPyC coatings are particles that 
allow unacceptable chlorine intrusion through the IPyC layer during SiC deposition. When particles are at an elevated temperature during coating and compacting, chlorine in the buffer layer can react with uranium in the kernel, causing it to migrate out of the kernel. Particles with defective IPyC coatings are detected by using x-ray imaging to look for excessive uranium dispersion in the buffer layer of particles deconsolidated from compacts. Particles with OPyC coating defects are particles that exhibit missing or damaged outer pyrocarbon, a condition that can occur during particle handling or compacting. The fraction of particles with defective $\mathrm{OPyC}$ is determined by visual inspection of particles deconsolidated from compacts.

The AGR-2 Fuel Specification (INL SPC-923) included a requirement for a uranium contamination fraction (grams exposed $U$ per grams $U$ in compact) of $\leq 2 \mathrm{E}-5$ at $95 \%$ confidence. Uranium contamination is defined as uranium that is not encapsulated by a fission gas retentive coating layer. It is determined from analysis of the first series of acid leach solutions obtained by LBL (before the burn) and includes any exposed kernels, uranium in the compact's graphite matrix, and uranium near the surface of the TRISO particles. For AGR-2 compacts, the total uranium contamination fraction was dominated by the exposed kernel fraction described above. The relatively high fractions of particles with exposed kernels reported in Table 4 was determined to most likely have occurred at B\&W during removal of the particles from the coating furnace via a suction transfer system. Compact lots LEU06-0P1-Z and LEU07-0P1-Z were rejected primarily because of these defects (LEU07 also had an unacceptable fraction of particles with defective IPyC). The uranium contamination fractions for LEU09-0P2-Z and LEU11-0P2-Z were also above the specified limit at 95\% confidence, but these compacts were dispositioned as acceptable for use in the irradiation. This disposition was partially justified by the fact that the actual measured defect fractions were less than 2E-5 and analysis of a larger sample size may have eventually provided data that would satisfy the specification at $95 \%$ confidence.

Improvements in the particle handling systems have been made at $B \& W$ as a result of the lessons learned from the AGR-2 fuel fabrication campaign. Future exposed kernel fractions are expected to be significantly reduced from the levels reported in Table 4 . In the LBL analysis, compacts were inspected in sets of five compacts each. It is useful to consider the results from the sample sets that did not contain compacts with exposed kernel defects. The total amount of uranium not contained by SiC can be determined by analyzing all the acid leach solutions obtained by LBL (both before and after the burn). Table 5 summarizes this analysis for only those fuel compact sets with no exposed kernels or defective SiC. This provides a measure of the uranium contamination in the outer pyrocarbon and graphite matrix.

Table 5. Uranium not contained by SiC in compacts with intact SiC

\begin{tabular}{|c|c|c|c|c|}
\hline Defect Property & LEU06 & LEU07 & LEU09 & LEU11 \\
\hline $\begin{array}{c}\text { Number of compacts analyzed with no } \\
\text { exposed kernels or defective SiC }\end{array}$ & 10 & 20 & 65 & 75 \\
\hline $\begin{array}{c}\text { Total uranium measured by LBL } \\
\text { (gU) }\end{array}$ & $2.90 \mathrm{E}-5$ & $1.05 \mathrm{E}-4$ & $3.22 \mathrm{E}-4$ & $7.19 \mathrm{E}-5$ \\
\hline $\begin{array}{c}\text { Fraction of uranium outside SiC } \\
\text { (gU/gU in compact) }\end{array}$ & $2.31 \mathrm{E}-6$ & $4.19 \mathrm{E}-6$ & $3.94 \mathrm{E}-6$ & $9.66 \mathrm{E}-7$ \\
\hline
\end{tabular}




\section{Pyrocarbon Anisotropy}

The anisotropy of the pyrocarbon layers was measured before and after compacting using the Two-Modulator Generalized Ellipsometry Microscope (2-MGEM). Table 6 lists the average diattenuation measured on 10 particles from each of the four AGR-2 fuel batches. Provided in parentheses in Table 6 are the corresponding values for average optical Bacon anisotropy factor (BAFo), calculated from the diattenuation $(\mathrm{N})$ as BAFo $=(1+\mathrm{N}) /(1-\mathrm{N})$. The diattenuation increased by $27-41 \%$ for the IPyC and by $59-67 \%$ for the OPyC. This was caused by the 1 hour, $1800^{\circ} \mathrm{C}$ heat-treatment of the compacts. The effect on pyrocarbon anisotropy and density of heat-treatment during $\mathrm{SiC}$ deposition and compacting has been studied and reported by Hunn, Jellison, and Lowden ${ }^{1}$.

Table 6. Effect of heat-treatment on optical diattenuation of pyrocarbon layer

\begin{tabular}{|c|c|c|c|c|}
\hline & Sample ID & As-Coated & After Compacting & \% Change \\
\hline \multirow{6}{*}{ IPyC } & LEU06 & $\begin{array}{c}0.0113 \pm 0.0002 \\
(1.0228 \pm 0.0005)\end{array}$ & $\begin{array}{c}0.0145 \pm 0.0008 \\
(1.0295 \pm 0.0017)\end{array}$ & $28 \%$ \\
\cline { 2 - 5 } & \multirow{6}{*}{ LEU07 } & $\begin{array}{c}0.0118 \pm 0.0006 \\
(1.0239 \pm 0.0013)\end{array}$ & $\begin{array}{c}0.0150 \pm 0.0006 \\
(1.0305 \pm 0.0013)\end{array}$ & $27 \%$ \\
\cline { 2 - 5 } & \multirow{2}{*}{ LEU09 } & $\begin{array}{c}0.0116 \pm 0.0004 \\
(1.0236 \pm 0.0008)\end{array}$ & $\begin{array}{c}0.0155 \pm 0.0016 \\
(1.0315 \pm 0.0033)\end{array}$ & $34 \%$ \\
\cline { 2 - 5 } & \multirow{2}{*}{ LEU11 } & $\begin{array}{c}0.0111 \pm 0.0009 \\
(1.0225 \pm 0.0019)\end{array}$ & $\begin{array}{c}0.0157 \pm 0.0012 \\
(1.0319 \pm 0.0025)\end{array}$ & $41 \%$ \\
\hline \hline \multirow{6}{*}{ OPyC } & \multirow{2}{*}{ LEU06 } & $\begin{array}{c}0.0083 \pm 0.0005 \\
(1.0167 \pm 0.0010)\end{array}$ & $\begin{array}{c}0.0136 \pm 0.0003 \\
(1.0275 \pm 0.0006)\end{array}$ & $64 \%$ \\
\cline { 2 - 5 } & LEU07 & $\begin{array}{c}0.0081 \pm 0.0003 \\
(1.0163 \pm 0.0006)\end{array}$ & $\begin{array}{c}0.0129 \pm 0.0007 \\
(1.0262 \pm 0.0014)\end{array}$ & $59 \%$ \\
\cline { 2 - 5 } & LEU09 & $\begin{array}{c}0.0088 \pm 0.0004 \\
(1.0177 \pm 0.0008)\end{array}$ & $\begin{array}{c}0.0143 \pm 0.0006 \\
(1.0290 \pm 0.0013)\end{array}$ & $63 \%$ \\
\cline { 2 - 5 } & \multirow{2}{*}{ LEU11 } & $\begin{array}{c}0.0073 \pm 0.0004 \\
(1.0147 \pm 0.0008)\end{array}$ & $\begin{array}{c}0.0122 \pm 0.0005 \\
(1.0246 \pm 0.0011)\end{array}$ & $67 \%$ \\
\hline
\end{tabular}

Average BAFo provided in parentheses.

${ }^{1}$ J.D. Hunn, G.E. Jellison Jr., and R.A. Lowden, “Increase in pyrolytic carbon optical anisotropy and density during processing of coated particle fuel due to heat treatment," J. Nucl. Mater. 374 (2007) 445-452. 


\section{Compact Surface Appearance}

A record of the typical surface appearance of the AGR-2 fuel compacts was obtained using a Leica MZ16 stereo microscope. At the lowest available magnification, two images were required to capture the entire length of each compact. The camera was attached to one viewport and the samples were illuminated using a ring light. The viewing angle was $\sim 15^{\circ}$, so some image distortion is present. Reflection from the ring light appears as two bright lines down the length of the compact. At least 12 compacts from the available archives of each compact lot were imaged. Table 7 lists the ID numbers of the imaged compacts. Appendix A contains images of each compact in Table 7. Example images from each lot are discussed below.

Table 7. AGR-2 archive compacts imaged by stereoscope

\begin{tabular}{|c|c|l|}
\hline Compact Lot & $\begin{array}{c}\text { Number } \\
\text { Imaged }\end{array}$ & \multicolumn{1}{|c|}{ Compact ID Numbers } \\
\hline LEU06-OP1-Z & 16 & $\begin{array}{l}002,004,006,008,009,011,012,017,019,020,021,022, \\
025,026,028,029\end{array}$ \\
\hline LEU07-OP1-Z & 24 & $\begin{array}{l}008,015,016,036,054,063,065,067,071,073,084,089, \\
098,102,109,113,116,126,131,132,137,143,148,151\end{array}$ \\
\hline LEU09-OP2-Z & 12 & $002,004,005,038,057,069,089,102,130,139,158,165$ \\
\hline LEU11-OP2-Z & 12 & $018,045,062,066,074,085,091,136,147,152,186,198$ \\
\hline
\end{tabular}

\section{LEU06-OP1-Z}

Figure 1 and Figure 2 show compact LEU06-OP1-Z019. This was the 37th compact fabricated in the LEU06-OP1-Z campaign and it had a surface appearance that was typical for this compact lot (Appendix A-1). The ends of the compacts were well formed with reasonably sharp edges and no obvious handling damage. The compacts had a slightly mottled appearance that showed the position of the particles just below the surface, perhaps due to some local variation in the matrix density. This mottled appearance was absent at either end due to a thin matrix-only region. These "end caps" were more obvious in the x-ray images discussed in the next section. Some scratches were observed along the length of the compact and probably occurred during ejection from the die. Very minor pitting or pullout could be observed on some compacts, sometimes located at the terminal points of the longitudinal scratches. 


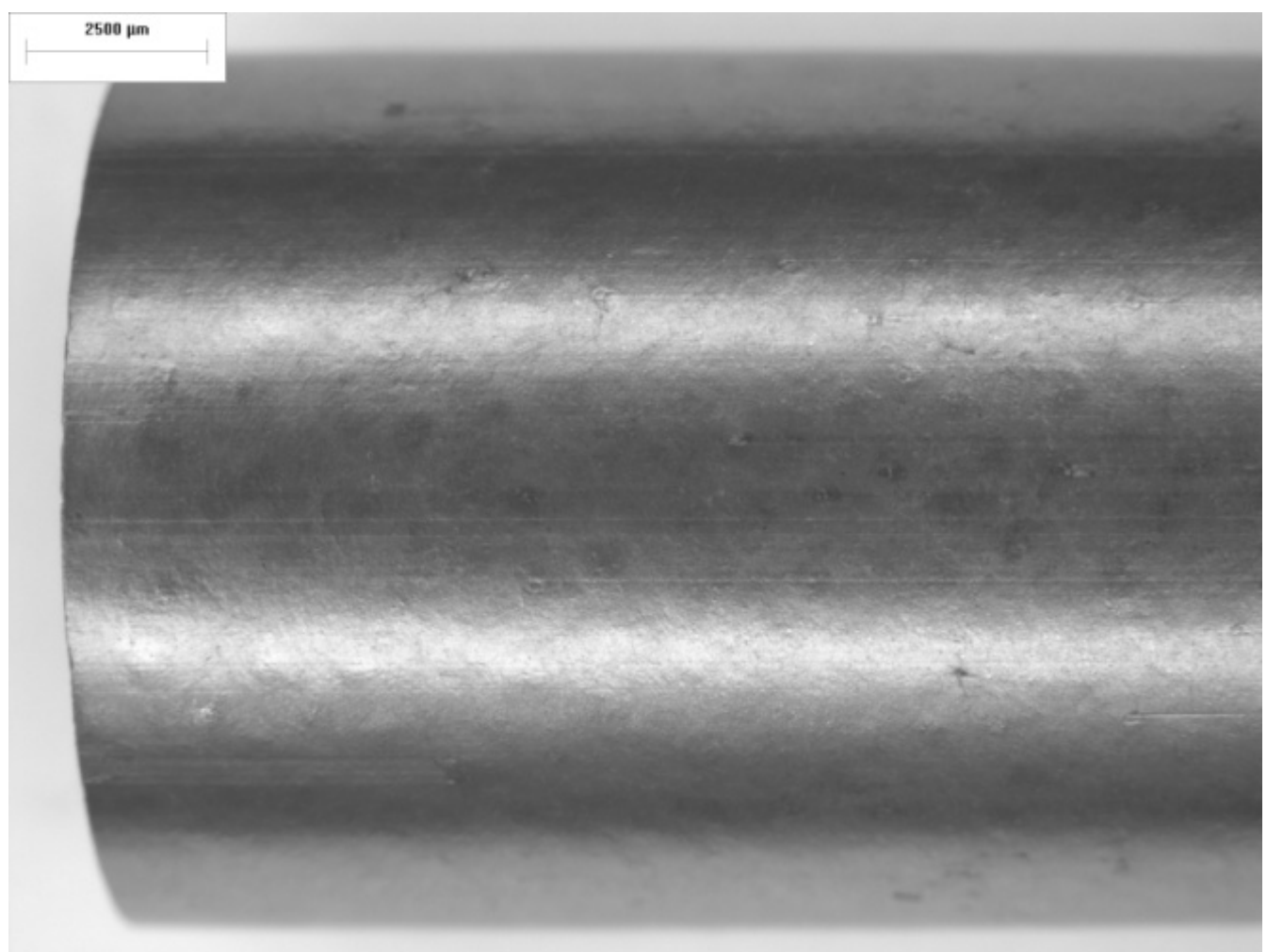

Figure 1. One end of compact LEU06-0P1-Z019.

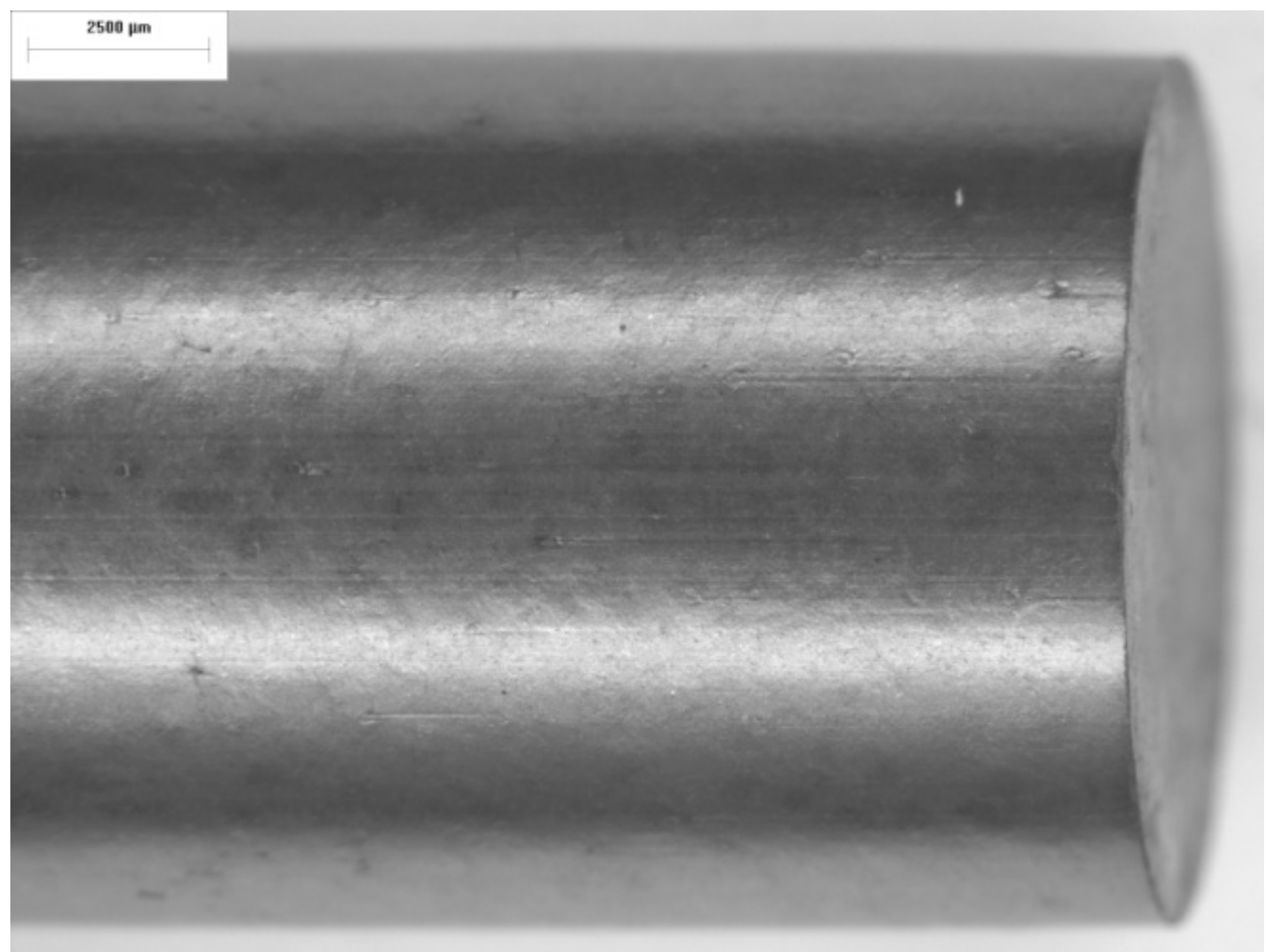

Figure 2. Other end of compact LEU06-0P1-Z019. 


\section{LEU07-OP1-Z}

Figure 3 and Figure 4 show compact LEU07-OP1-Z015. This was the 12th compact fabricated in the LEU07-OP1-Z campaign and it had a surface appearance that was typical for this compact lot (Appendix A-2). The surface appearance of the LEU07-OP1-Z compacts was similar to the LEU06-OP1-Z compact lot discussed above. In addition, some of the compacts had features that appeared to be open regions between adjacent overcoated particles. An example is circled in Figure 4. The reason for these features is not known. The packing fraction for LEU07-OP1-Z was a little lower than LEU06-OP1-Z, due to the smaller particle volume, but the matrix density was slightly higher (Table 2). LEU06-OP1-Z was also compacted at a higher die temperature $\left(95^{\circ} \mathrm{C}\right)$ compared to the other AGR-2 compact lots, which were compacted between $65^{\circ} \mathrm{C}$ and $75^{\circ} \mathrm{C}$.

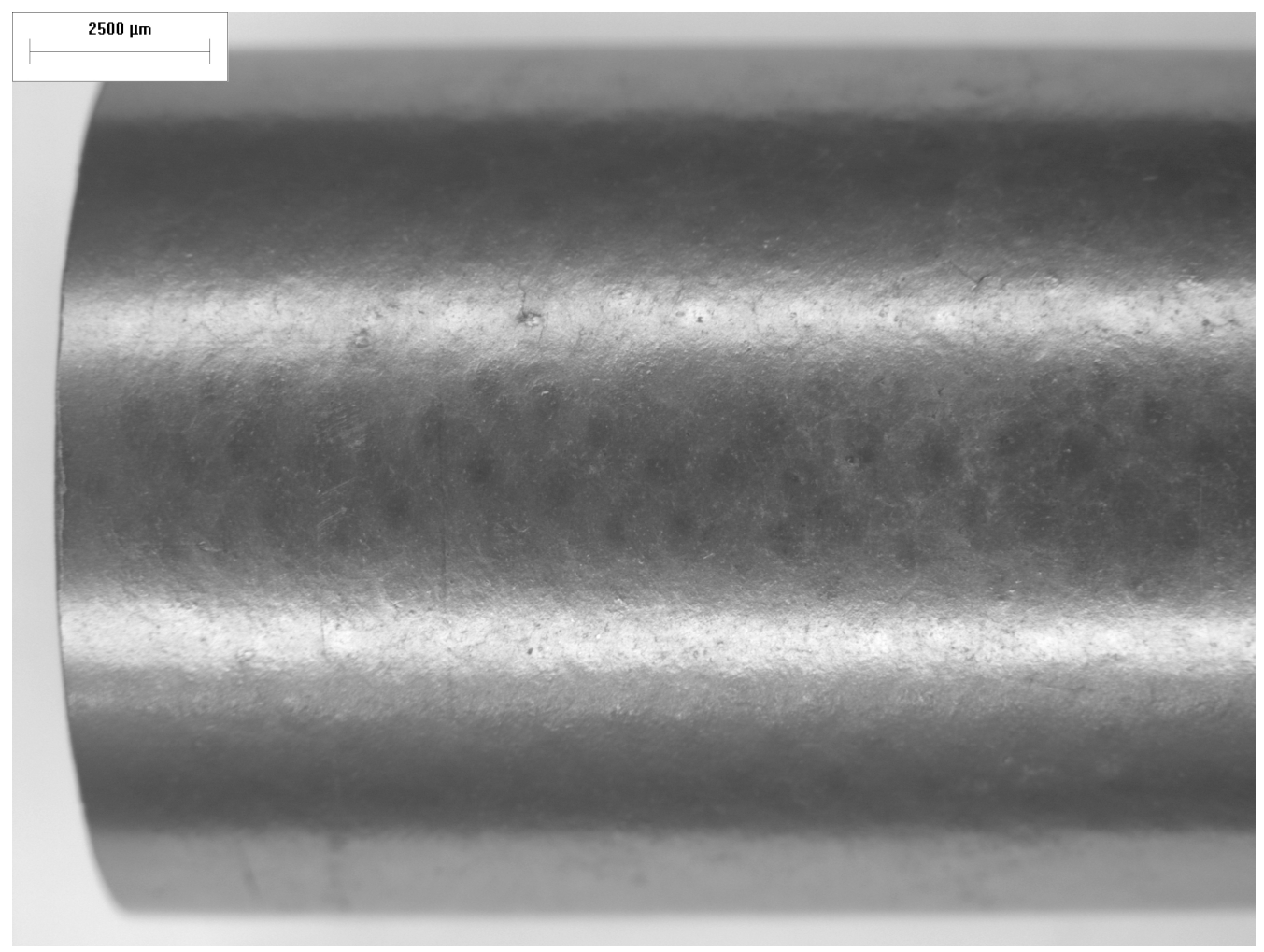

Figure 3. One end of compact LEU07-0P1-Z015. 


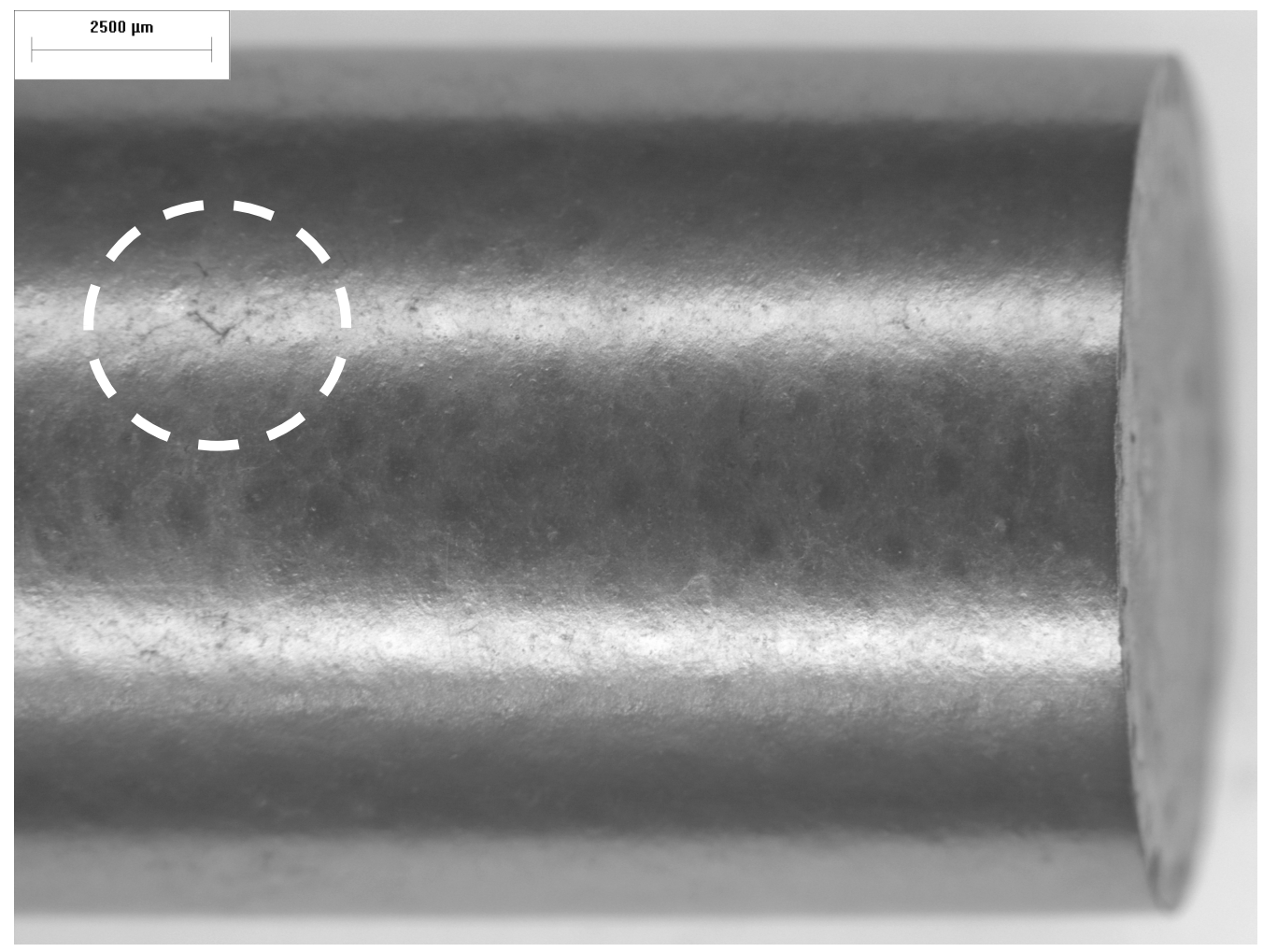

Figure 4. Other end of compact LEU07-0P1-Z015. Extended pit, possibly corresponding to overcoated particle boundaries, is circled.

\section{LEU09-OP2-Z}

Figure 5 and Figure 6 show compact LEU09-0P2-Z102. This was the 158th compact fabricated in the LEU09-OP2-Z campaign and it had a surface appearance that was typical for this compact lot (Appendix A-3). The surface appearance of the LEU09-0P2-Z compacts was similar to the LEU06-0P1-Z and the LEU07-0P1-Z compact lots discussed above. The LEU09-0P2-Z compacts also showed some narrow open regions between overcoated particles, as seen in the LEU07-OP1-Z compact lot. However, there were no obvious longitudinal scratches in the LEU09-0P2-Z compacts. This is likely due to a significant change in the compact extraction process.

Between the LEU06 and LEU07 campaigns and the LEU09 and LEU11 campaigns, a Carver manual hydraulic press was replaced with a Promess servo-electric press. The Promess press provided pressing rate and piston displacement control to three decimal place precision. This enabled the pressing rate and compact length to be precisely set and repeated for each individual compacting charge. Extraction of the compacts from the die was also done at a slower and more constant rate using the Promess press. Figure 7 and Figure 8 show the distribution in compact length for LEU06-0P1-Z and LEU09-0P2-Z. The effect of the introduction of the Promess press can clearly be seen.

One of the compacts in the LEU09-OP2-Z archive set (Z057) showed an unusual degraded surface appearance. The reason for this degraded appearance is unknown, but it has the appearance of moderate oxidation of the surface. This compact is shown in Figure 9 and Figure 10. 


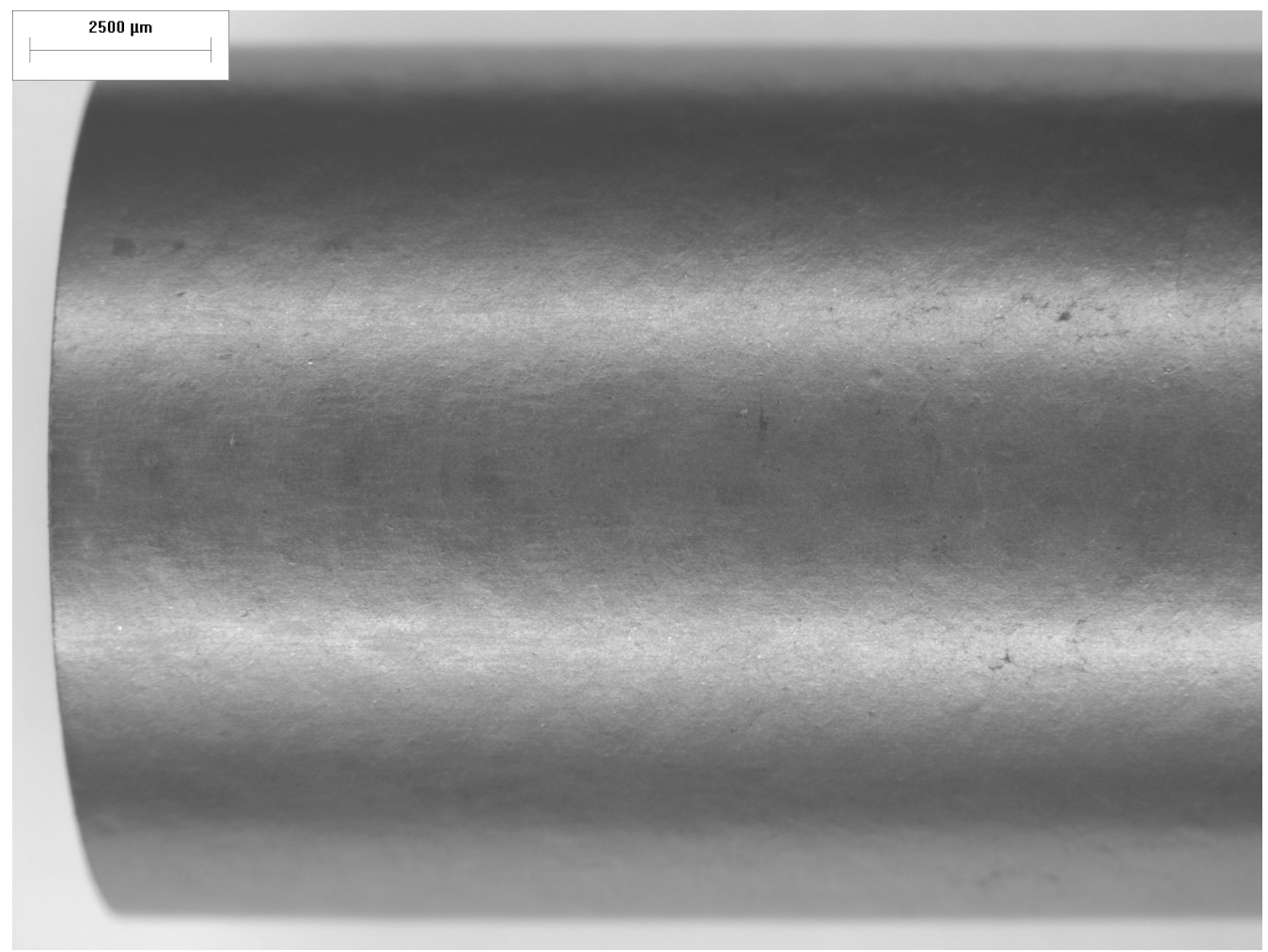

Figure 5. One end of compact LEU09-0P2-Z102.

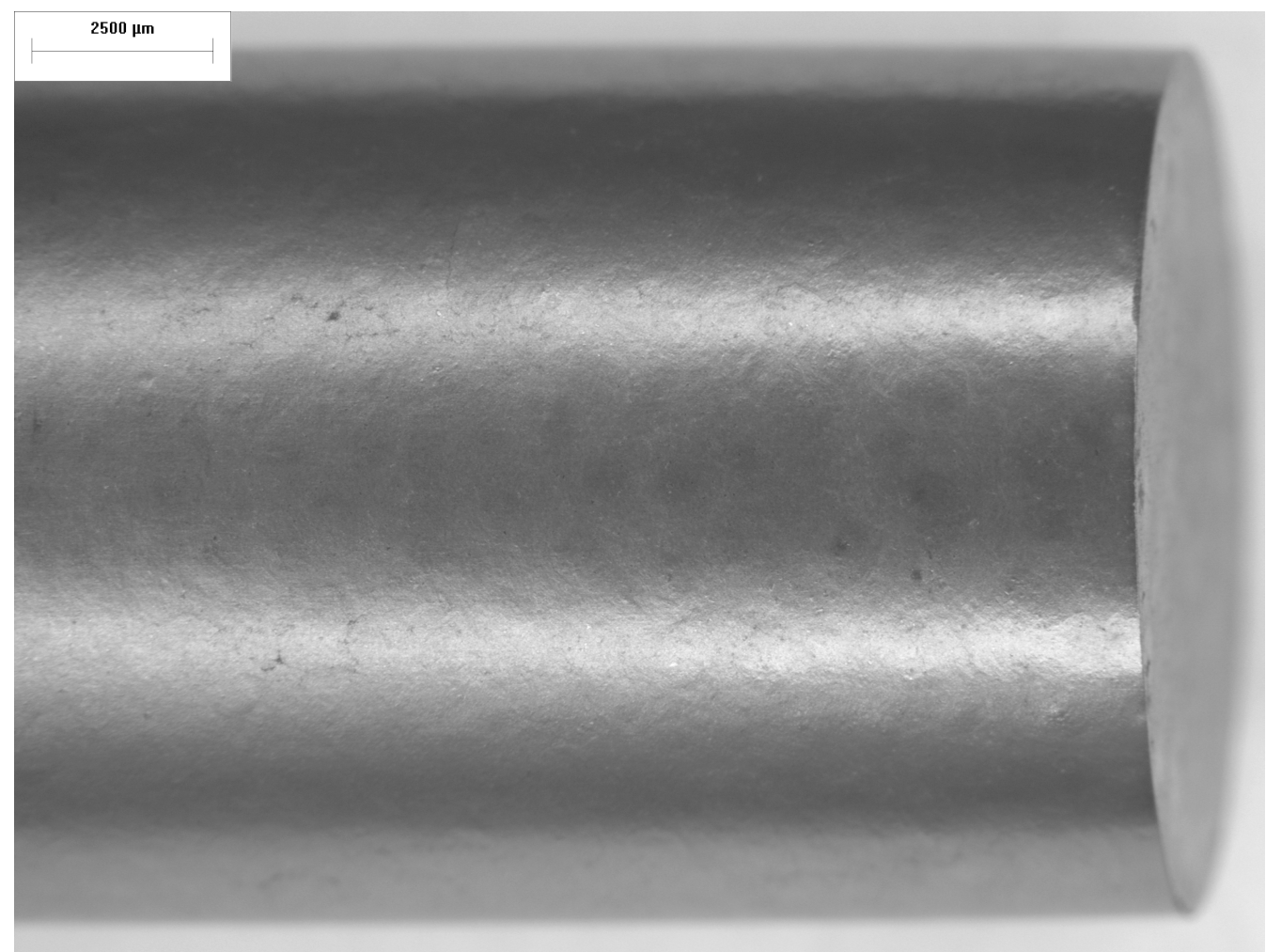

Figure 6. Other end of compact LEU09-0P2-Z102. 


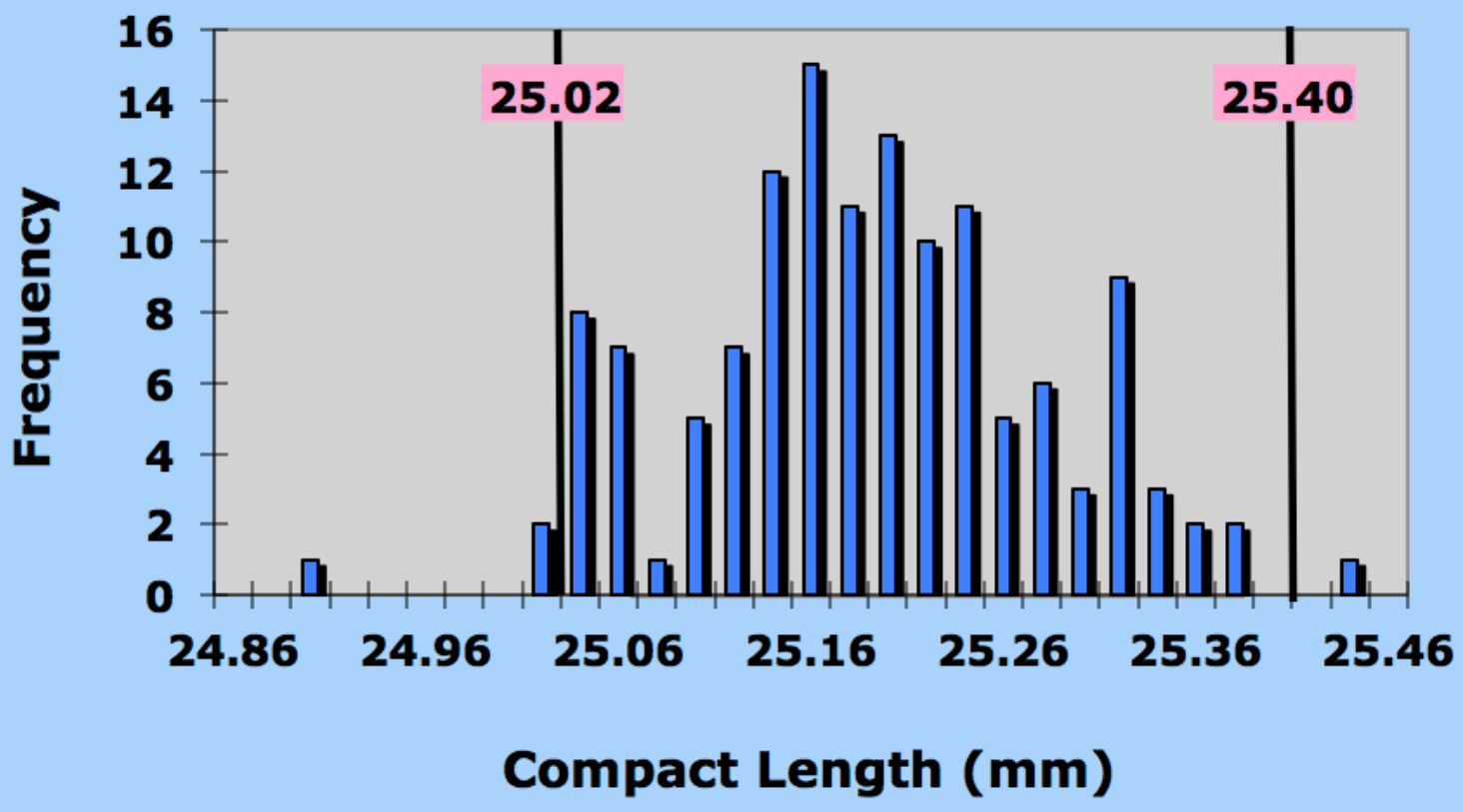

Figure 7. LEU06-0P1-Z compact length distribution. Vertical lines show specified limits.

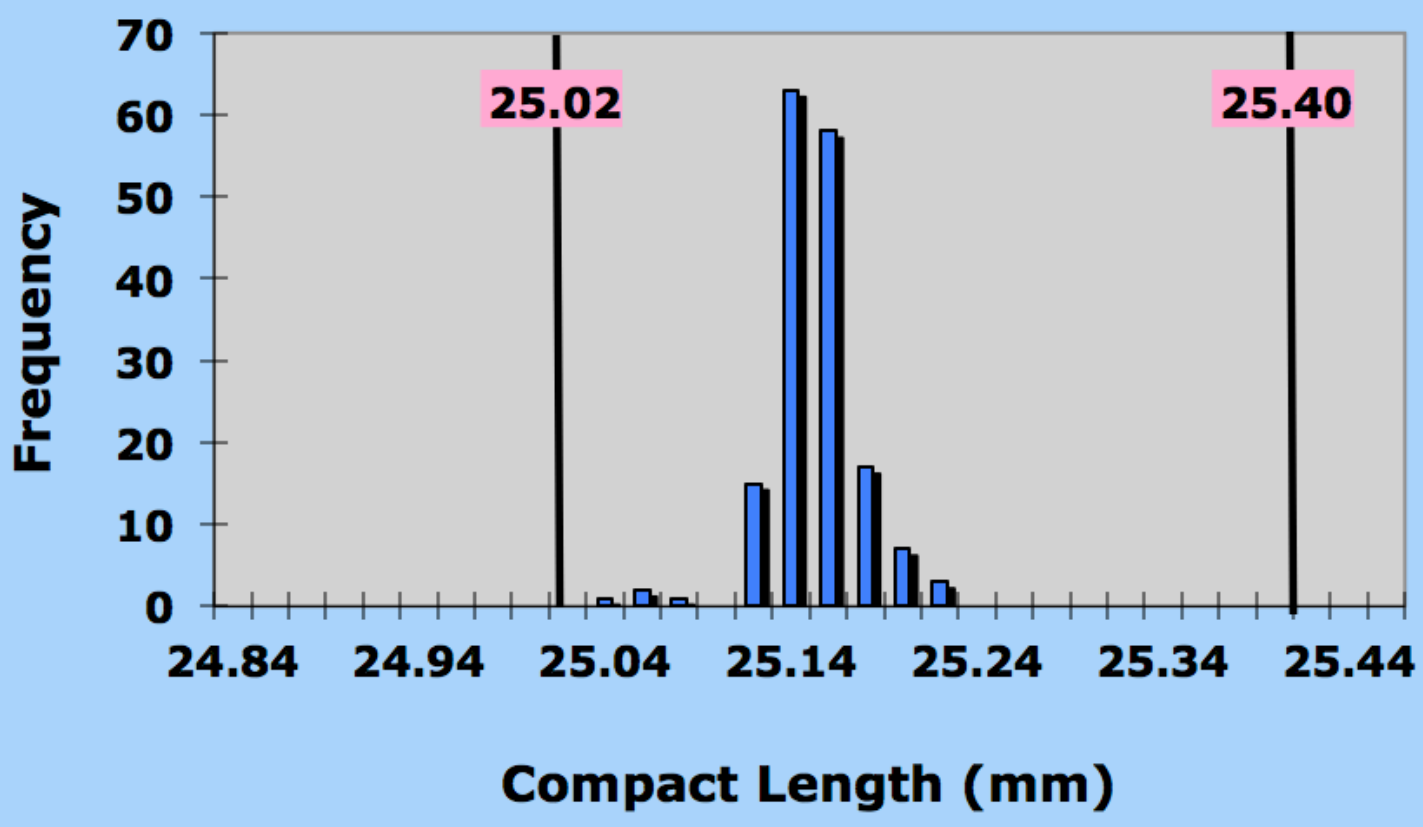

Figure 8. LEU09-0P2-Z compact length distribution. Vertical lines show specified limits. 


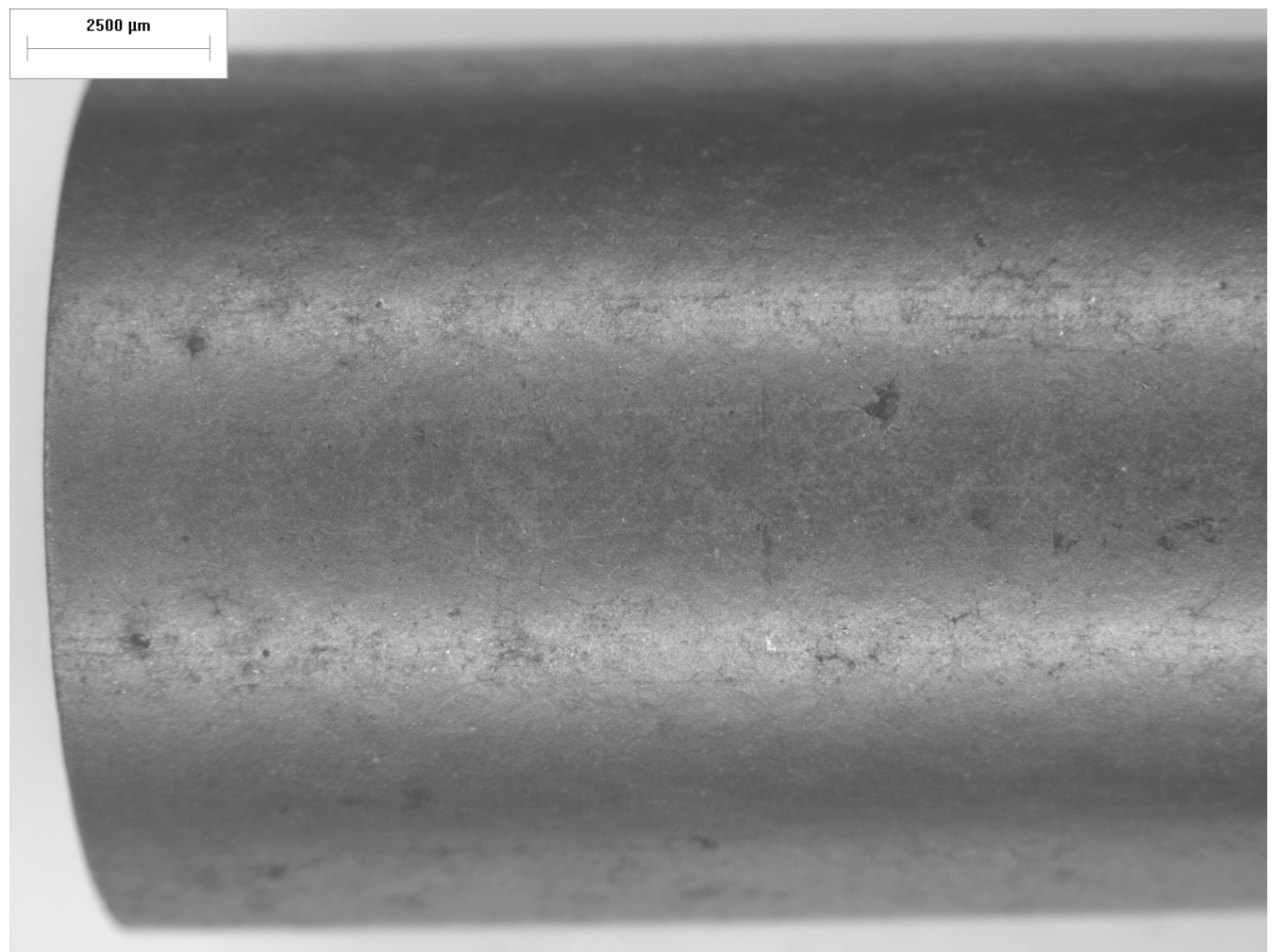

Figure 9. One end of compact LEU09-0P2-Z057.

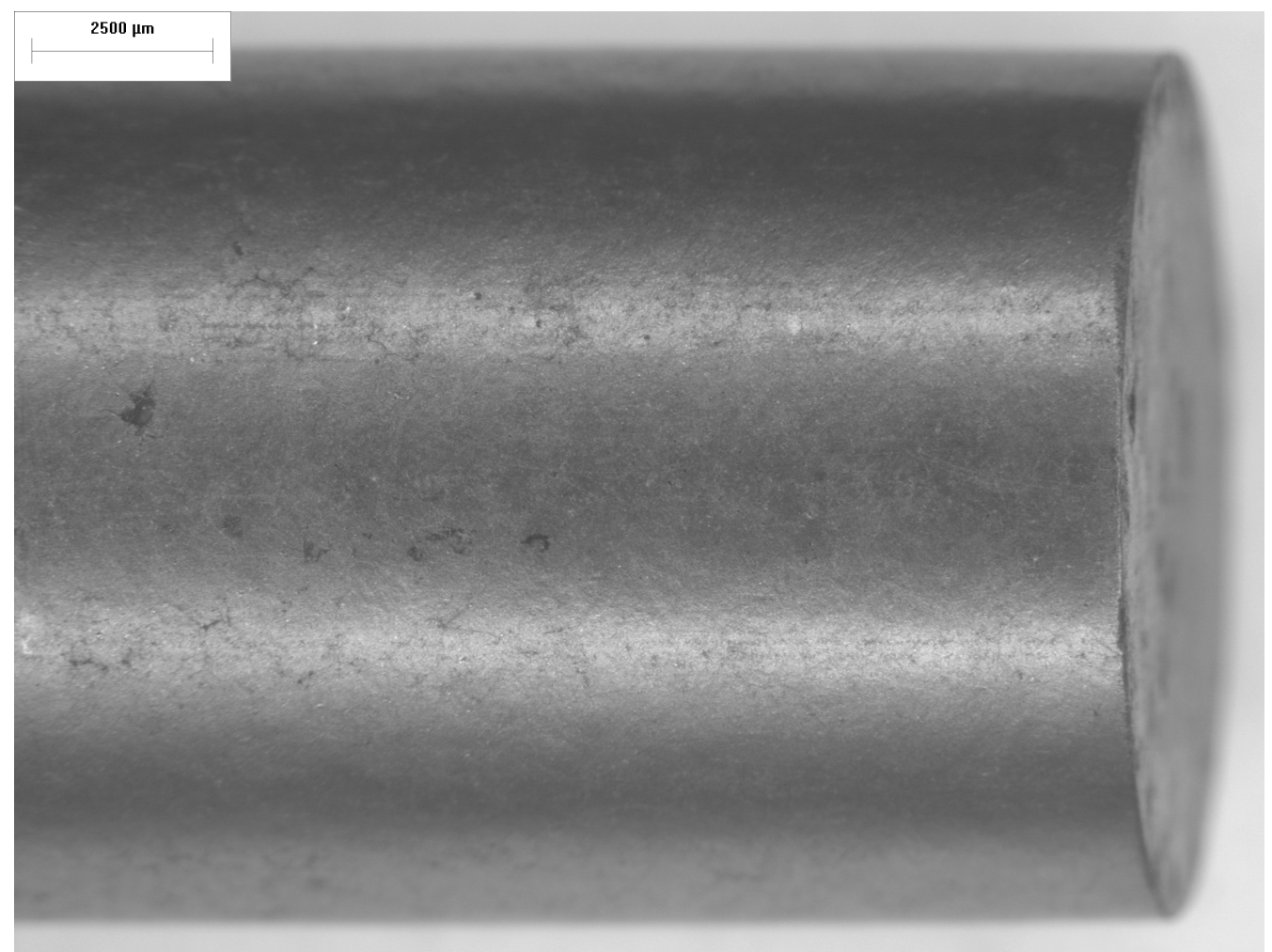

Figure 10. Other end of compact LEU09-OP2-Z057. 


\section{LEU11-OP2-Z}

The LEU11-OP2-Z compacts were significantly different from the three UCO fuel compact lots. The packing fraction was lower, the matrix density was higher, and the overcoat thickness was greater (Table 2). It is not surprising, therefore, that the surface appearance was significantly different as well. Figure 11 and Figure 12 show compact LEU11-OP2-Z147. This was the 199th compact fabricated in the LEU11-OP2-Z campaign and it had a surface appearance that was typical for this compact lot (Appendix A-4). Like LEU09-OP2-Z, the other compact lot made using the Promess press, LEU11-OP2-Z did not show any significant longitudinal scratches. The mottled appearance was almost absent due to the thicker overcoat. There was also very little pitting or pullout observed.

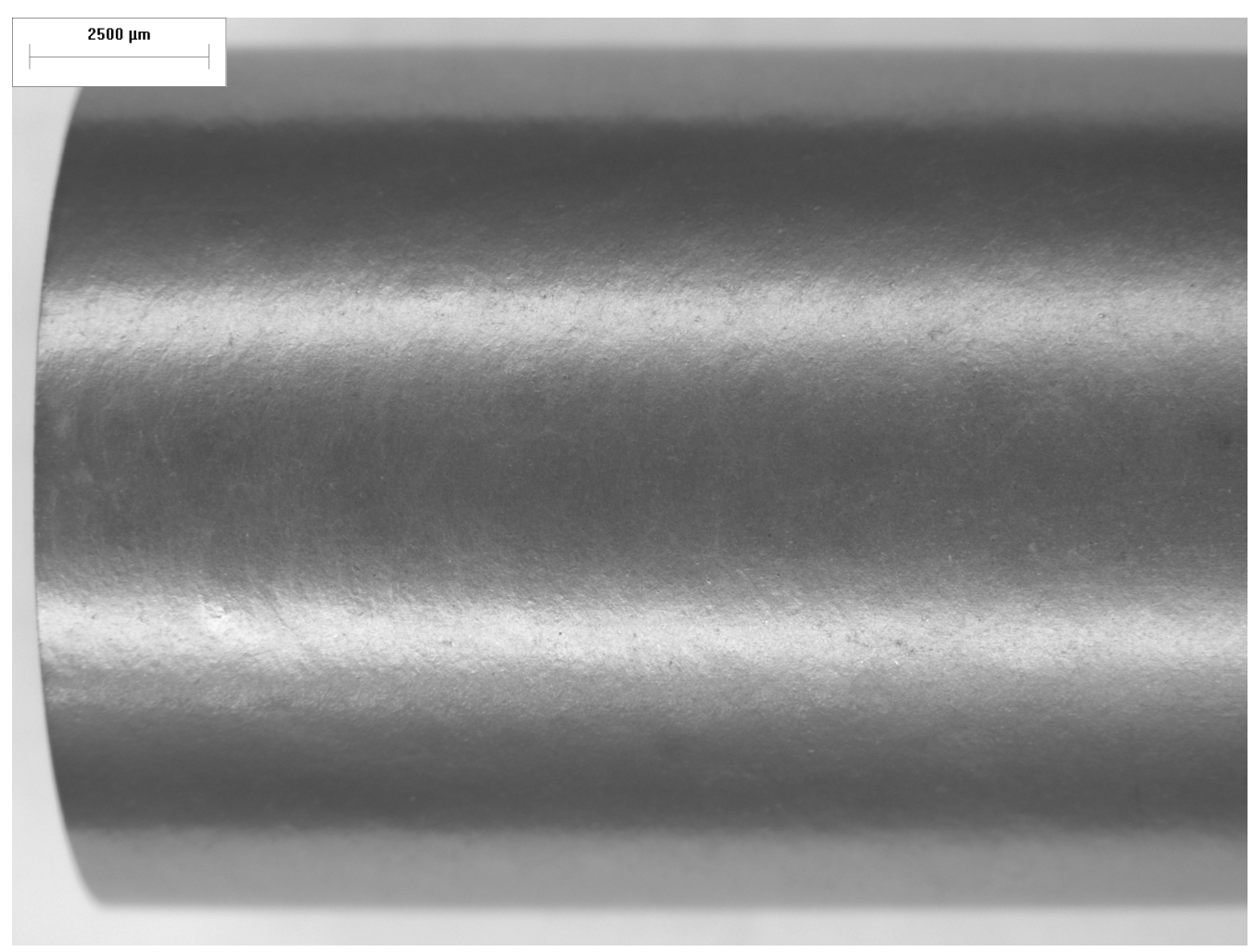

Figure 11. One end of compact LEU11-OP2-Z147. 


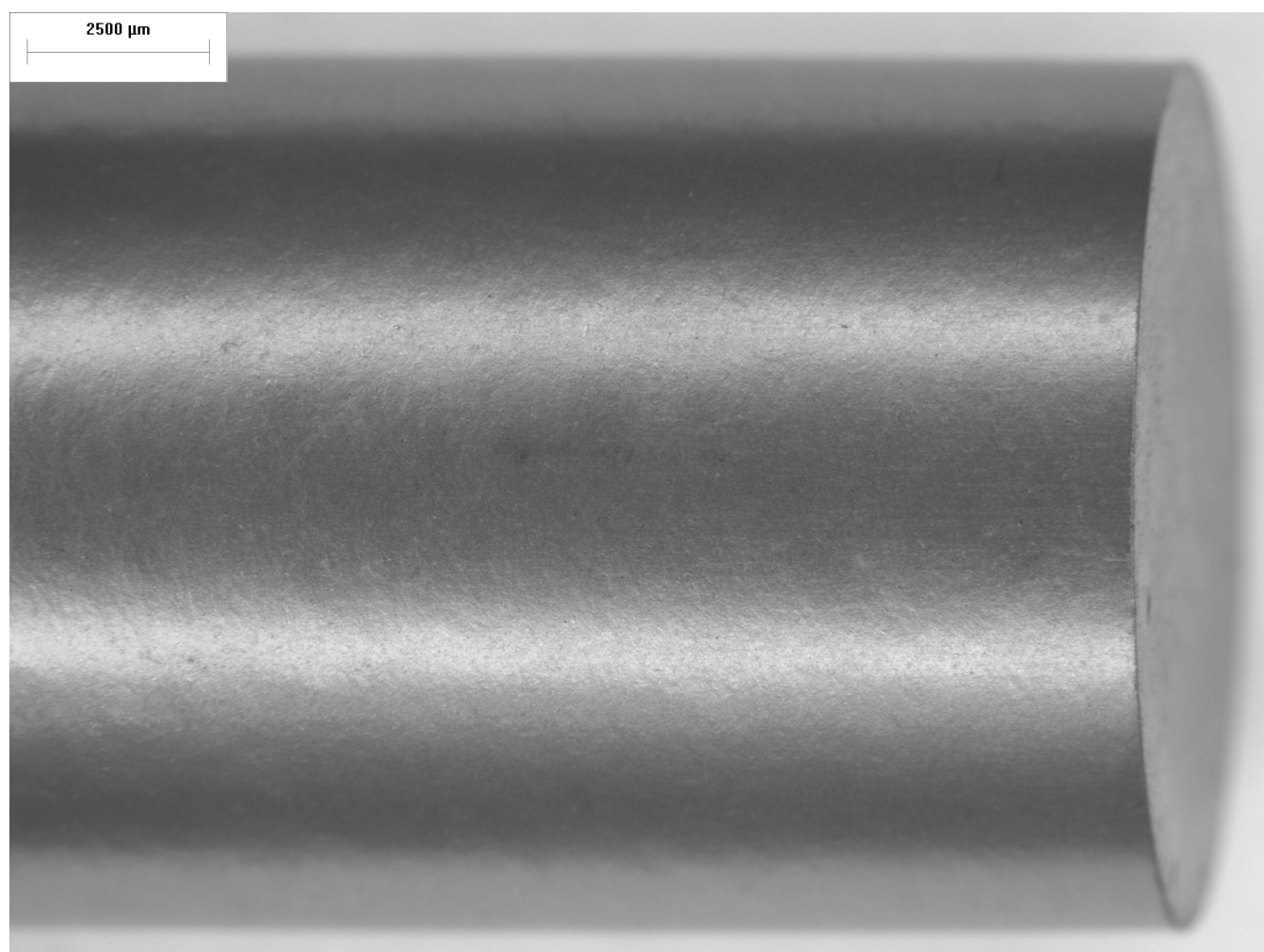

Figure 12. Other end of compact LEU11-0P2-Z147. 


\section{X-ray Radiographs of AGR-2 Compacts}

$\mathrm{X}$-ray images were obtained using a Seifert $320 \mathrm{x}$-ray unit operating at $50 \mathrm{kV}$ and $10 \mathrm{~mA}$ and Agfa Structurix D3 film. The x-ray film was located $122 \mathrm{~cm}$ from the source. Compacts were laid directly on the x-ray film and radiographs obtained using a $12 \mathrm{sec}$ exposure. At least 12 compacts from the available archives of each compact lot were imaged. Table 8 lists the ID numbers of the imaged compacts. Appendix B contains images of each compact in Table 8. Example images from each lot are discussed below.

Table 8. AGR-2 archive compacts imaged by x-ray radiography

\begin{tabular}{|c|c|l|}
\hline Compact Lot & $\begin{array}{c}\text { Number } \\
\text { Imaged }\end{array}$ & \multicolumn{1}{|c|}{ Compact ID Numbers } \\
\hline LEU06-OP1-Z & 16 & $\begin{array}{l}002,004,006,008,009,011,012,017,019,020,021,022, \\
025,026,028,029\end{array}$ \\
\hline LEU07-OP1-Z & 24 & $\begin{array}{l}008,015,016,036,054,063,065,067,071,073,084,089, \\
098,102,109,113,116,126,131,132,137,143,148,151\end{array}$ \\
\hline LEU09-OP2-Z & 12 & $002,004,005,038,057,069,089,102,130,139,158,165$ \\
\hline LEU11-OP2-Z & 12 & $018,045,062,066,074,085,091,136,147,152,186,198$ \\
\hline
\end{tabular}

The x-ray conditions were optimized to be able to distinguish the SiC coating layer with minimal loss of sensitivity for the compact boundaries. Edge detection along the length of the compact cylinder was limited because the $\mathrm{x}$-ray path length was too short to get appreciable x-ray attenuation close to the edge. Edge detection at the top and the bottom of the compact cylinder was more reliable because of the longer x-ray path length. One end of the compact was typically better defined than the other because it was closer to the centerline of the x-ray source. The end of the compact away from the centerline appeared slightly "fuzzy" because the x-rays were penetrating at a slight angle with respect to the flat face of the compact.

The orientation of the radiographs in Appendix B should correspond to the orientation of the compact in the die. Compacts were pressed using a heated, double acting die. The die was heated between $65^{\circ} \mathrm{C}$ and $75^{\circ} \mathrm{C}$ (except for LEU06, which was pressed at $95^{\circ} \mathrm{C}$ ). Approximately $0.10 \mathrm{~g}$ of matrix was added to the top and bottom of each compact in order to create matrix "end caps." The end caps were formed by first pouring a matrix charge into the heated die, followed by the overcoated particles, and then a second charge of matrix. This forming method created a thin $(\sim 0.25 \mathrm{~mm}$ thick) fuel free zone on the ends of the compact, called end caps. These end caps can be seen in the x-ray images. The bottom end cap tended to be more uniform in thickness compared to the top because the bottom matrix charge could be leveled by tapping the die prior to loading overcoated particles. The top end cap uniformity was limited by the distribution of the overcoated particles and there was some variation from compact to compact.

Figure 13 shows a typical compact from each AGR-2 fuel compact lot. Compacts from the three UCO fuel compact lots (LEU06, LEU07, and LEU09) had a similar appearance 
because of the similarity in the TRISO particles and number of particles per compact. The lower packing fraction of the $\mathrm{UO}_{2}$ fuel compacts (LEU11) was obvious in the apparent particle density in the radiograph.

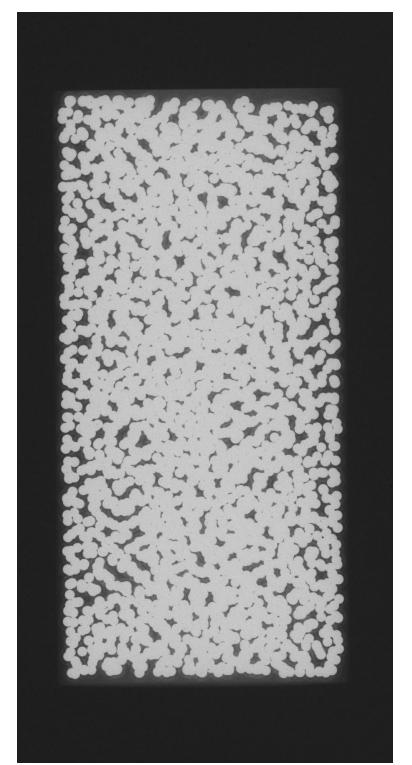

LEU06-OP1-Z002

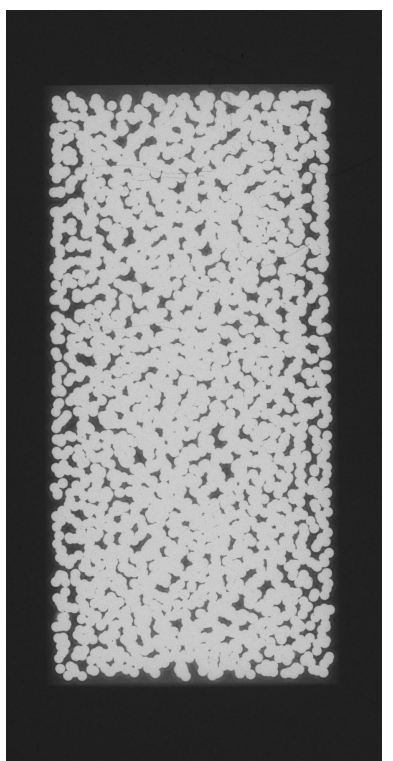

LEU07-OP1-Z008

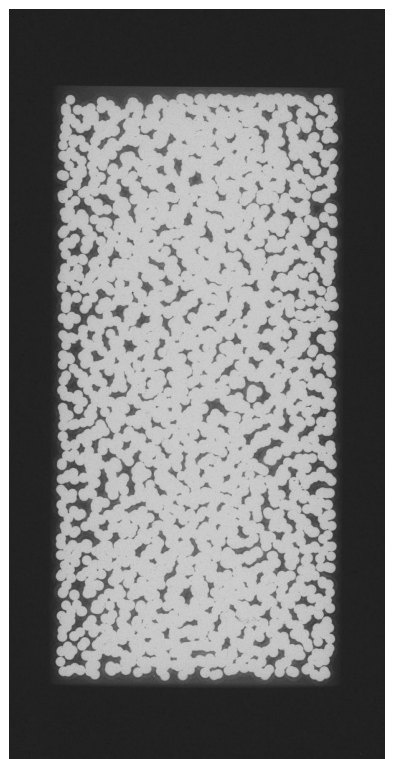

LEU09-OP2-Z002

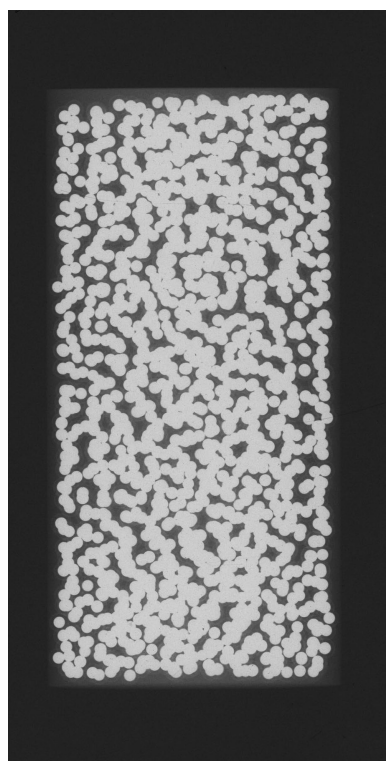

LEU11-OP2-Z018

Figure 13. Comparison of typical compacts from each AGR-2 fuel compact lot.

Figure 14 through Figure 17 are larger images of representative compacts from each lot. Close inspection of these figures will show that the end caps were not completely free of fuel particles. Some particles appear to be at or very close to the compact surface at both ends of the compact. Careful examination of the radiographs in Appendix B revealed that this occurred on all the UCO compacts. As discussed above, it was more difficult to resolve the compact edge along the length of the cylinder, but it appeared that the particles along these walls were also at or near the surface. 

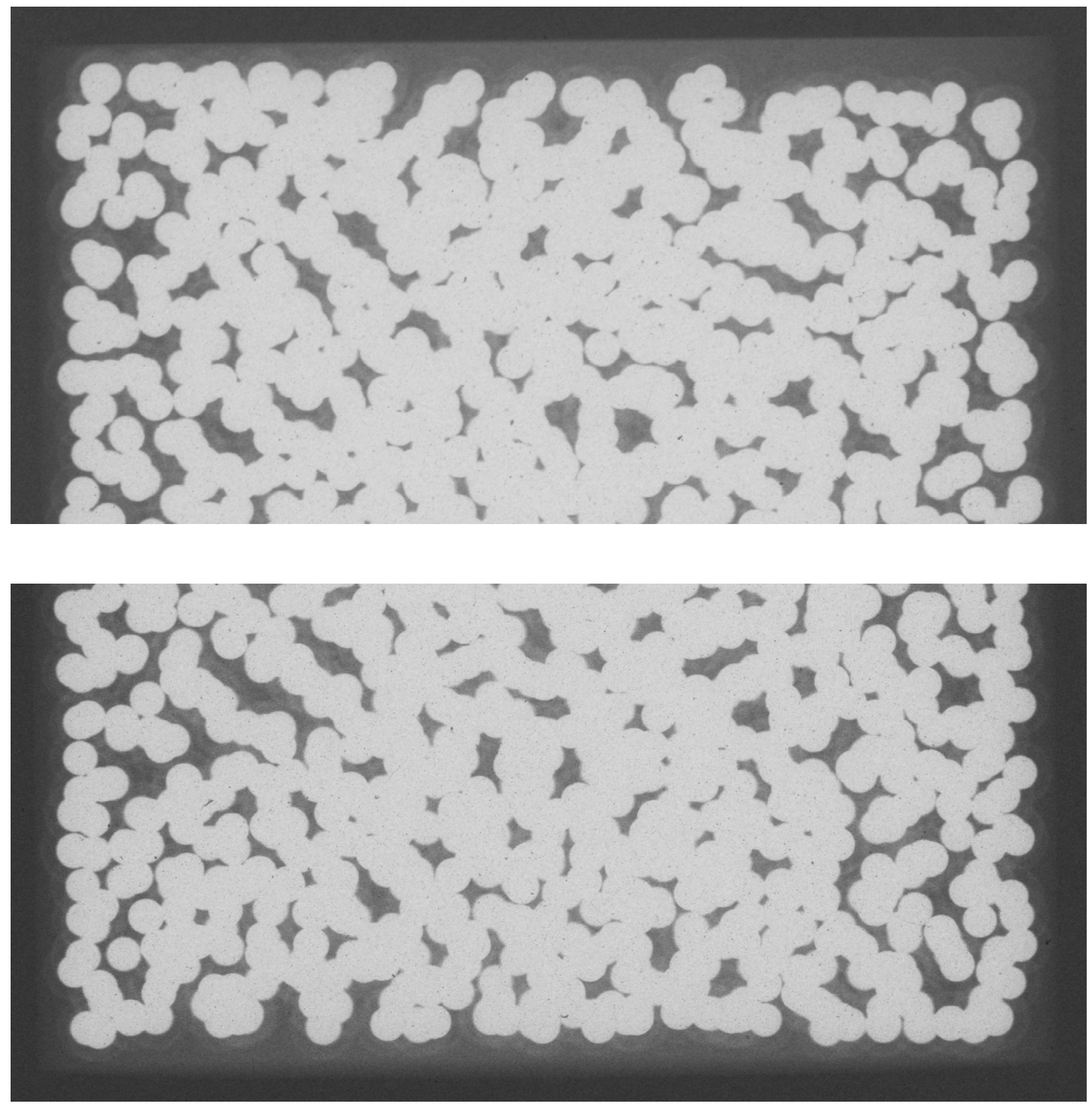

Figure 14. Top and bottom of LEU06-0P1-Z002 compact. 

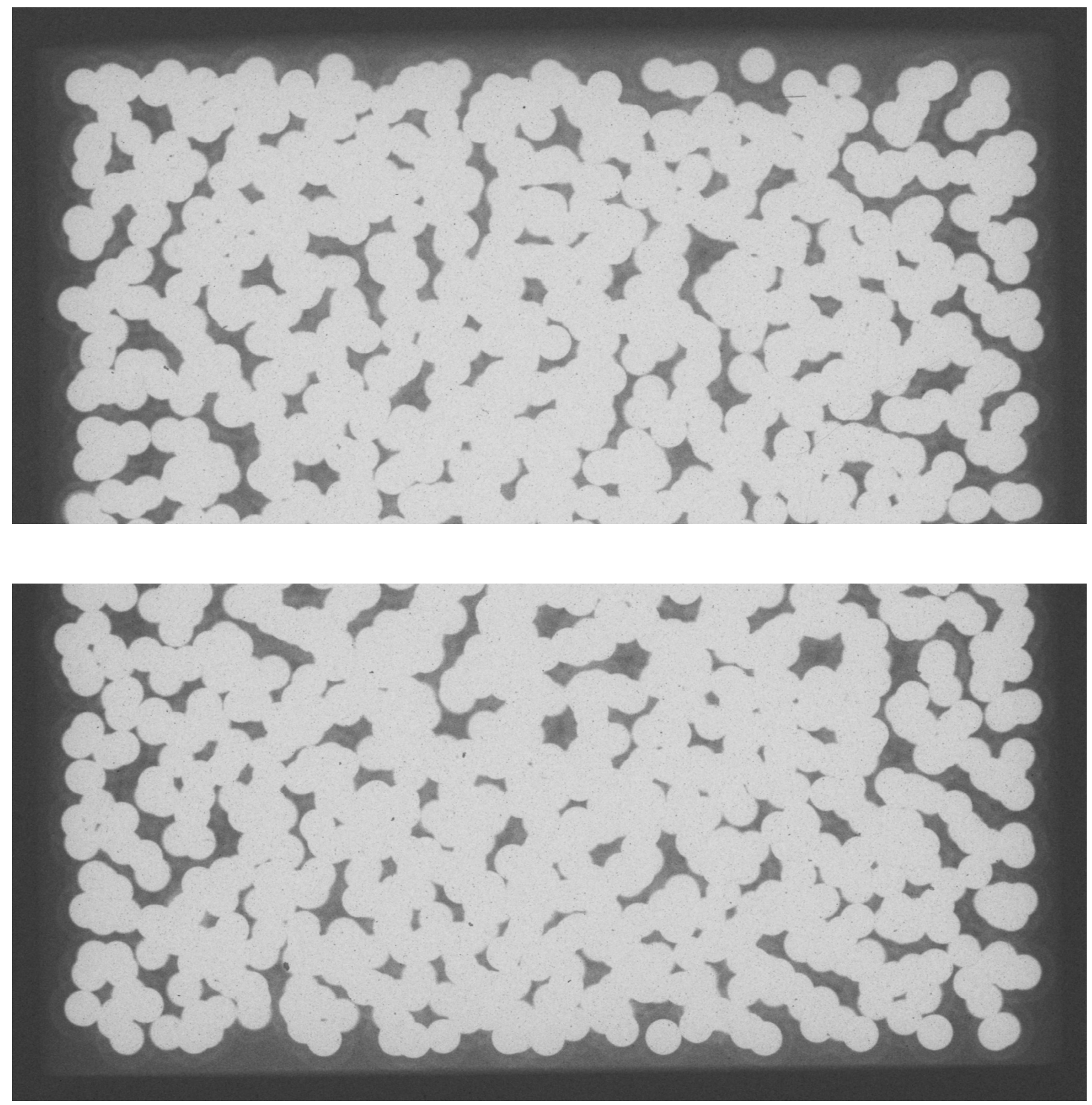

Figure 15. Top and bottom of LEU07-0P1-Z073 compact. 

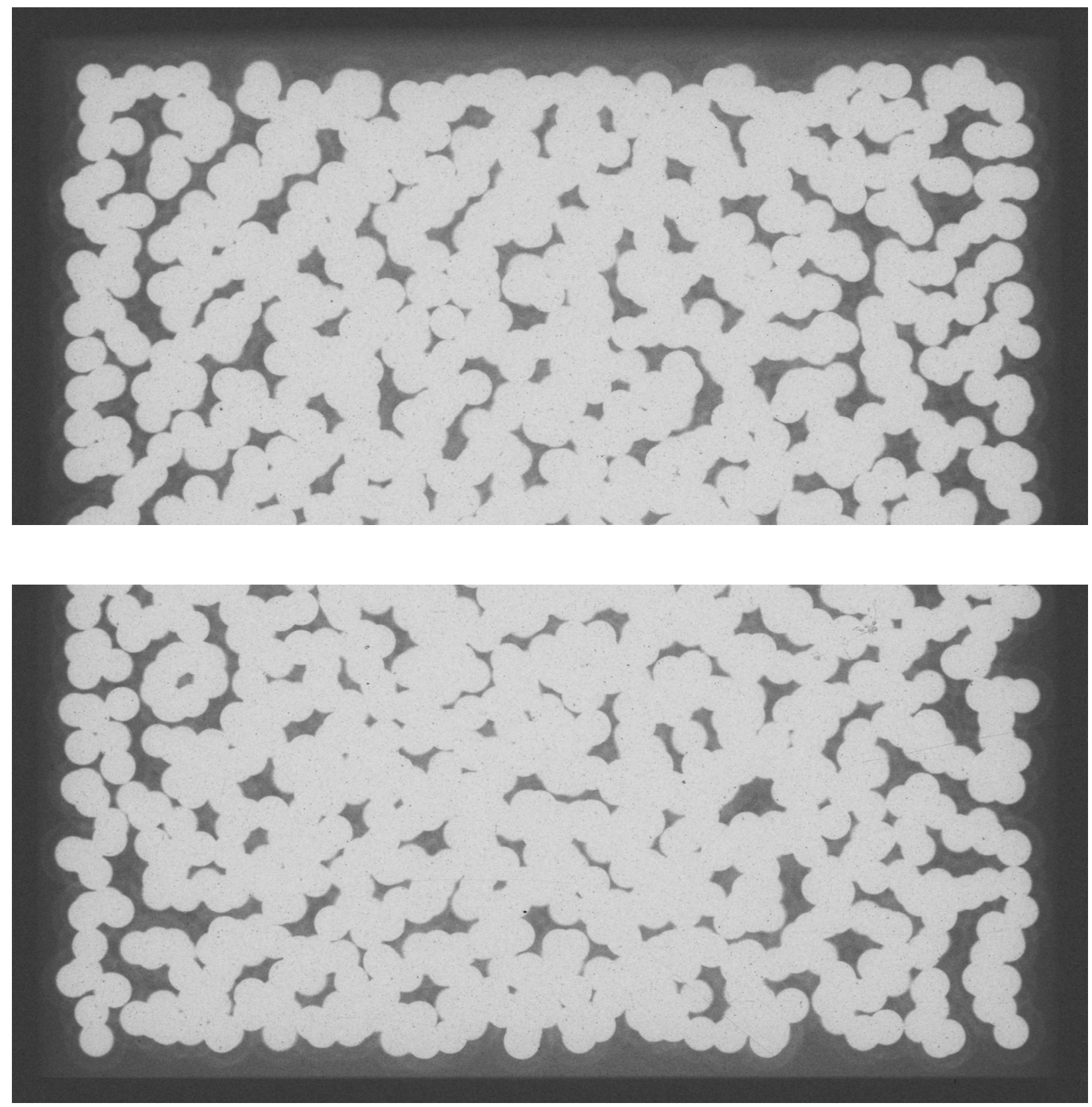

Figure 16. Top and bottom of LEU09-0P2-Z130 compact. 

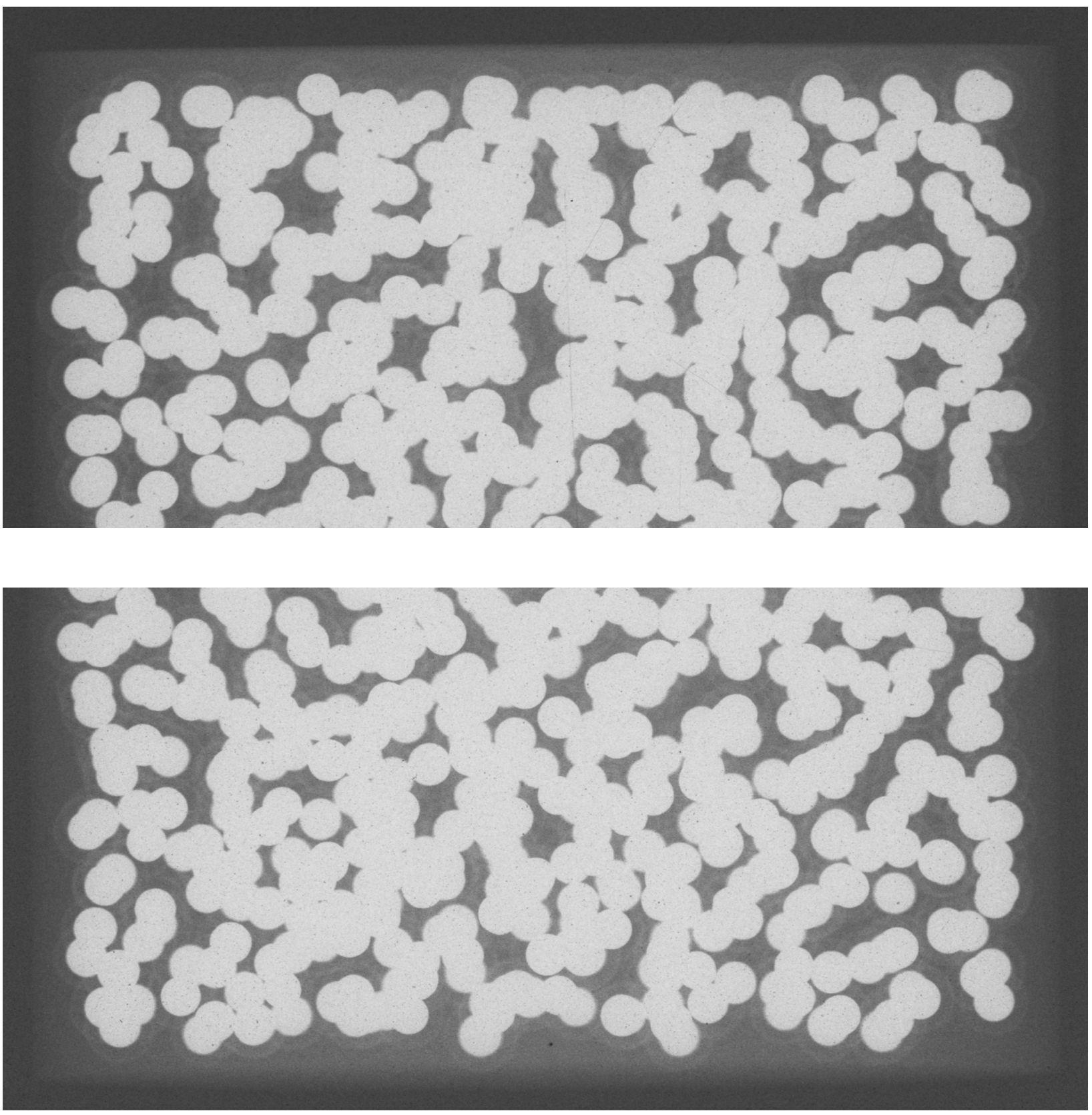

Figure 17. Top and bottom of LEU11-0P2-Z045 compact.

The lower packing fraction in the LEU11-OP2-Z $\mathrm{UO}_{2}$ compact lot resulted in a significantly thicker overcoat being applied to each particle (Table 9). Close inspection of the LEU11-OP2-Z compacts (Figure 17 and Appendix B-4) showed that there was clearly a thicker matrix-only region between the particles and the compact surface for these compacts. There were still a few particles that appeared to be at or near the surface, but comparatively fewer than for the UCO compacts. The presence of this mostly fuel free matrix layer at the surface of the compact was also evident in the external appearance of the $\mathrm{UO}_{2}$ compacts (Figure 11 and Figure 12), compared to the UCO compacts that showed a mottled appearance due to particles close to the surface. 
Table 9. Properties of AGR-2 overcoating layer prior to compacting

\begin{tabular}{|c|c|c|}
\hline Compact Lot & $\begin{array}{c}\text { Average Overcoat } \\
\text { Thickness }(\boldsymbol{\mu m})\end{array}$ & $\begin{array}{c}\text { Approximate Density } \\
\text { of Overcoat }\left(\mathbf{g} / \mathbf{c m}^{3}\right)\end{array}$ \\
\hline LEU06-OP1-Z & 215 & 1.16 \\
\hline LEU07-OP1-Z & 235 & 1.12 \\
\hline LEU09-OP2-Z & 215 & 1.21 \\
\hline LEU11-OP2-Z & 390 & 1.14 \\
\hline
\end{tabular}




\section{Analysis of AGR-2 Compact Sections}

Two compacts were selected from each of the four AGR-2 archive sets for sectioning and subsequent materialography. The compacts were sectioned according to the special instructions provided in AGR-CHAR-SOG-18. This involved using a computer controlled saw to slowly feed the compact against a thin diamond impregnated disc. This cutting procedure was optimized to produce minimum damage to the cut surface and reduce particle pullout so that only minimum grinding and polishing would be required. This was found to be advantageous because excessive grinding on a rotary wheel tended to degrade the surface finish, due to additional particle pullout. One compact from each group was used to obtain two cross-section cuts perpendicular to the cylinder axis (designated as lateral sections). AGR-2 compacts were formed by pressing simultaneously from both ends in a double-acting die. Therefore, in order to see possible effects of the force gradient associated with the AGR-2 compacting process, lateral sections were taken from positions approximately $1 / 4$ and $1 / 2$ way along the length of the compact. The second compact selected from each group was cut length-wise along the cylinder axis (designated as a longitudinal section).

Materialographic preparation included vacuum potting the compact sections face-down in two-part epoxy. This process allowed a thin layer of epoxy to move under the cut surface and fill any holes left by particle pullout that occurred during the sectioning. Grinding and polishing was then performed per AGR-CHAR-DAM-38 to obtain a final surface finish suitable for optical imaging. Table 10 lists the ID numbers of the sectioned, polished, and imaged compacts. Appendix C contains images of each compact in Table 10. Example images from each lot are discussed below.

\section{Table 10. AGR-2 archive compacts sectioned and imaged with microscope}

\begin{tabular}{|c|c|c|}
\hline Compact Lot & Number Imaged & Compact ID Numbers \\
\hline LEU06-OP1-Z & 2 & 042,050 \\
\hline LEU07-0P1-Z & 2 & 016,036 \\
\hline LEU09-0P2-Z & 2 & 004,005 \\
\hline LEU11-OP2-Z & 2 & 062,066 \\
\hline
\end{tabular}

Optical images of each polished section were captured using a Leica DMRX microscope in bright field reflected light mode. Using a computer controlled X/Y stage, a mosaic of each section was constructed from a scanned array of images that covered the entire section. This allowed for higher resolution imaging than could be obtained in a single image at lower magnification. At the magnification chosen for making the mosaics, an 8x10 array of images was sufficient for the lateral sections, while longitudinal sections required a $15 \times 10$ array. If the mosaics in Appendix $\mathrm{C}$ are enlarged for better viewing of detail, some discontinuities may be seen at the boundaries between each individual image. These should not be mistaken as coating defects. 
Figure 18 shows a typical lateral compact section mosaic from each AGR-2 fuel compact lot. The dark gray circles are where epoxy has back-filled into voids left behind by particles dislodged during the cutting process. Fuel kernels in particles where the section passed below the particle mid-plane were also susceptible to dropping out. If a kernel came out during cutting, it was back-filled with epoxy and will appear as a dark gray spot. However, if it came out during grinding and polishing, a new void was created in the polished surface and this appears as a black spot in the image. Black spots also appear in some of the epoxy filled voids as a result of small bubbles in the epoxy. Some scratches are evident in each image and most often occurred as a result of kernels or small pieces of SiC pulled out during polishing.

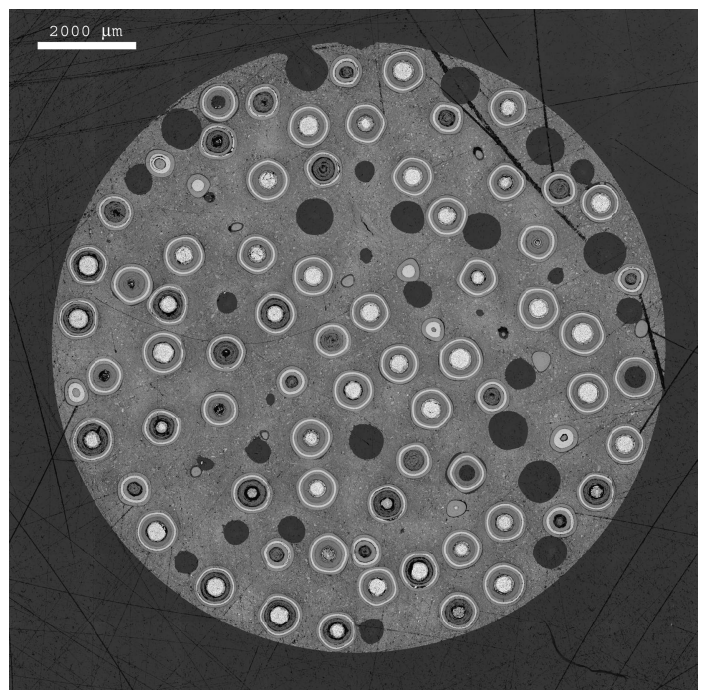

LEU06-OP1-Z050

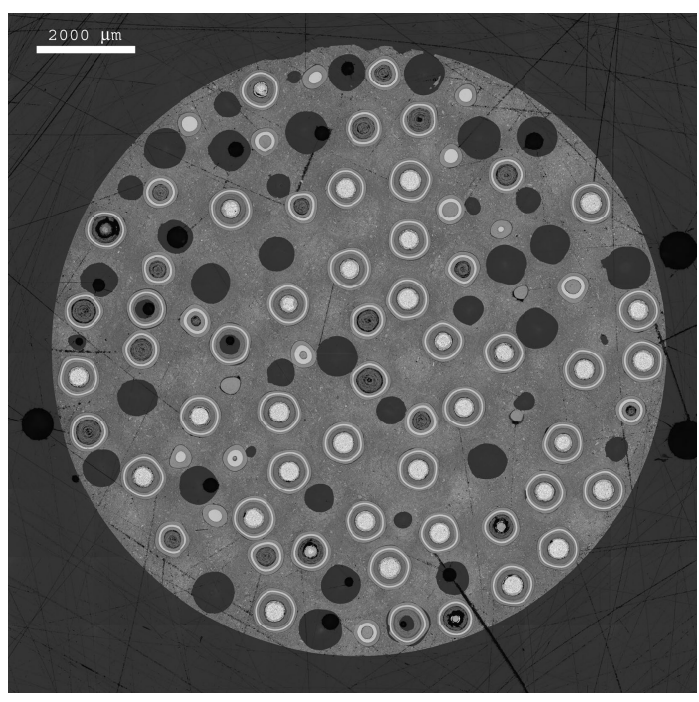

LEU09-OP2-Z004

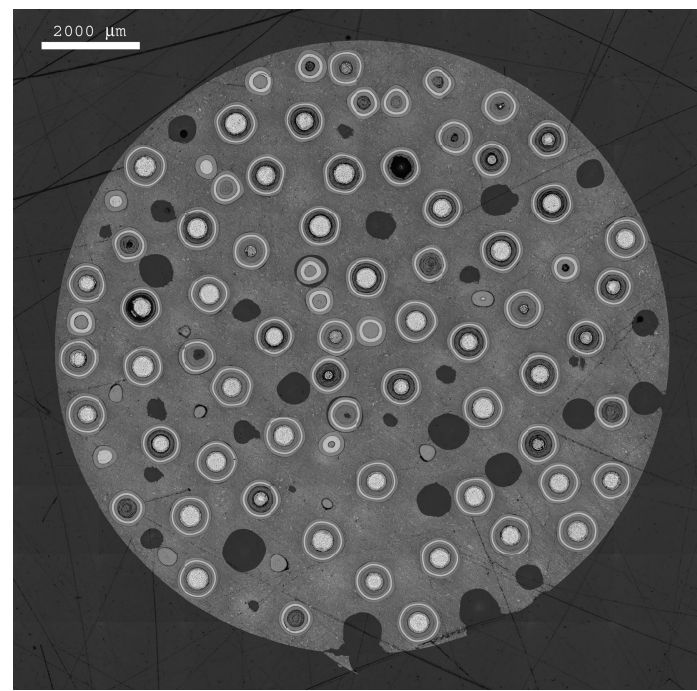

LEU07-OP1-Z016

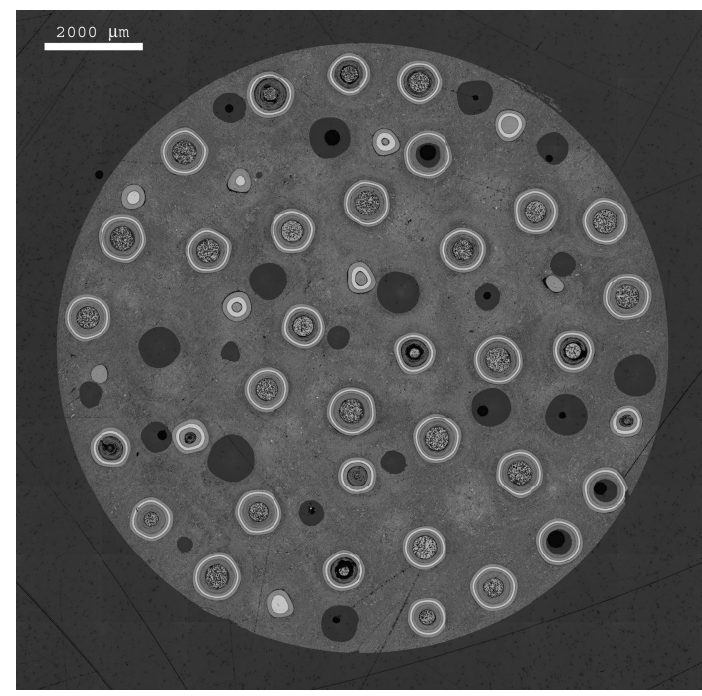

LEU11-OP2-Z062

Figure 18. Comparison of typical lateral sections from each AGR-2 fuel compact lot. 
The lateral sections of the compacts from the three UCO fuel compact lots (LEU06, LEU07, and LEU09) had a similar appearance because of the similarity in the TRISO particles and number of particles per compact. The lower packing fraction of the $\mathrm{UO}_{2}$ fuel compacts (LEU11) was obvious in the apparent particle density in the cross-section image mosaic in Figure 18. The lateral sections also showed a tendency for the particles to line up along the sides of the compact.

Close inspection of Figure 18 and the images in Appendix $\mathrm{C}$ will also reveal that some particles are very close, if not touching. Figure 19 shows some higher resolution images of some of these particles. It is difficult to estimate the fraction of particles in the compact that are in contact. Given the number observed in a single planar section, particle contact is apparently widespread, at least for the higher packing fraction UCO compacts.
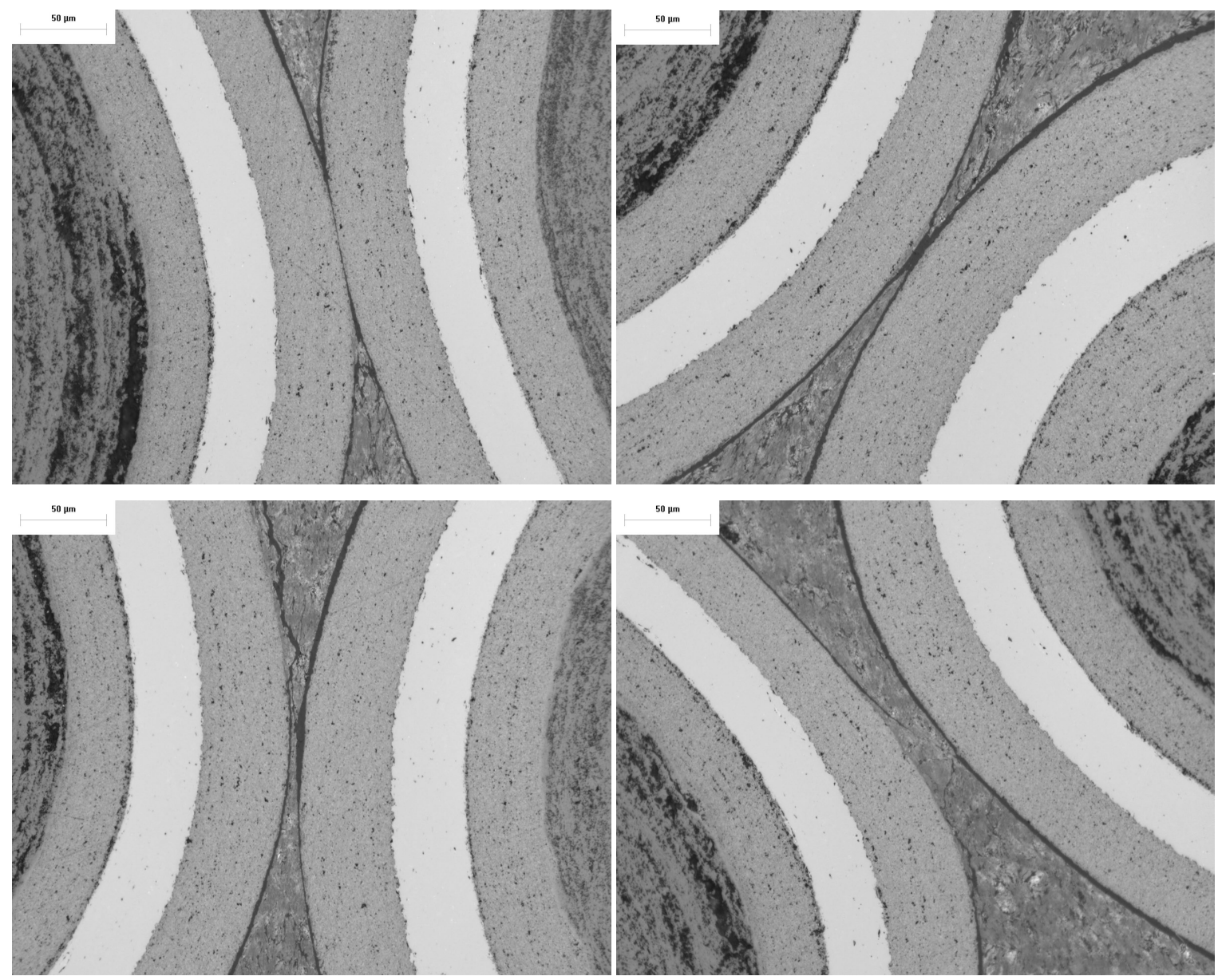

Figure 19. Examples of particles from LEU09-0P2-Z005 with little or no matrix separating them at the closest point visible in the polished plane.

Figure 20 shows two longitudinal sections from LEU07-OP1-Z036 and LEU11-OP2Z066. Again, it is evident in these images that some particles are very close or in contact with each other, even in the lower packing fraction $\mathrm{UO}_{2}$ compact. A non-uniformity in the particle distribution is also apparent. There appear to be areas of lower packing fraction and there seems to be a tendency for groups of particles to line up in a closely spaced string. 
As observed in the x-ray images and discussed in the previous section, some particles appear to have very little matrix separating them from the surface of the compact, especially for the higher packing fraction UCO compacts.
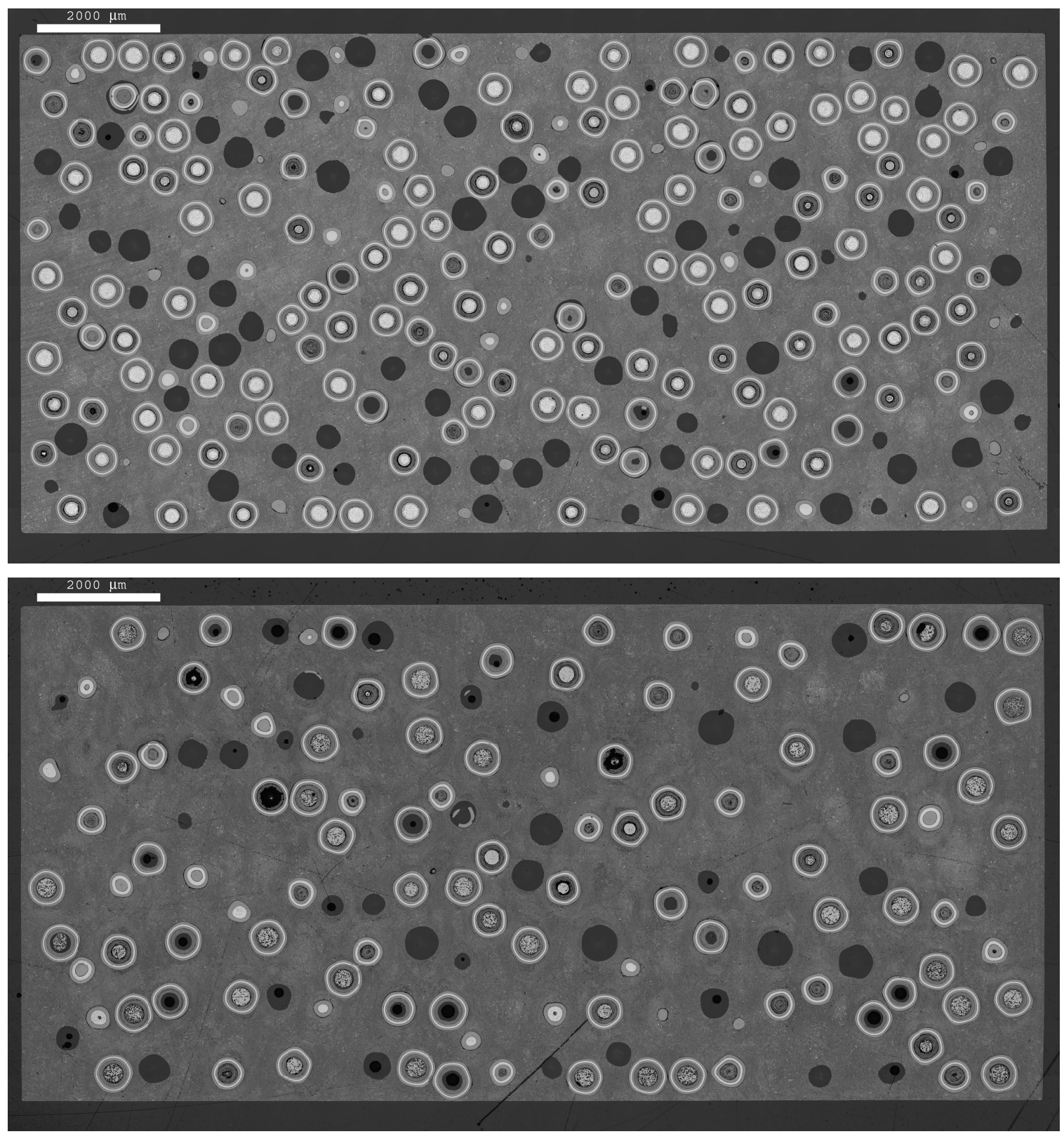

Figure 20. Comparison of longitudinal sections from a UCO fuel compact (Top: LEU07-OP1-Z036) and a $\mathrm{UO}_{2}$ fuel compact (Bottom: LEU11-OP2-Z066).

In addition to the mosaics, several higher magnification/higher resolution images are included in Appendix $\mathrm{C}$ of select areas of each section to capture examples of the embedded particles (Figure 21) and interparticle graphite matrix (Figure 22). Finally, a close-up of a region of interest on one typical particle was obtained using the microscope's highest power objective (Figure 23). These close-up images provide the best detail of the individual particle layer interfaces. 


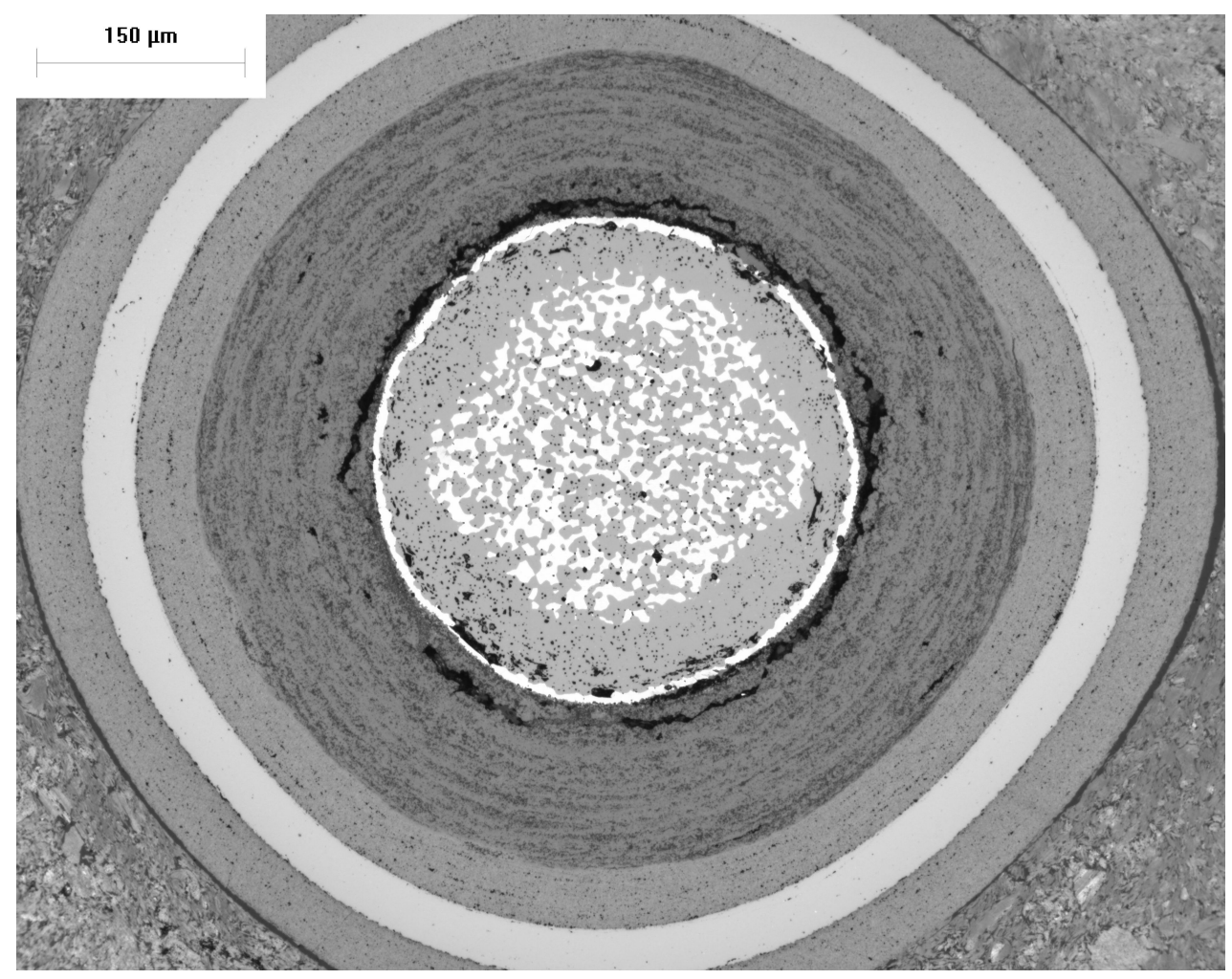

Figure 21. Example of embedded particle from LEU09-OP2-Z004.

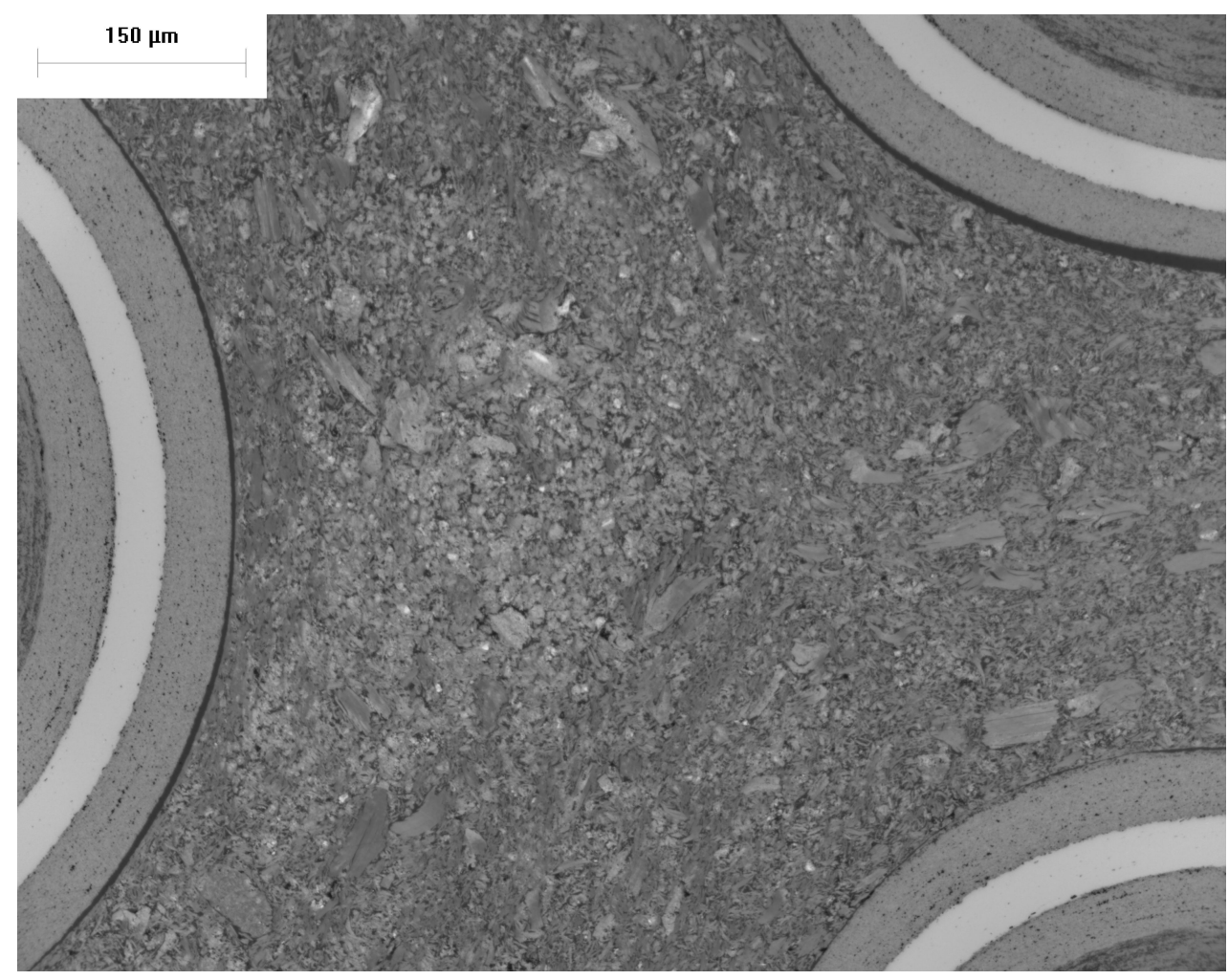

Figure 22. Example of matrix region from LEU09-OP2-Z004. 


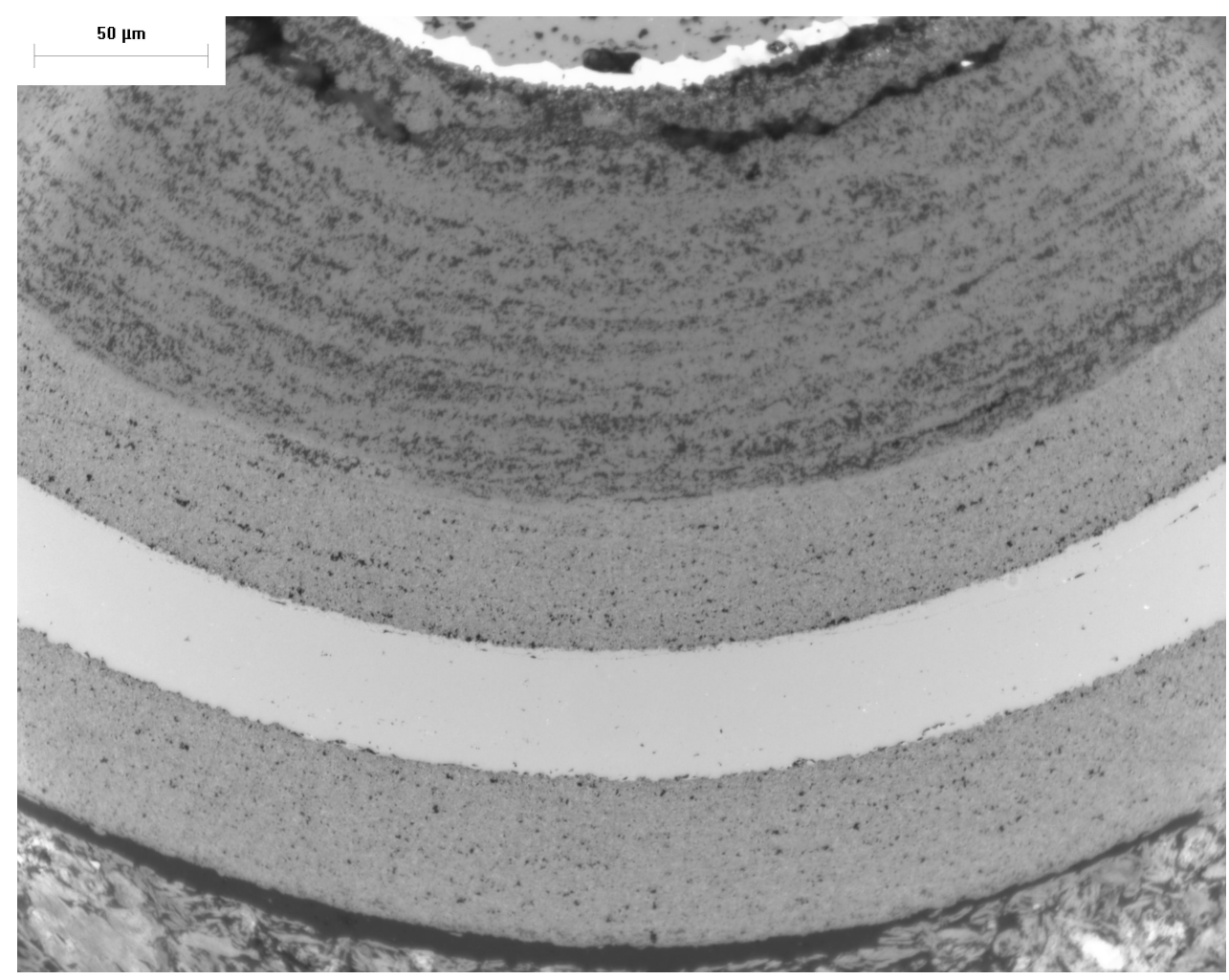

Figure 23. Higher magnification image of particle from LEU09-0P2-Z004. 


\section{Appendix A - Stereoscope Images of AGR-2 Fuel Compacts}

This appendix contains a record of the typical surface appearance of the AGR-2 fuel compacts. Compacts were positioned so a random side was imaged. Using a Leica MZ16 stereo microscope at the lowest available magnification, two images were required to capture the entire length of each compact. Note that the resulting image pairs shown in this appendix have not been stitched together and each shows about $2 / 3$ of the compact, with the center $1 / 3$ shown in both images. The camera was attached to one viewport and the samples were illuminated using a ring light. The viewing angle was $\sim 15^{\circ}$, so some image distortion is present. Reflection from the ring light appears as two bright lines down the length of the compact. 
Appendix A-1. Stereoscope images of archive compacts from LEU06-OP1-Z.

Appendix A-1 contains images of 16 archive compacts from compact lot LEU06-OP1-Z. The compacts are identified by the compact ID number, which can be traced back to the fabrication record for each compact. Compact lot LEU06-OP1-Z was fully characterized, but was not used in the AGR-2 irradiation test. 
Appendix A-1. Stereoscope images of archive compacts from LEU06-OP1-Z.

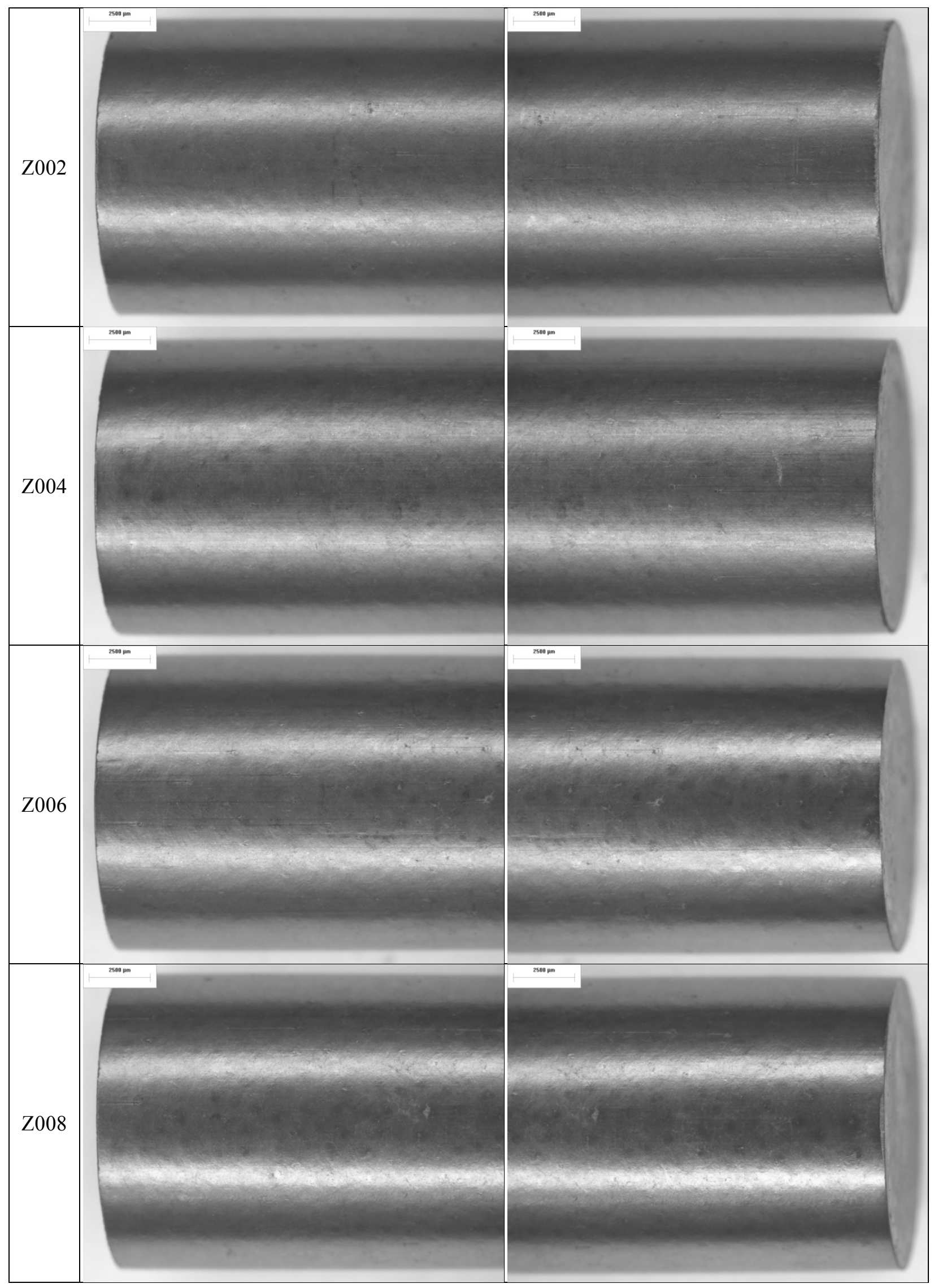


Appendix A-1. Stereoscope images of archive compacts from LEU06-OP1-Z.

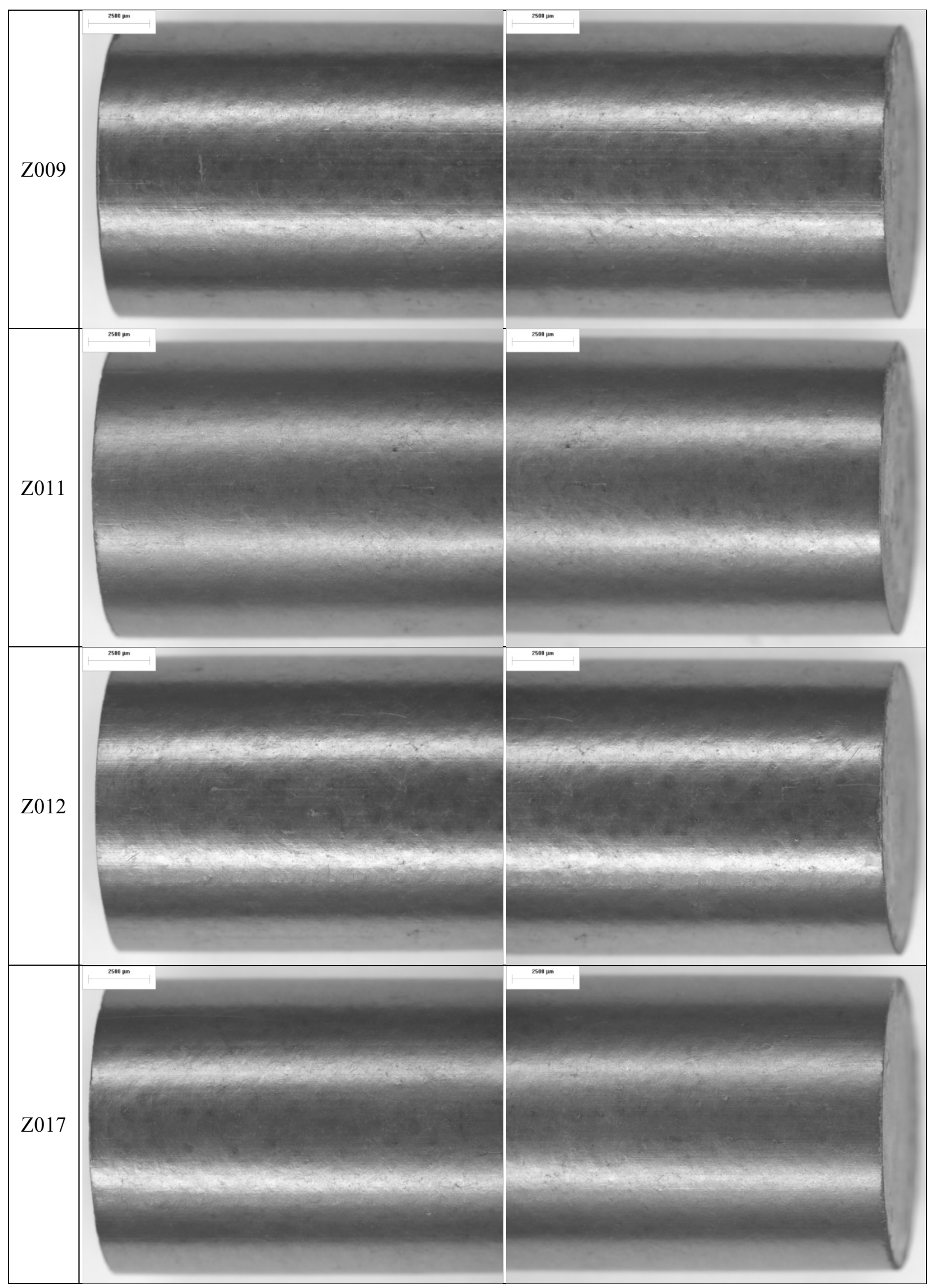


Appendix A-1. Stereoscope images of archive compacts from LEU06-OP1-Z.

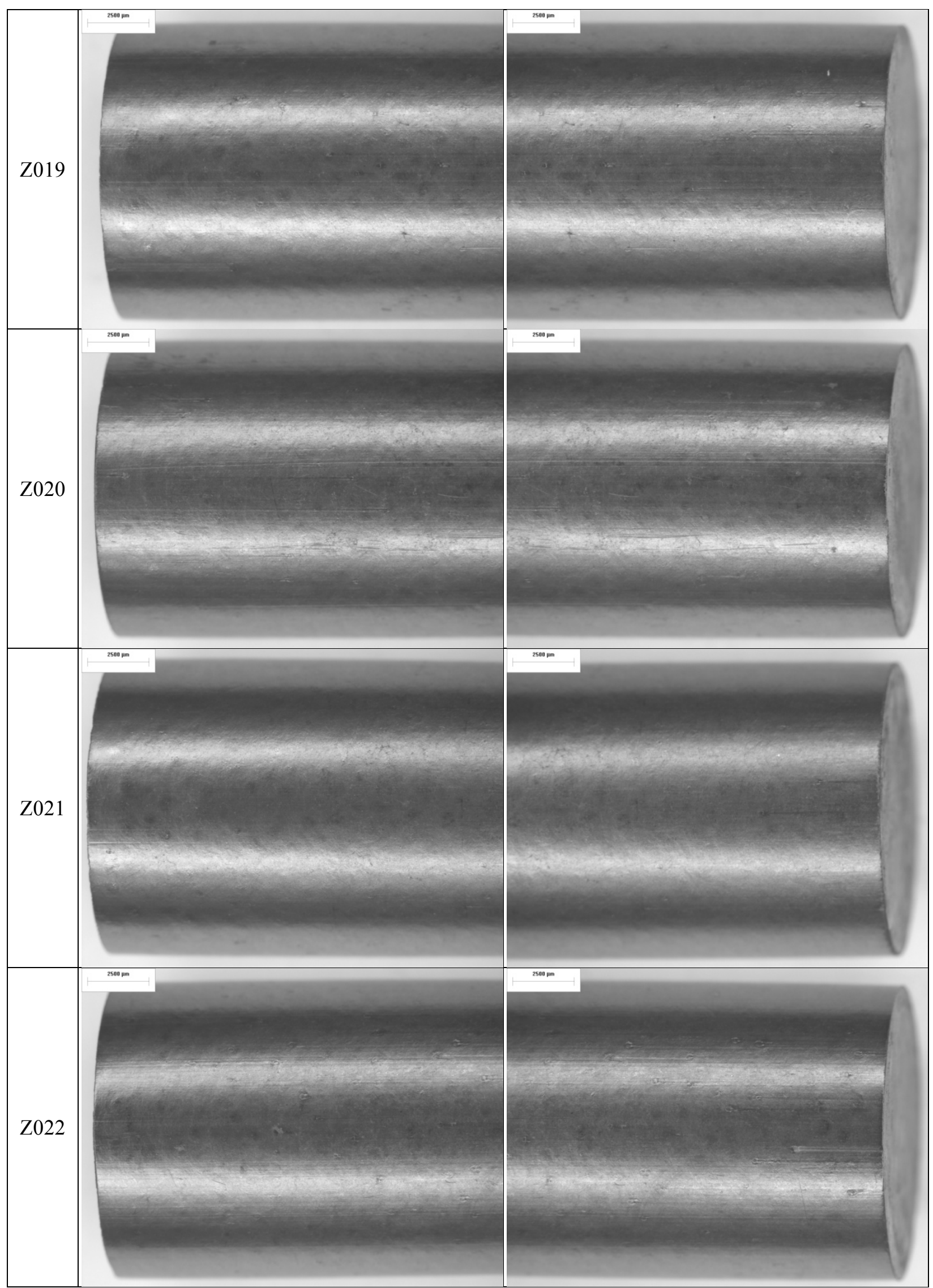


Appendix A-1. Stereoscope images of archive compacts from LEU06-OP1-Z.

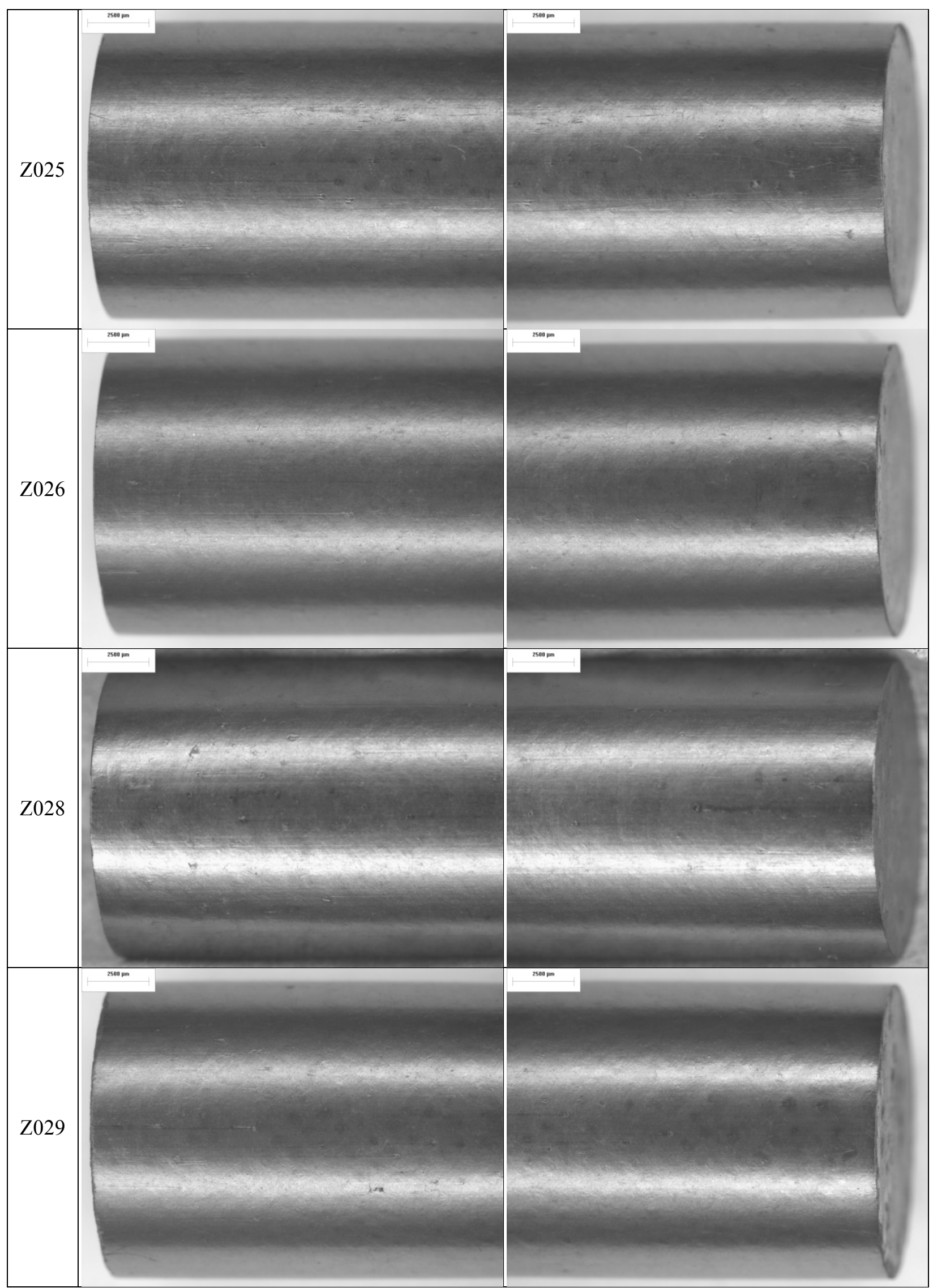


Appendix A-2. Stereoscope images of archive compacts from LEU07-OP1-Z.

Appendix A-2 contains images of 24 archive compacts from compact lot LEU07-OP1-Z. The compacts are identified by the compact ID number, which can be traced back to the fabrication record for each compact. Compact lot LEU07-OP1-Z was fully characterized, but was not used in the AGR-2 irradiation test. 
Appendix A-2. Stereoscope images of archive compacts from LEU07-OP1-Z.

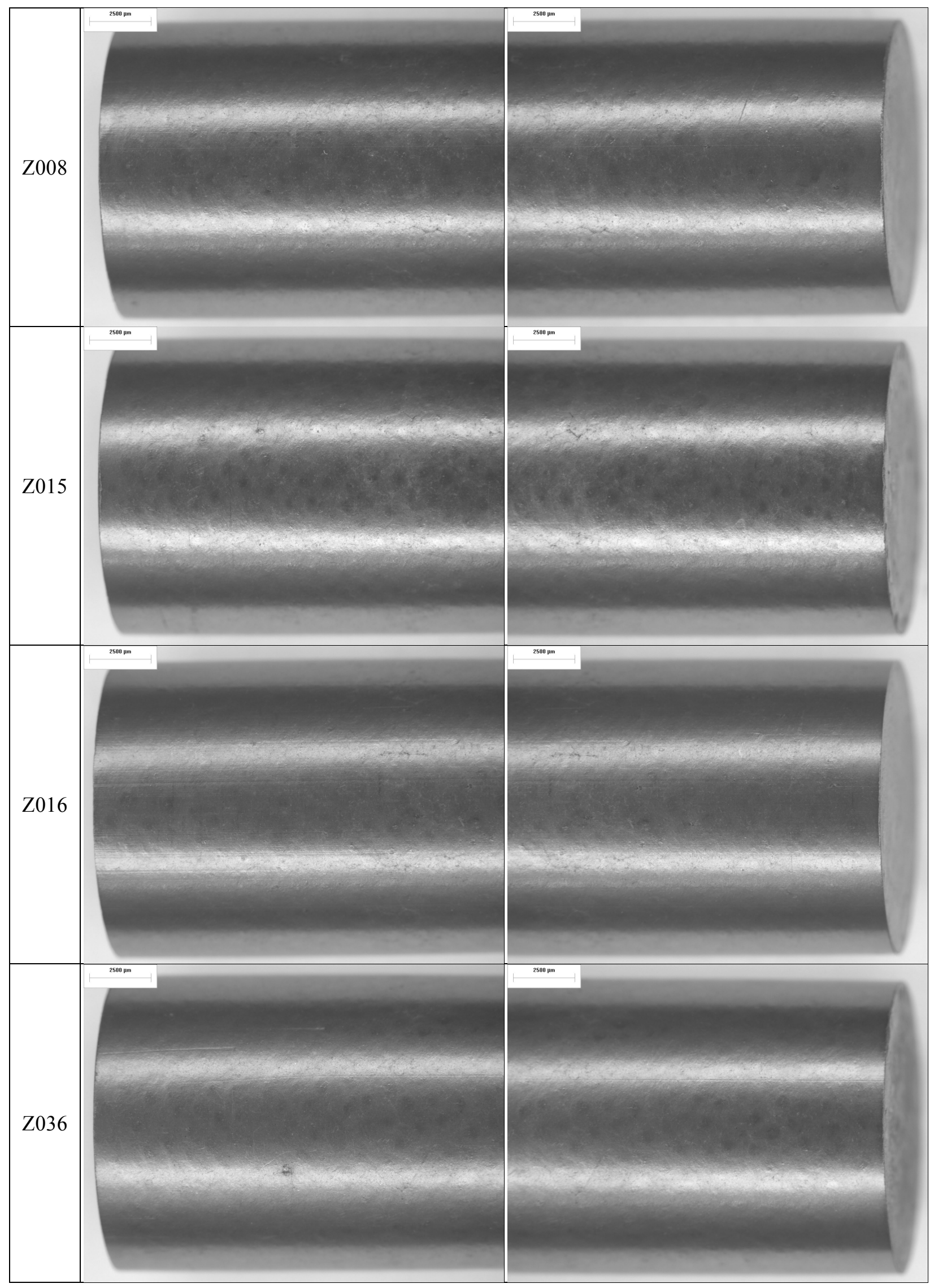


Appendix A-2. Stereoscope images of archive compacts from LEU07-OP1-Z.

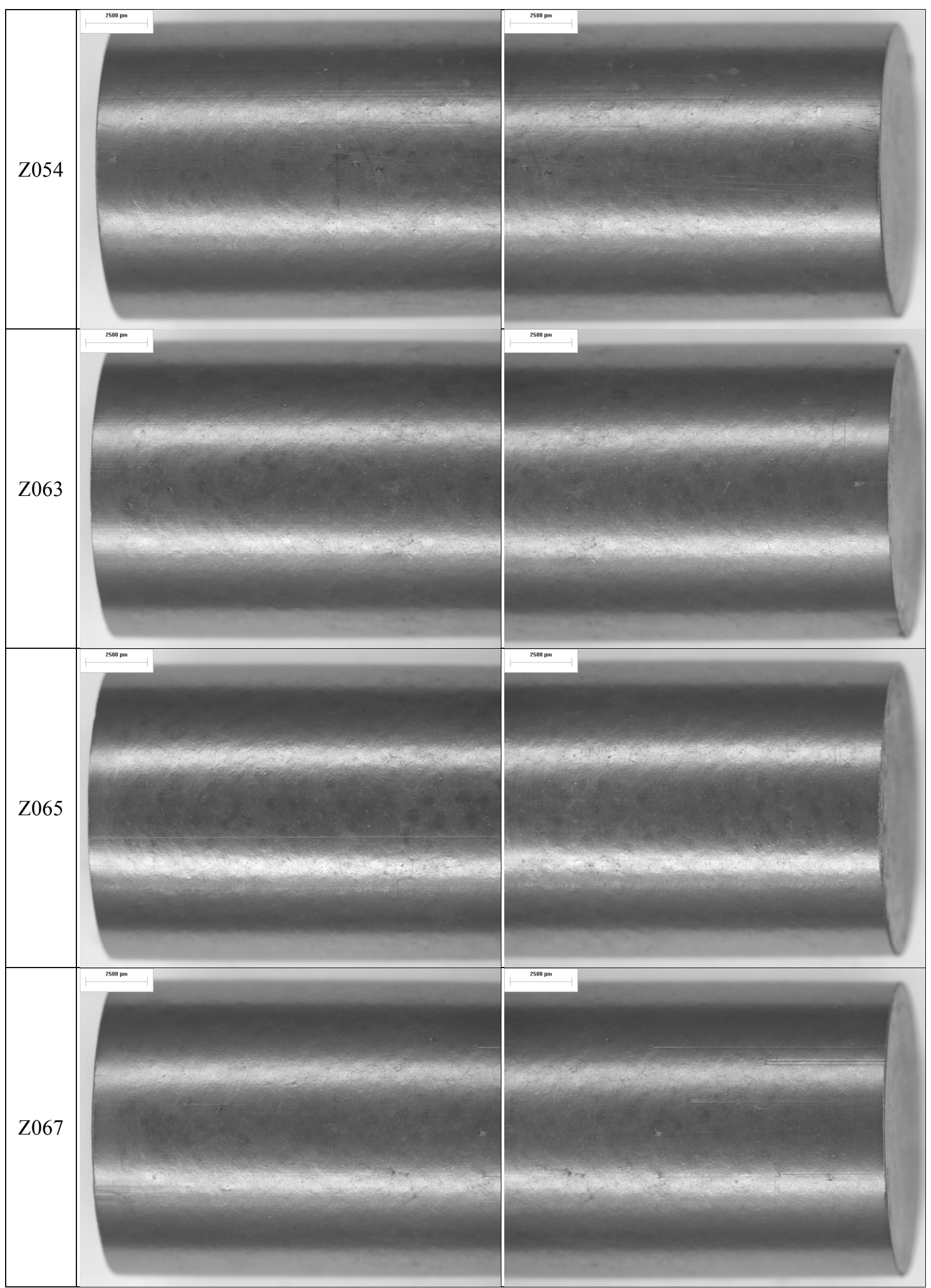


Appendix A-2. Stereoscope images of archive compacts from LEU07-OP1-Z.

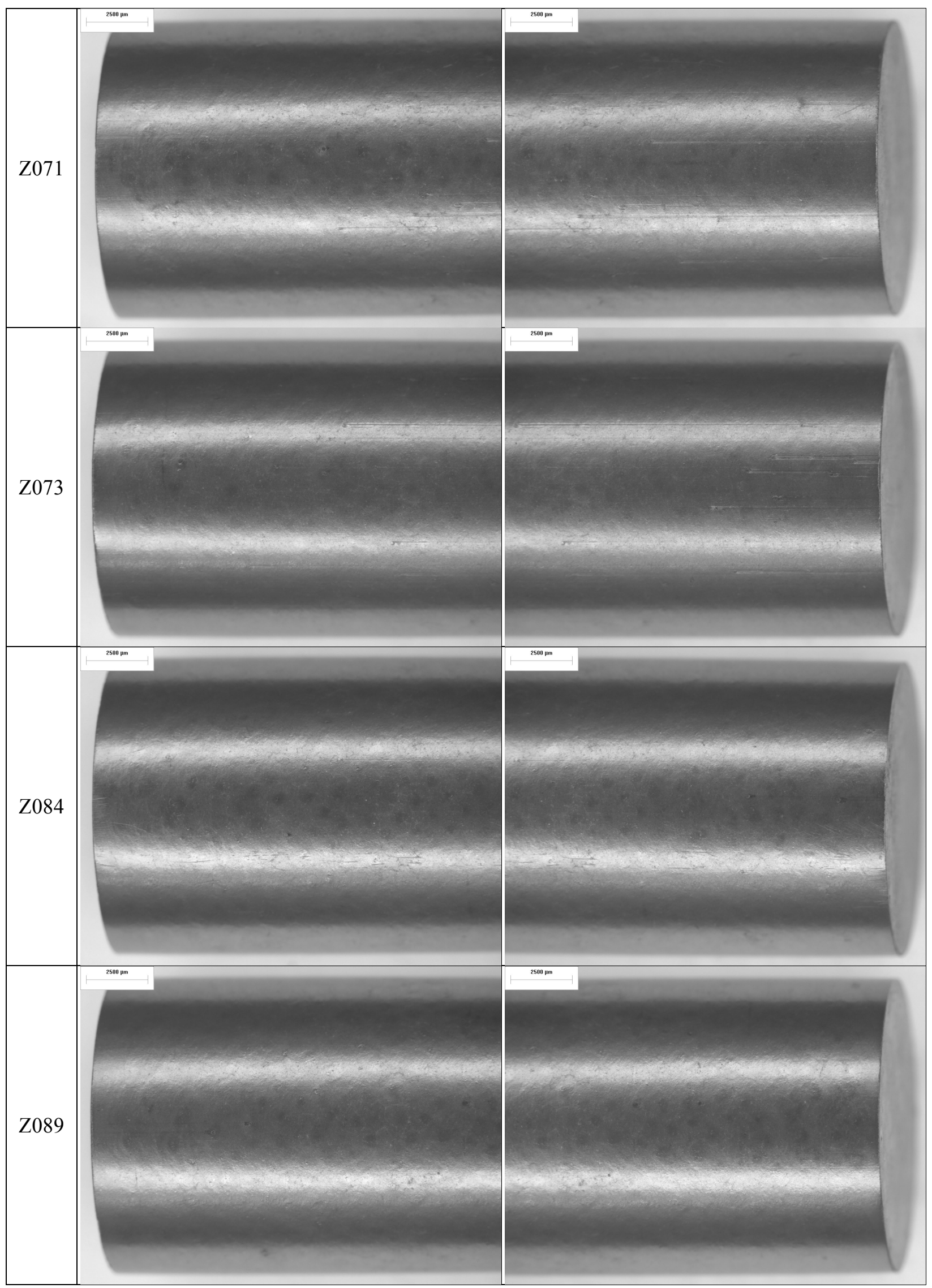


Appendix A-2. Stereoscope images of archive compacts from LEU07-OP1-Z.

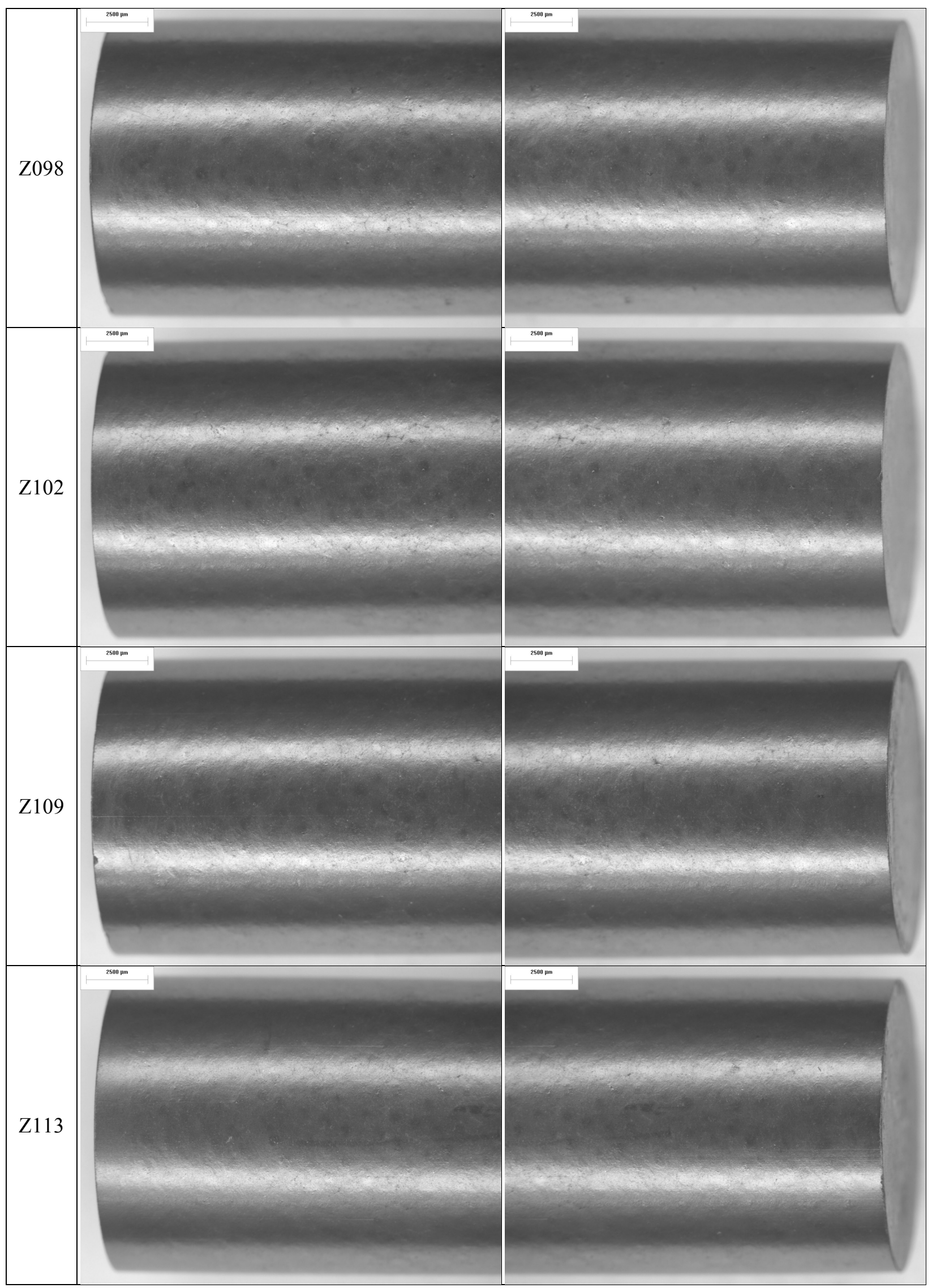


Appendix A-2. Stereoscope images of archive compacts from LEU07-OP1-Z.

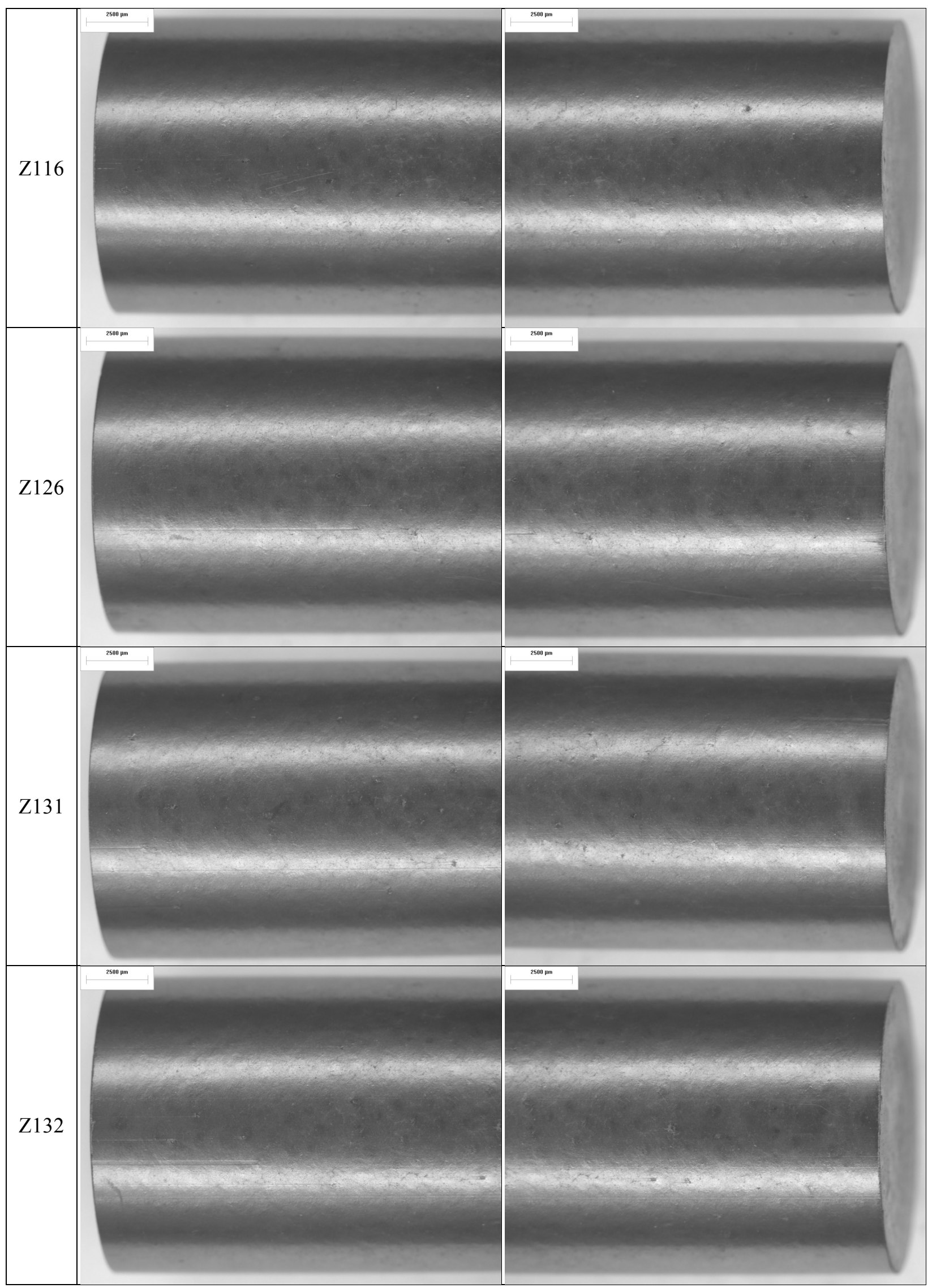


Appendix A-2. Stereoscope images of archive compacts from LEU07-OP1-Z.

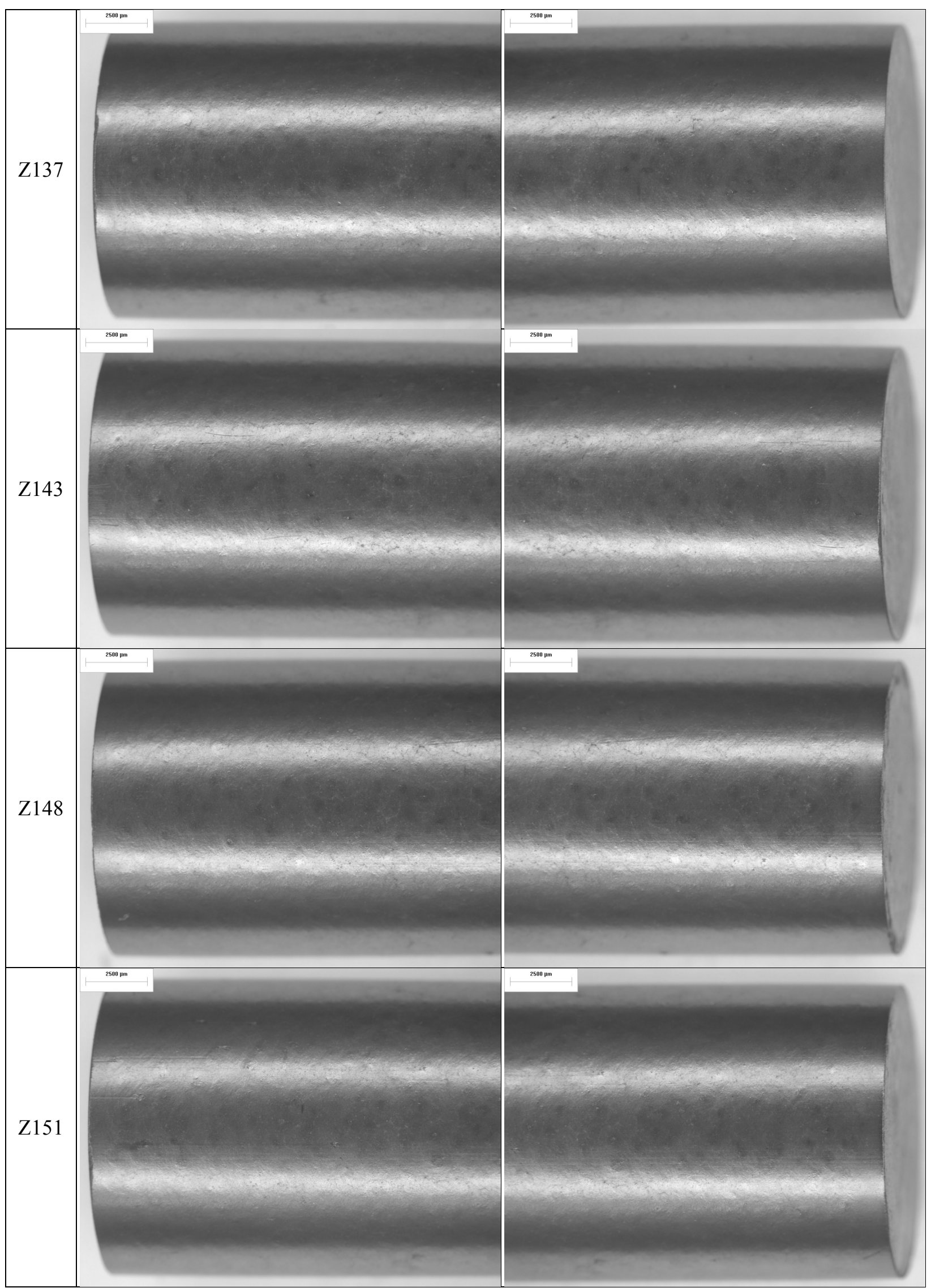


Appendix A-3. Stereoscope images of archive compacts from LEU09-OP2-Z.

Appendix A-3 contains images of 12 archive compacts from compact lot LEU09-OP2-Z. The compacts are identified by the compact ID number, which can be traced back to the fabrication record for each compact. These compacts are representative of those that were inserted into the AGR-2 irradiation test. 
Appendix A-3. Stereoscope images of archive compacts from LEU09-OP2-Z.

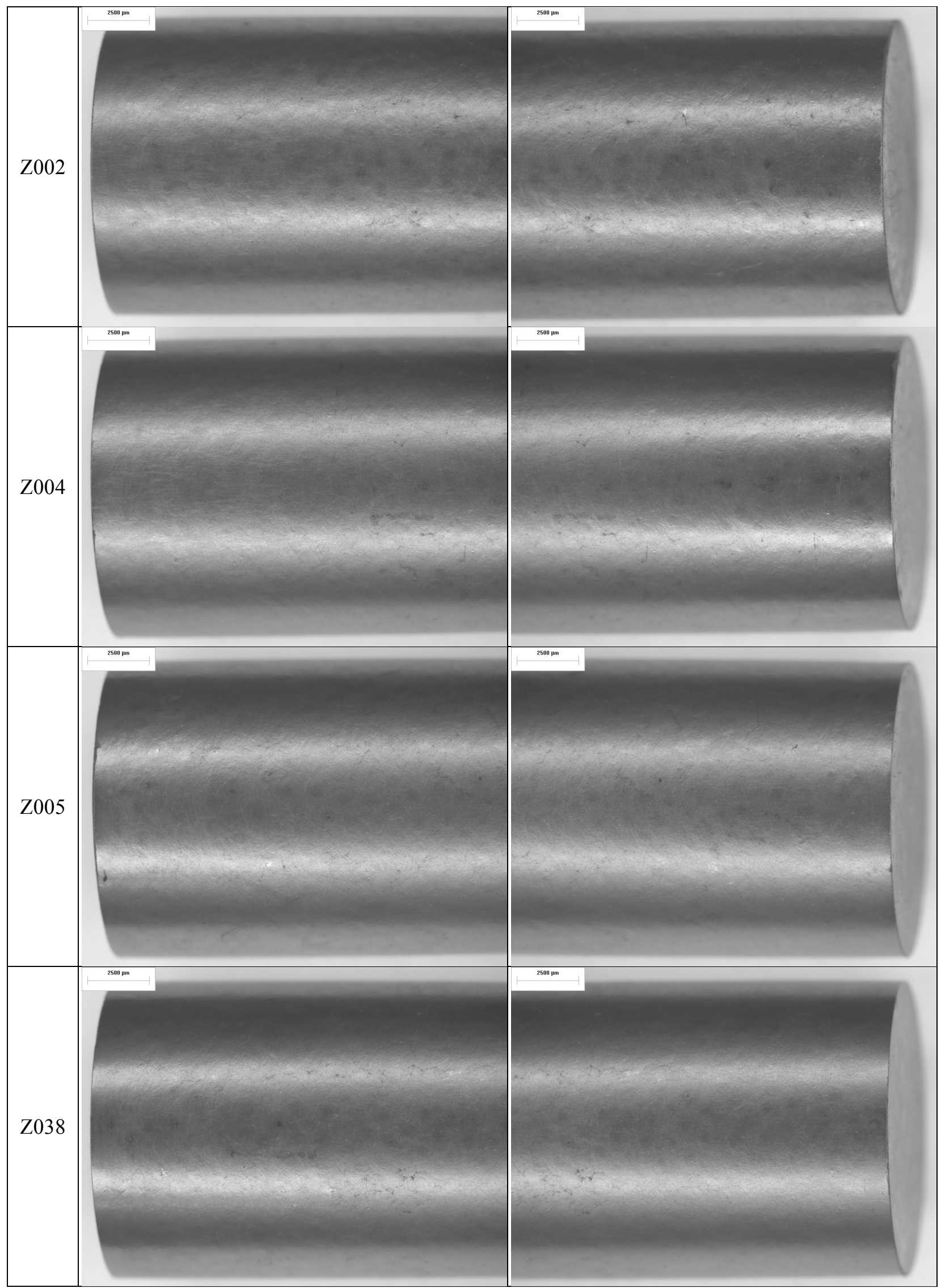


Appendix A-3. Stereoscope images of archive compacts from LEU09-OP2-Z.

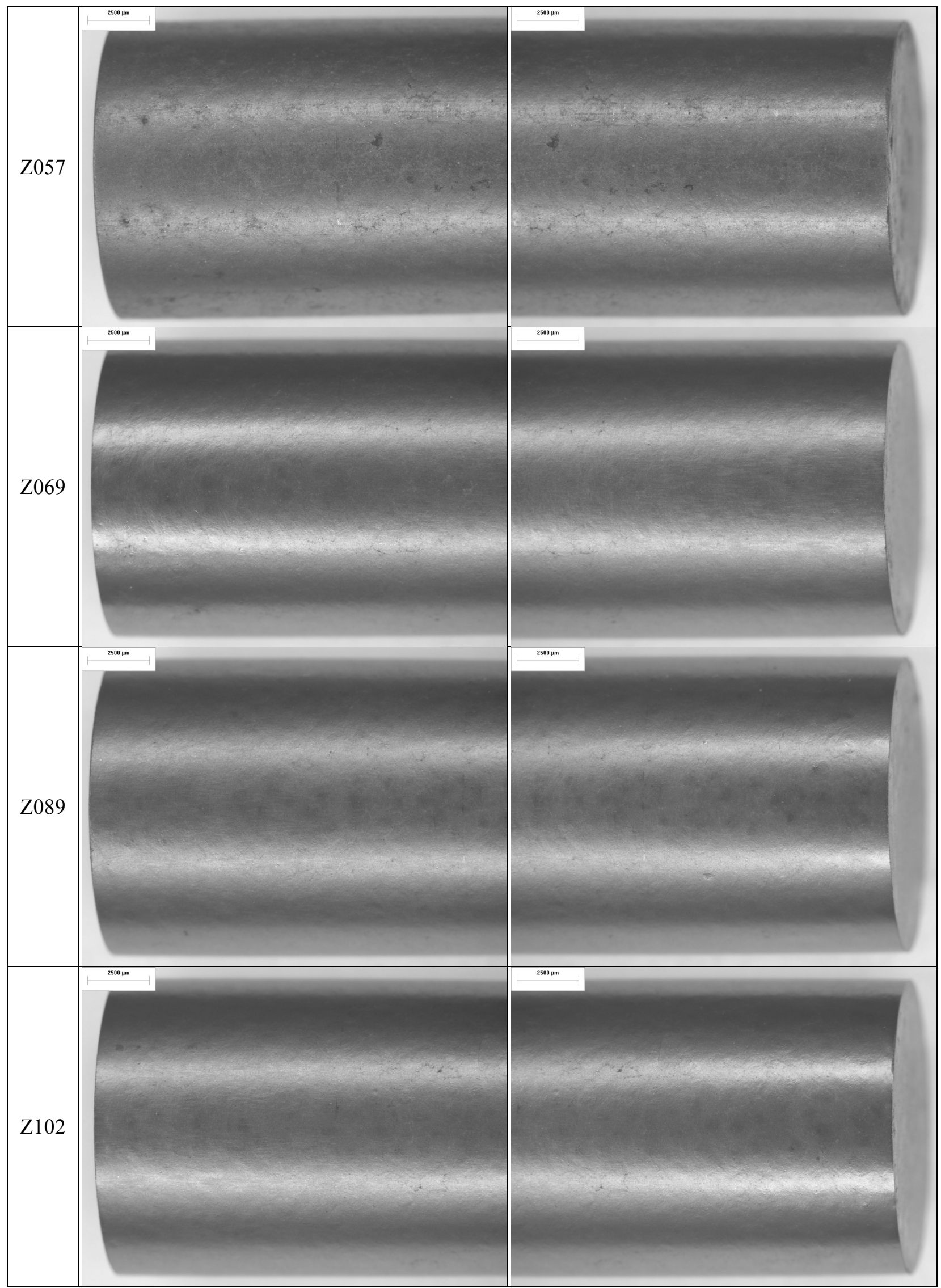


Appendix A-3. Stereoscope images of archive compacts from LEU09-OP2-Z.

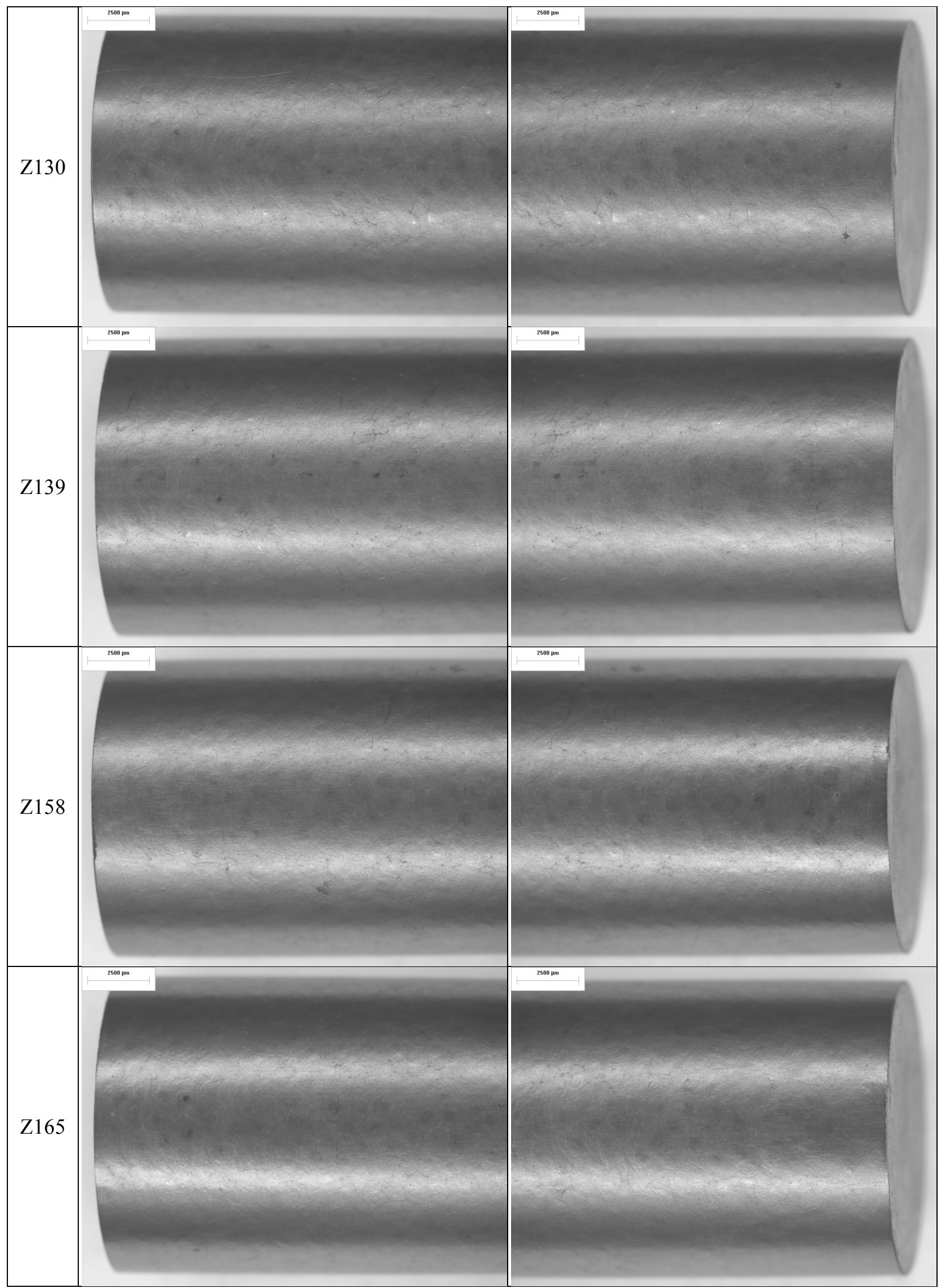


Appendix A-4. Stereoscope images of archive compacts from LEU11-OP2-Z.

Appendix A-4 contains images of 12 archive compacts from compact lot LEU11-OP2-Z. The compacts are identified by the compact ID number, which can be traced back to the fabrication record for each compact. These compacts are representative of those that were inserted into the AGR-2 irradiation test. 
Appendix A-4. Stereoscope images of archive compacts from LEU11-OP2-Z.

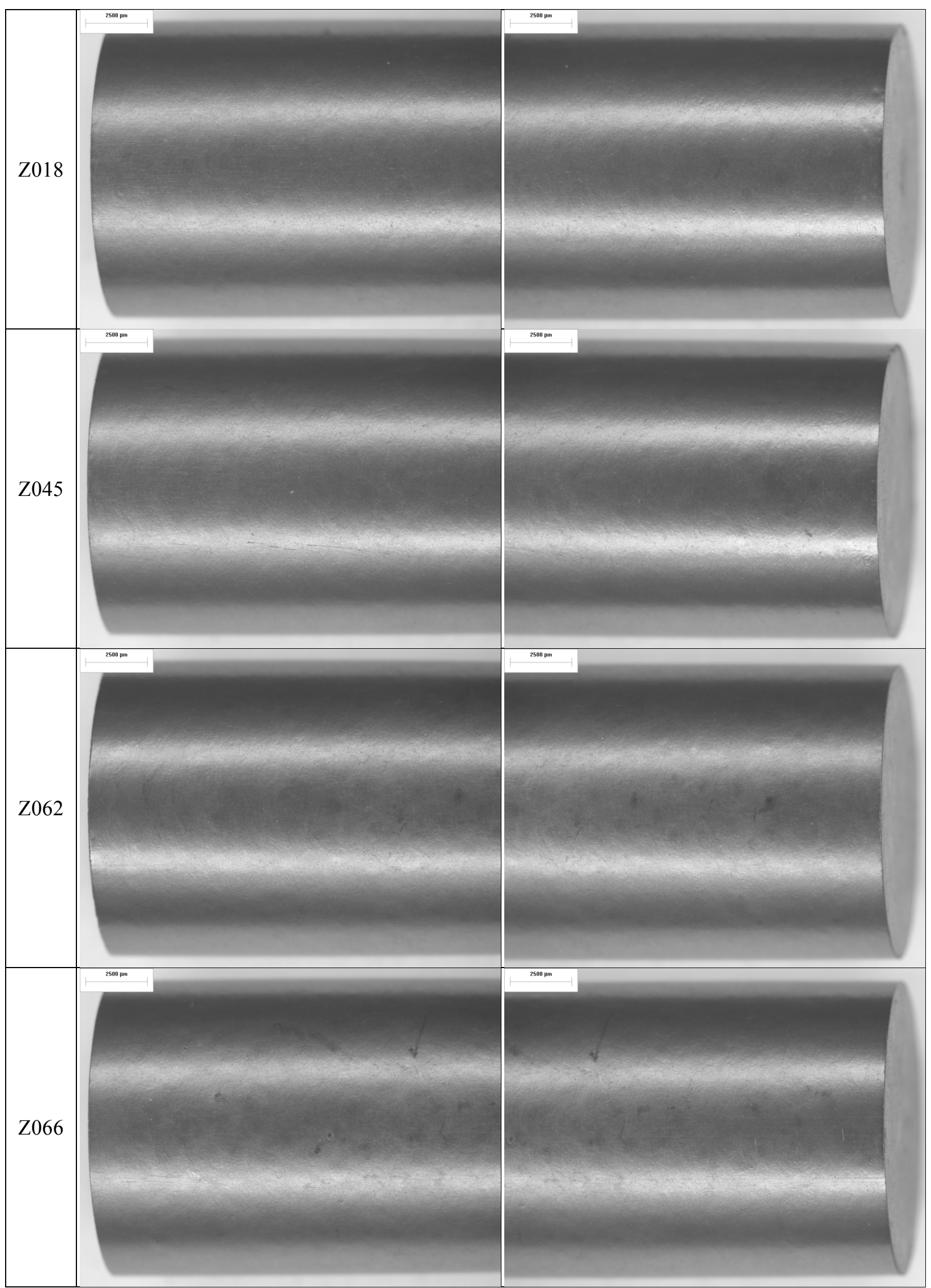


Appendix A-4. Stereoscope images of archive compacts from LEU11-OP2-Z.

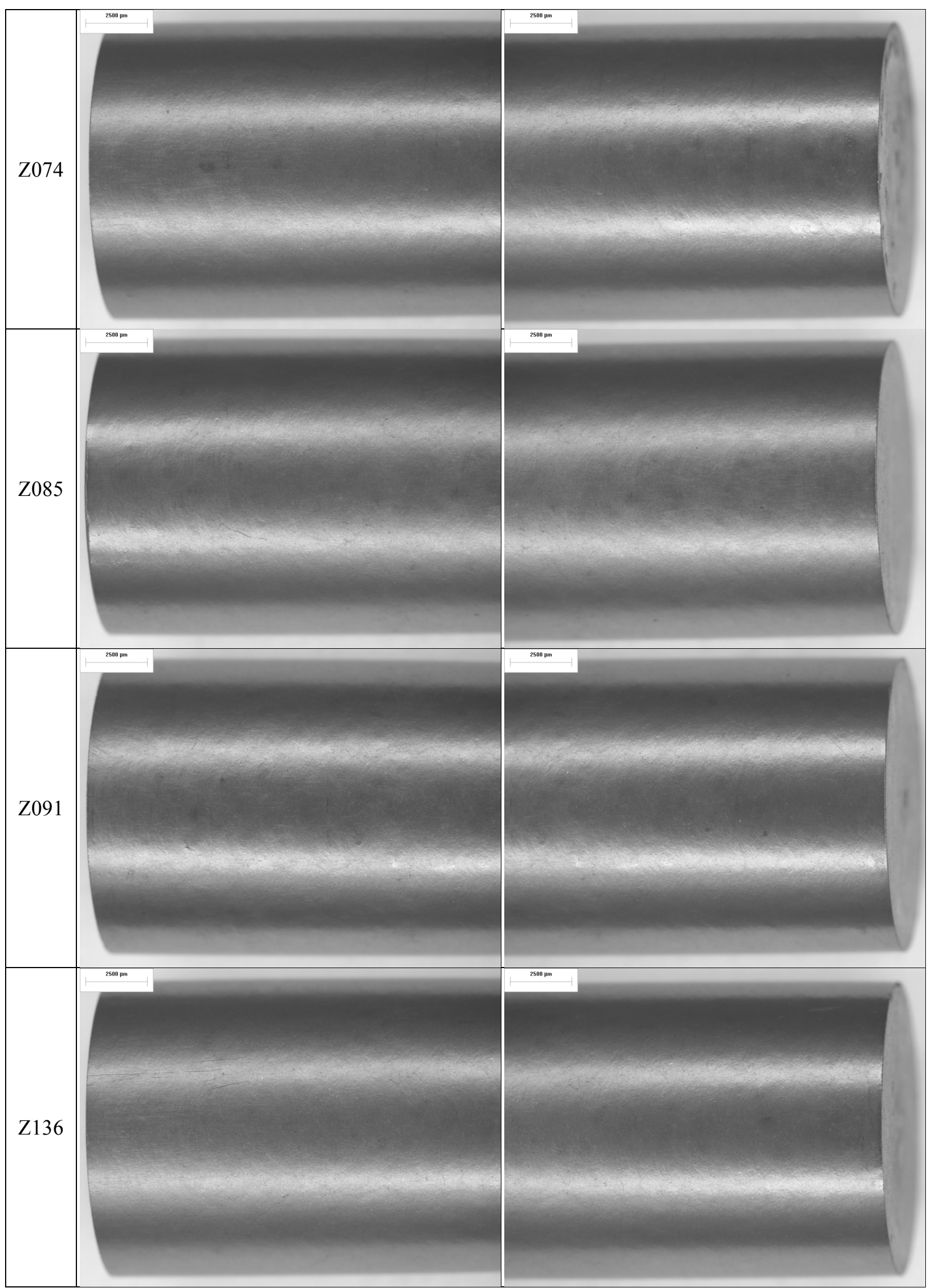


Appendix A-4. Stereoscope images of archive compacts from LEU11-OP2-Z.

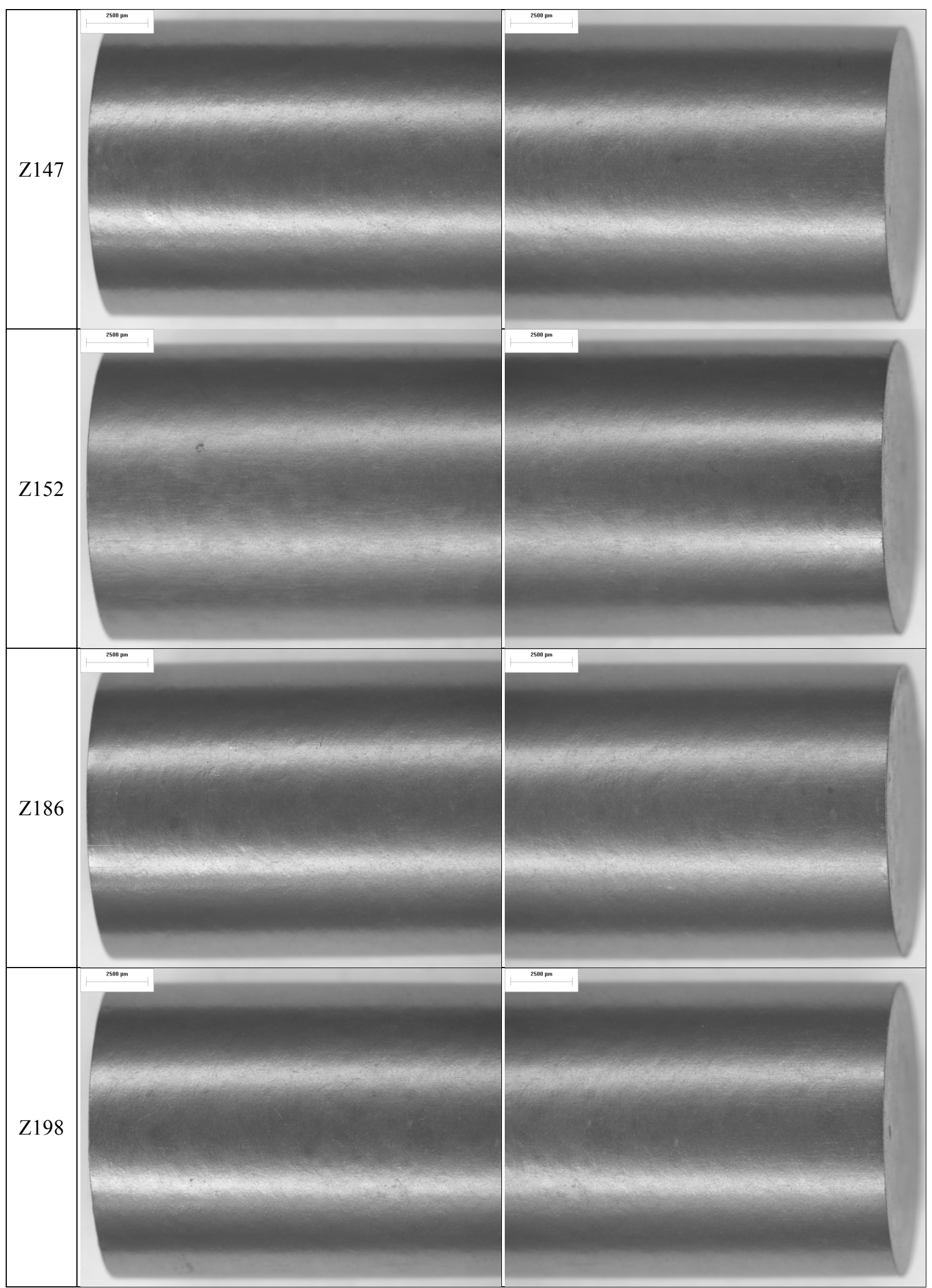




\section{Appendix B - X-ray Radiographs of AGR-2 Fuel Compacts}

This appendix contains a record of the typical radiographic appearance of the AGR-2 fuel compacts. The images were obtained using a Seifert $320 \mathrm{x}$-ray unit operating at $50 \mathrm{kV}$ and $10 \mathrm{~mA}$. The $\mathrm{x}$-ray film was located $122 \mathrm{~cm}$ from the source. Compacts were laid directly on the x-ray film and radiographs obtained using a 12 sec exposure.

The $\mathrm{x}$-ray conditions were optimized to be able to distinguish the $\mathrm{SiC}$ coating layer with minimal loss of sensitivity for the compact boundaries. Edge detection along the length of the compact cylinder was limited because the $x$-ray path length was too short to get appreciable x-ray attenuation close to the edge. Edge detection at the top and the bottom of the compact cylinder was more reliable because of the longer x-ray path length. One end of the compact was typically better defined than the other because it was closer to the centerline of the $\mathrm{x}$-ray source. The end of the compact away from the centerline appeared slightly "fuzzy" because the x-rays were penetrating at a slight angle with respect to the flat face of the compact.

The orientation of the radiographs in this appendix should correspond to the orientation of the compact in the die. 
Appendix B-1. X-ray radiographs of archive compacts from LEU06-OP1-Z.

Appendix B-1 contains x-ray radiographs of 16 archive compacts from compact lot LEU06-OP1-Z. The compacts are identified by the compact ID number, which can be traced back to the fabrication record for each compact. Compact lot LEU06-OP1-Z was fully characterized, but was not used in the AGR-2 irradiation test. 
Appendix B-1. X-ray radiographs of archive compacts from LEU06-OP1-Z.

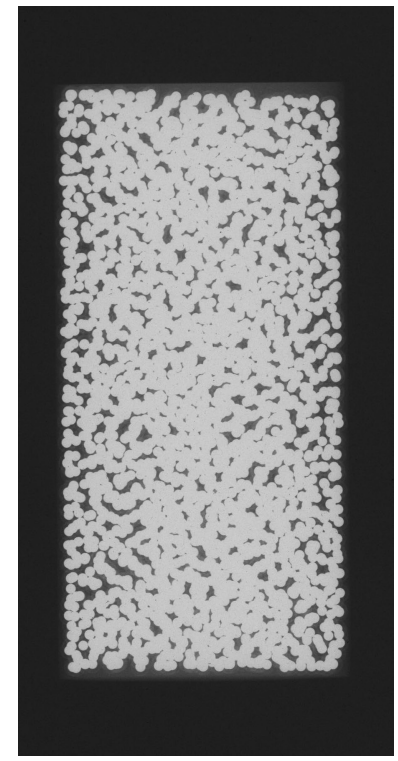

Z002

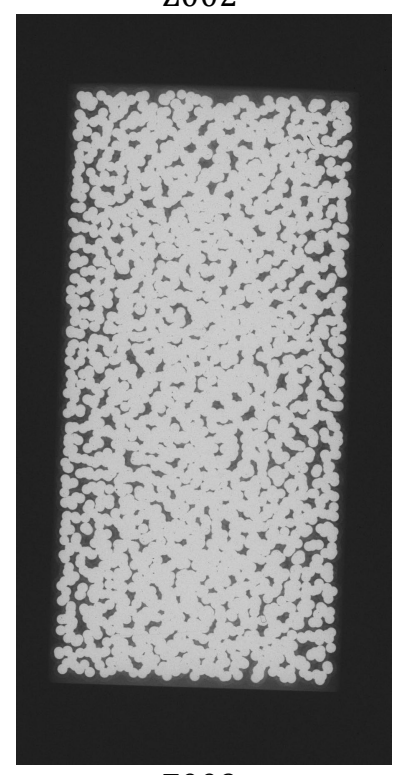

Z009

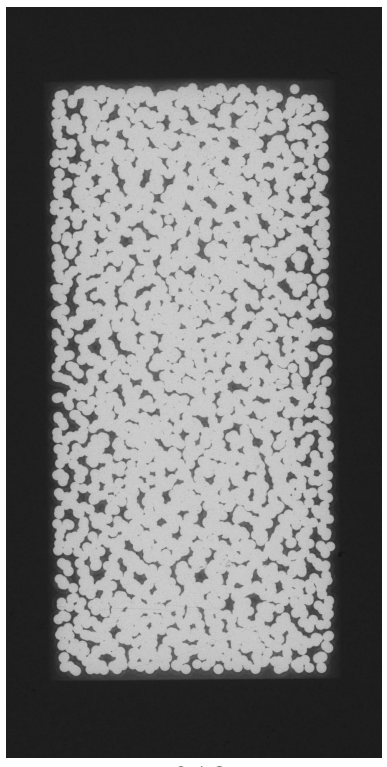

Z019

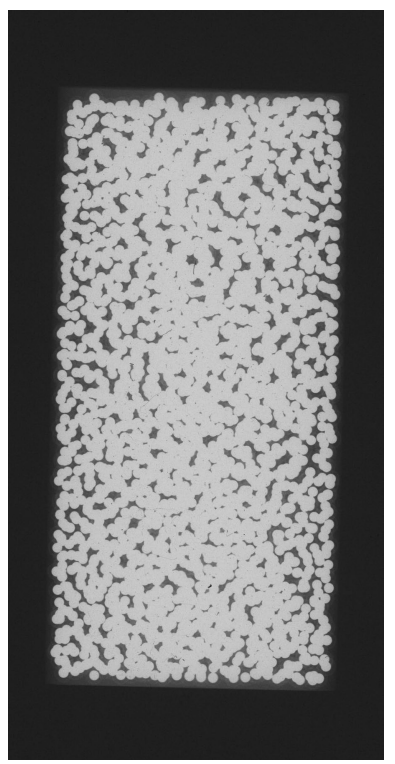

Z004

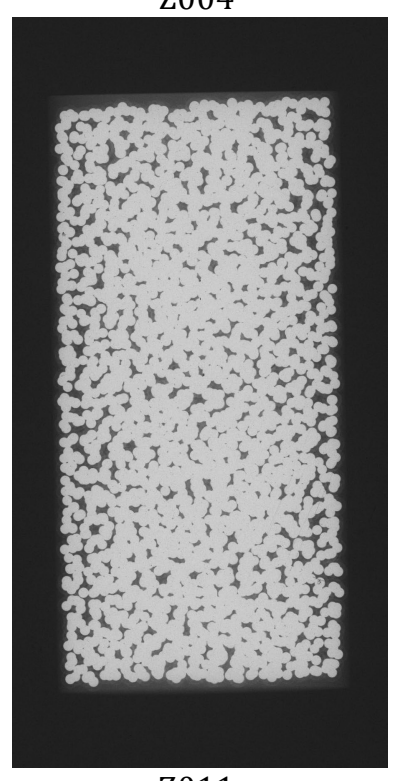

Z011

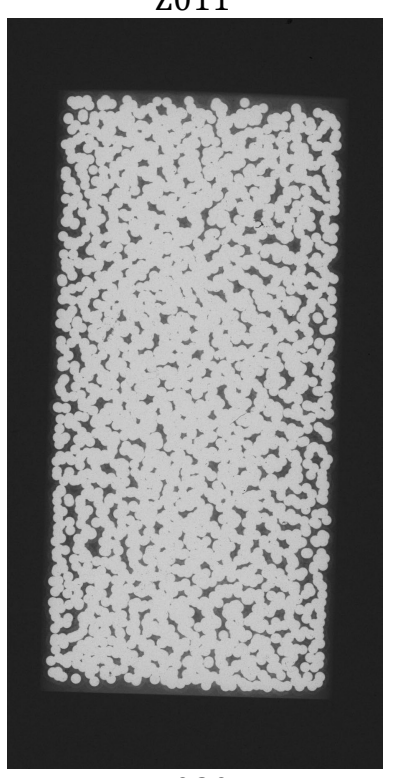

Z020

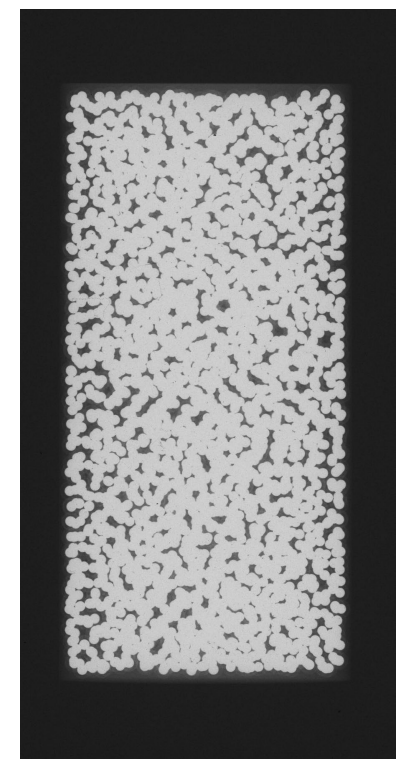

Z006

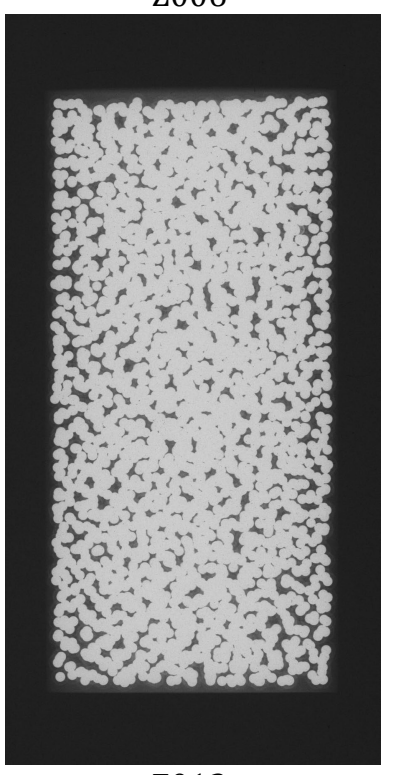

Z012

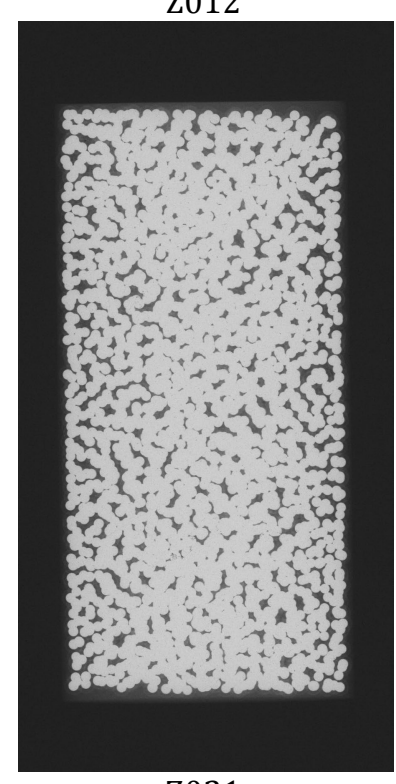

Z021

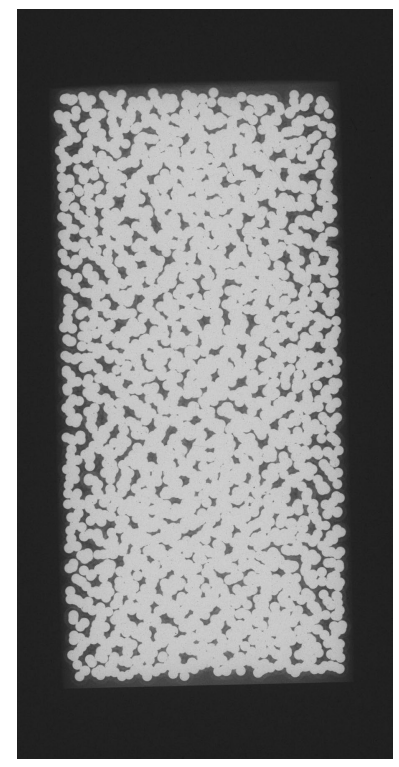

Z008

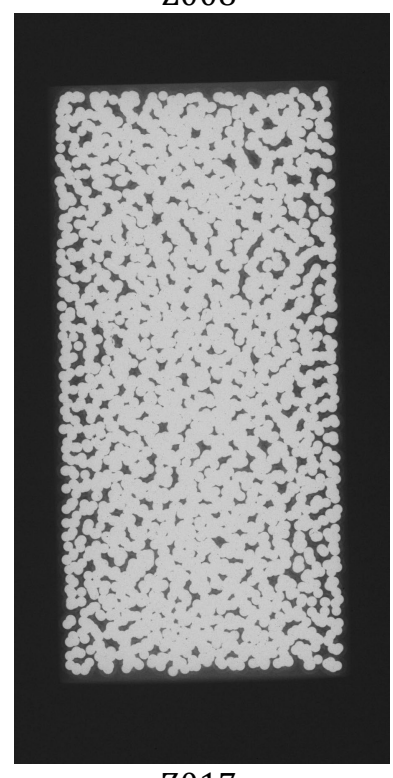

Z017

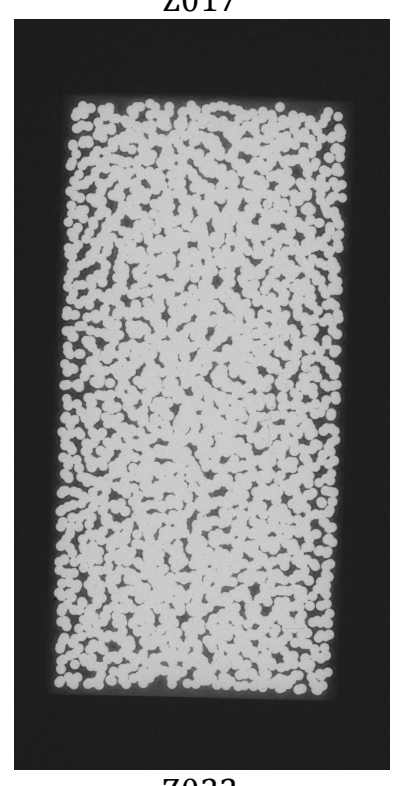

Z022 
Appendix B-1. X-ray radiographs of archive compacts from LEU06-OP1-Z.

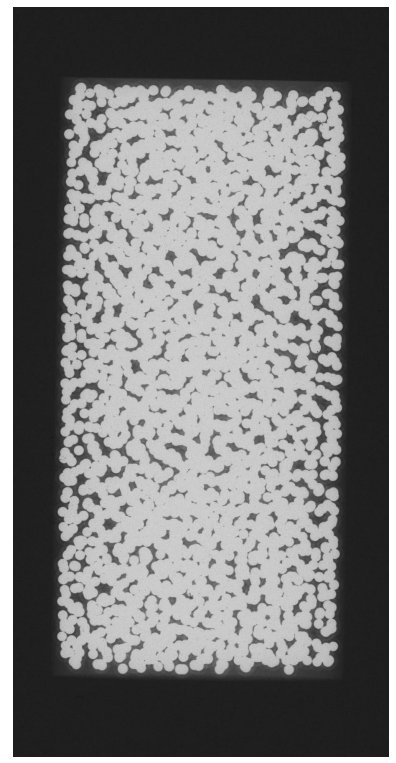

Z025

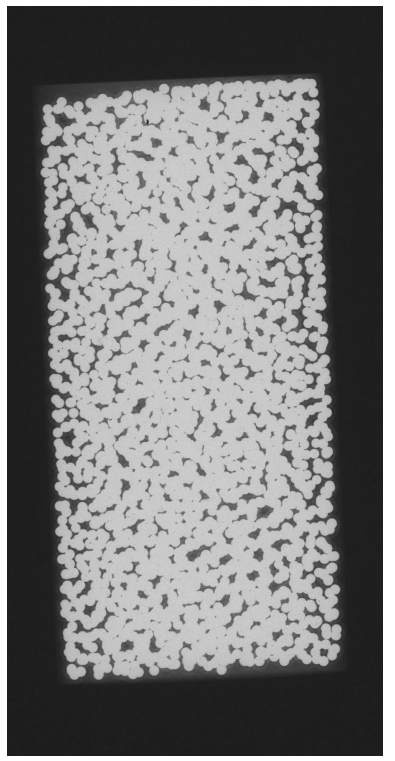

Z026

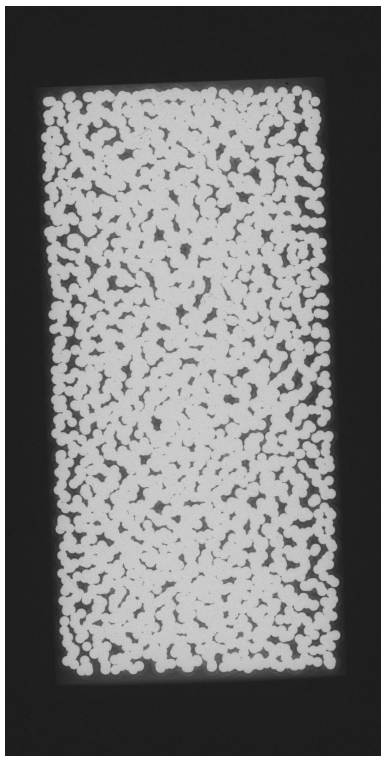

Z028

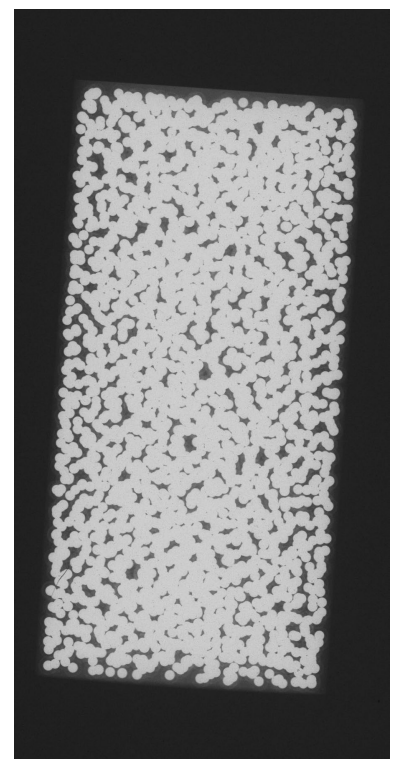

Z029 
Appendix B-2. X-ray radiographs of archive compacts from LEU07-OP1-Z.

Appendix B-2 contains x-ray radiographs of 24 archive compacts from compact lot LEU07-OP1-Z. The compacts are identified by the compact ID number, which can be traced back to the fabrication record for each compact. Compact lot LEU07-OP1-Z was fully characterized, but was not used in the AGR-2 irradiation test. 
Appendix B-2. X-ray radiographs of archive compacts from LEU07-OP1-Z.

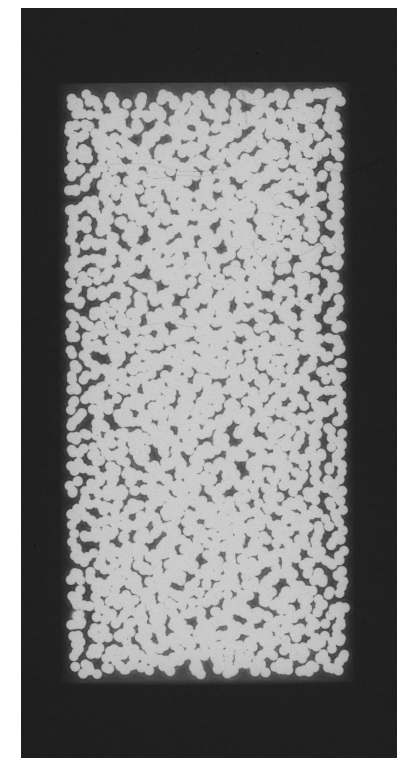

Z008

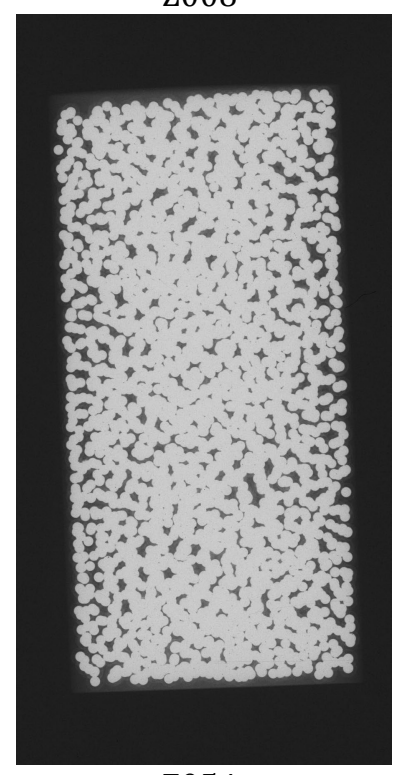

Z054

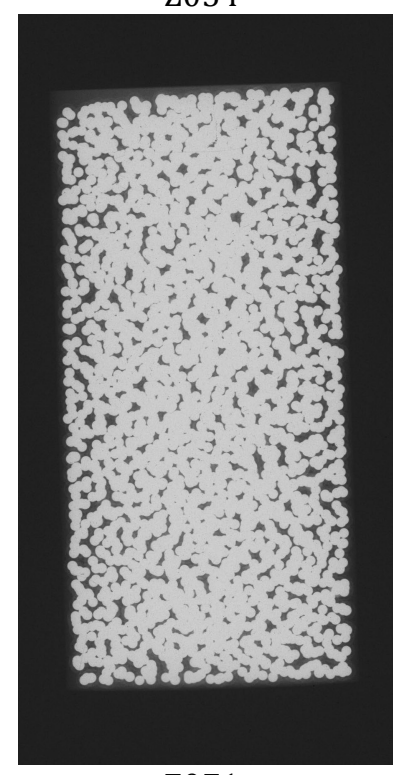

Z071

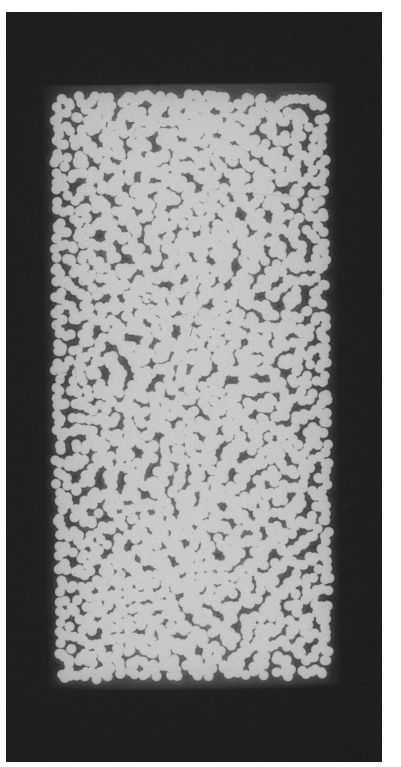

Z015

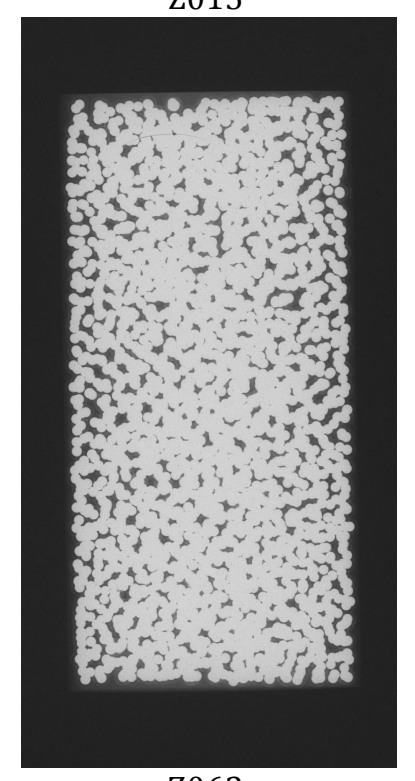

Z063

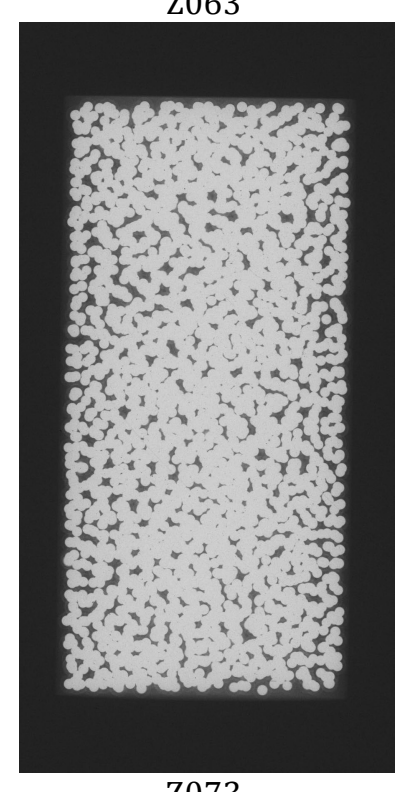

Z073

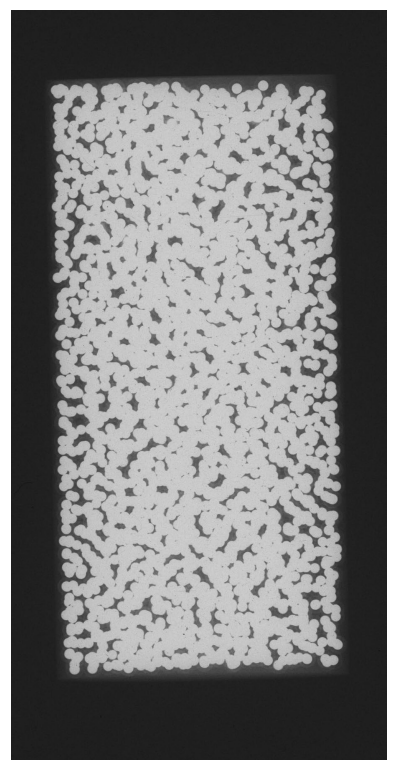

Z016

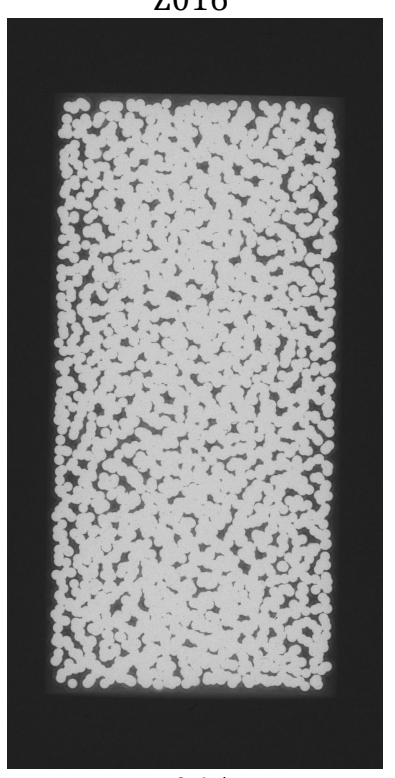

Z065

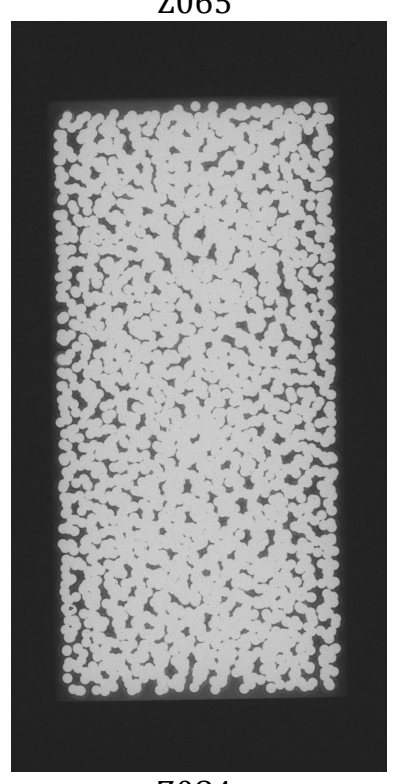

Z084

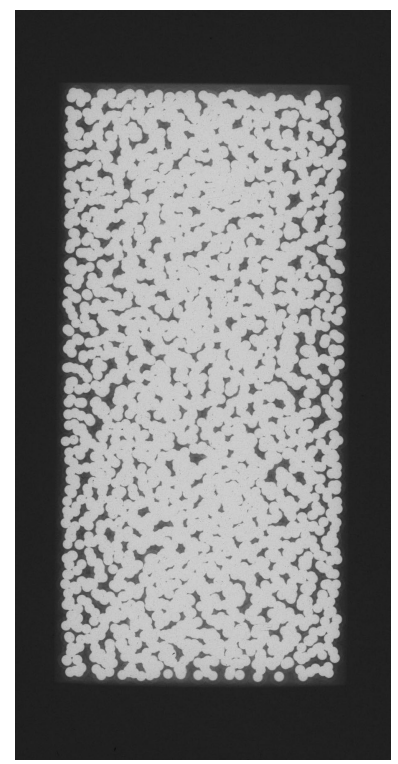

Z036

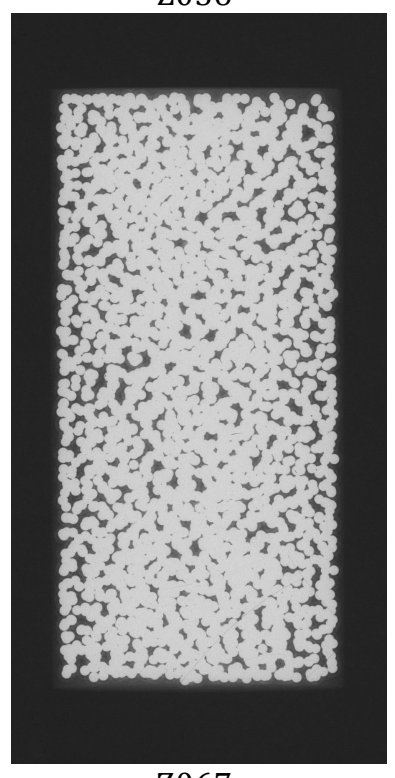

Z067

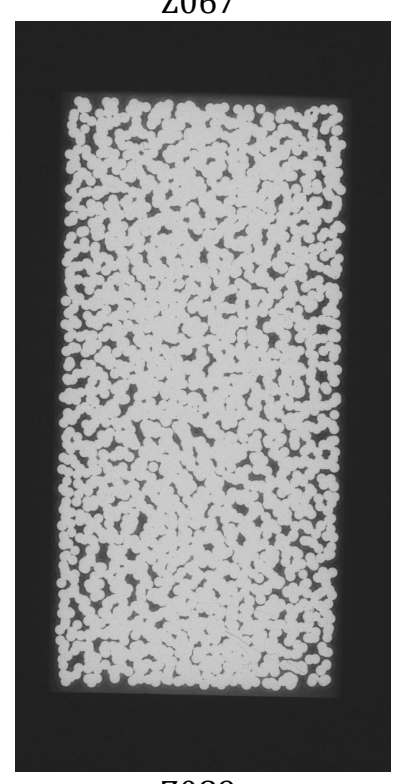

Z089 
Appendix B-2. X-ray radiographs of archive compacts from LEU07-OP1-Z.

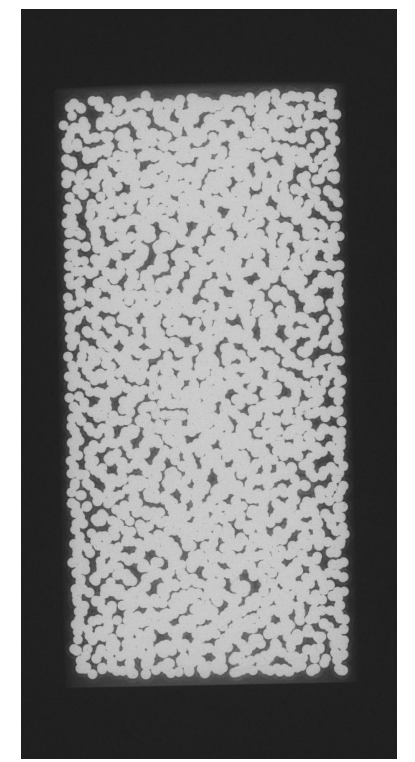

Z098

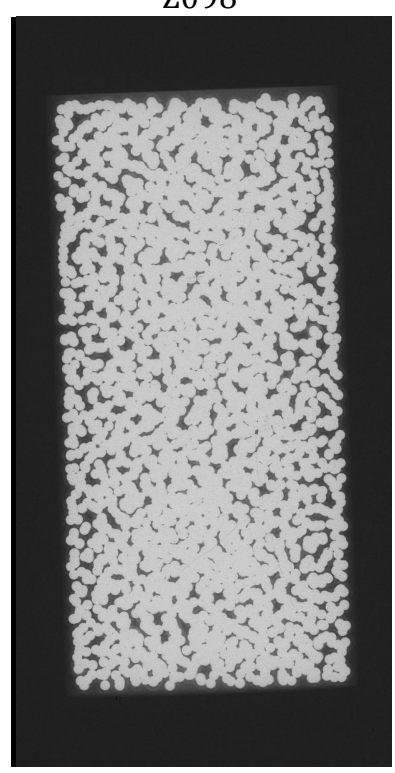

Z116

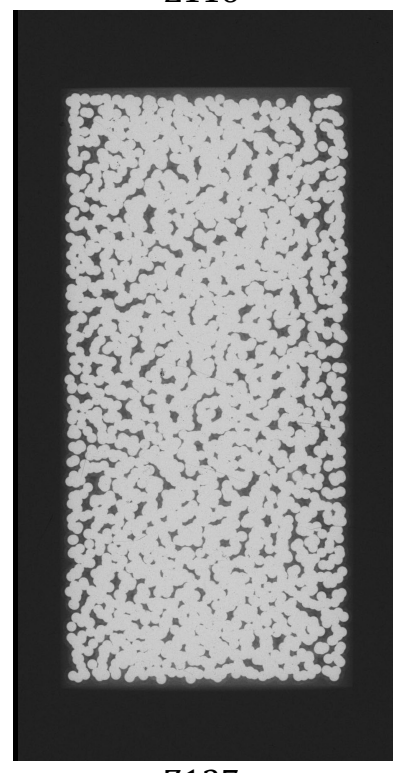

Z137

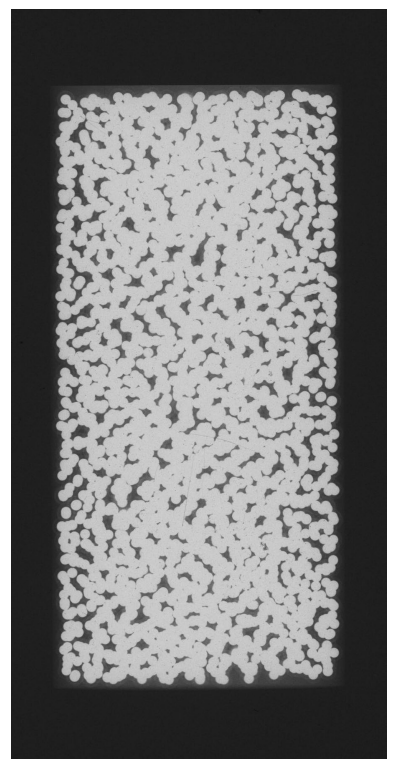

Z102

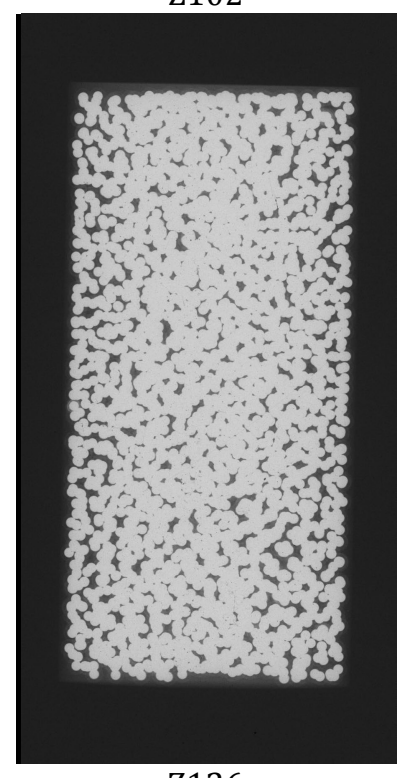

Z126

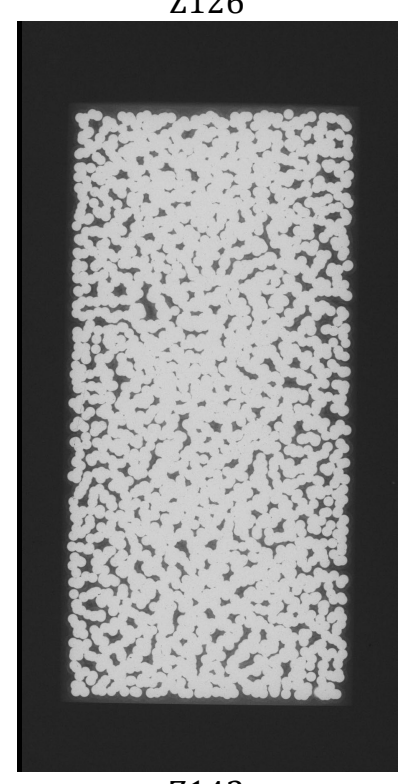

Z143

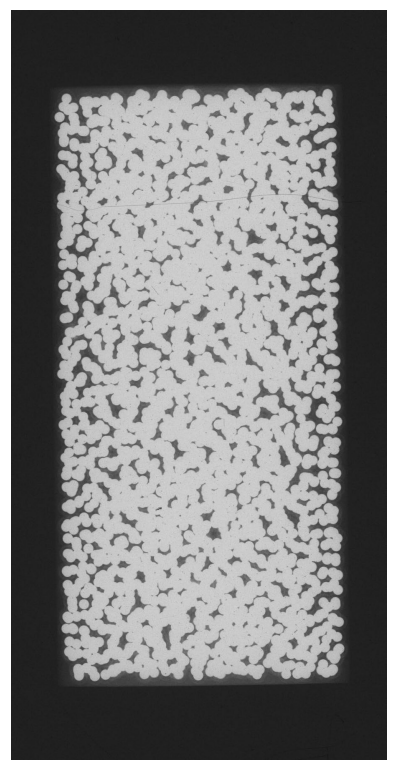

Z109

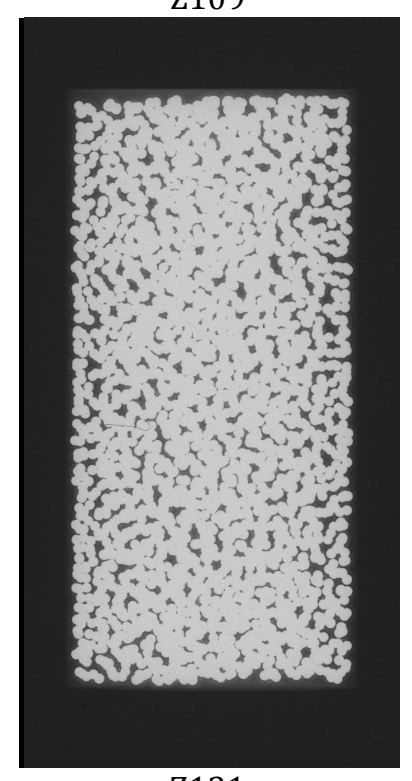

Z131

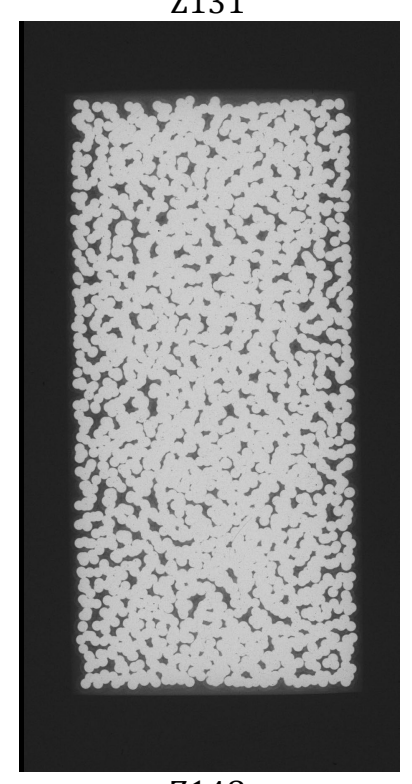

Z148

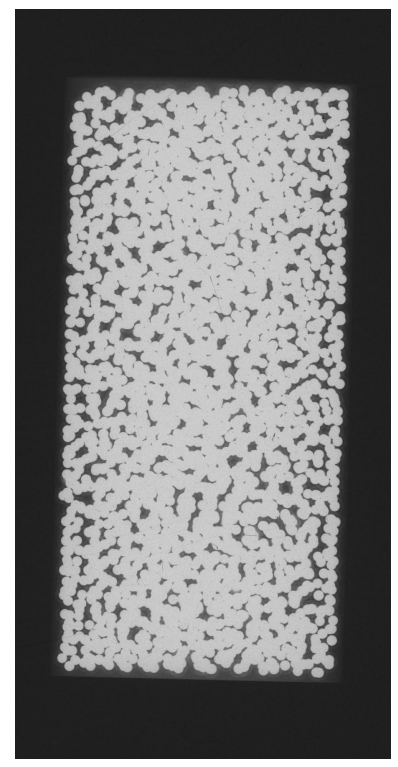

Z113

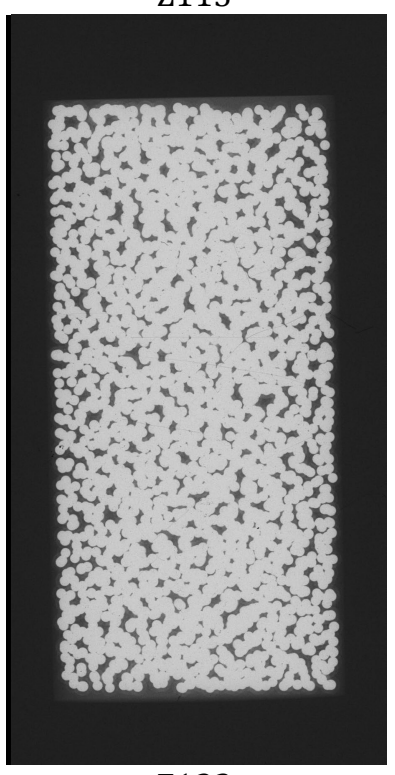

Z132

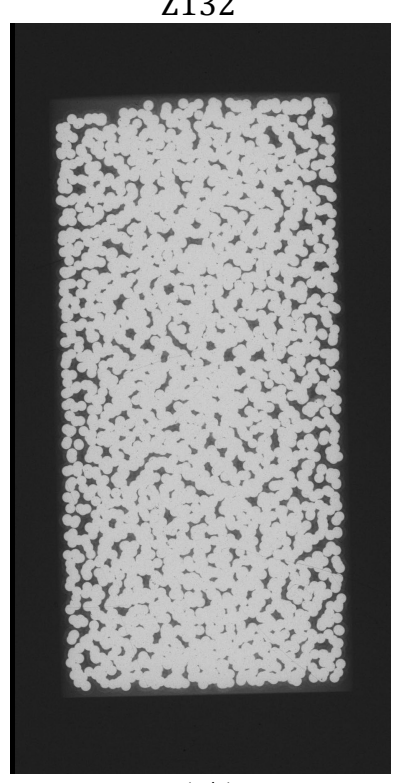

Z151 
Appendix B-3. X-ray radiographs of archive compacts from LEU09-OP2-Z.

Appendix B-3 contains x-ray radiographs of 12 archive compacts from compact lot LEU09-OP2-Z. The compacts are identified by the compact ID number, which can be traced back to the fabrication record for each compact. These compacts are representative of those that were inserted into the AGR-2 irradiation test. 
Appendix B-3. X-ray radiographs of archive compacts from LEU09-OP2-Z.

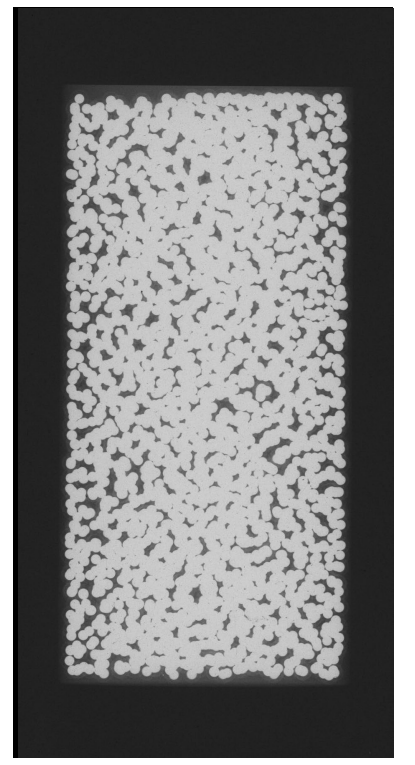

Z002

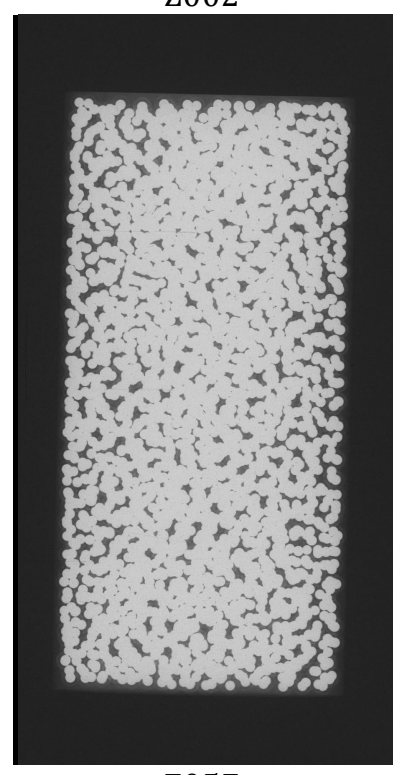

Z057

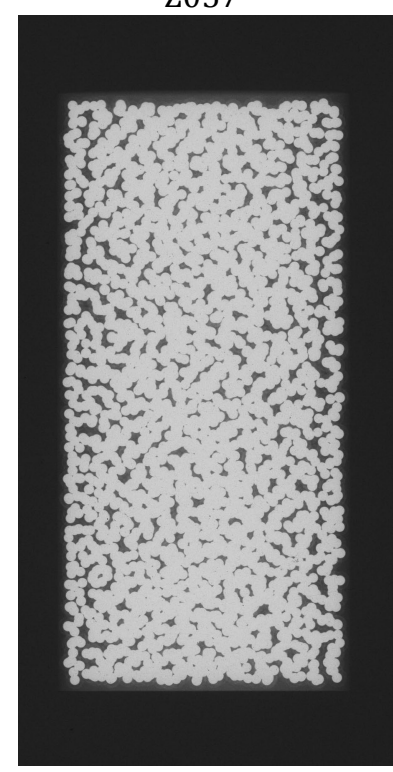

Z130

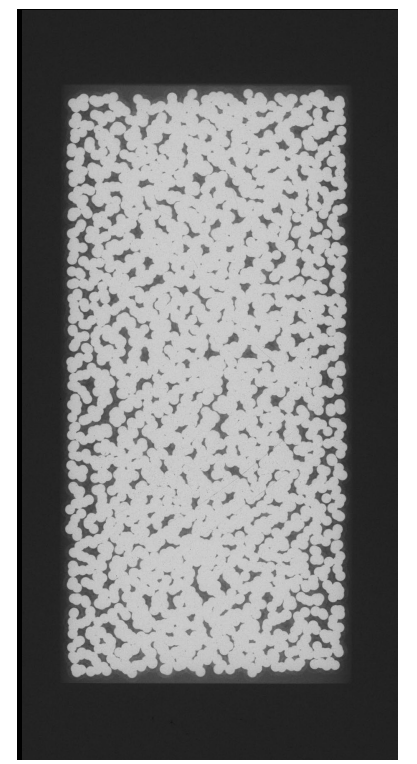

Z004

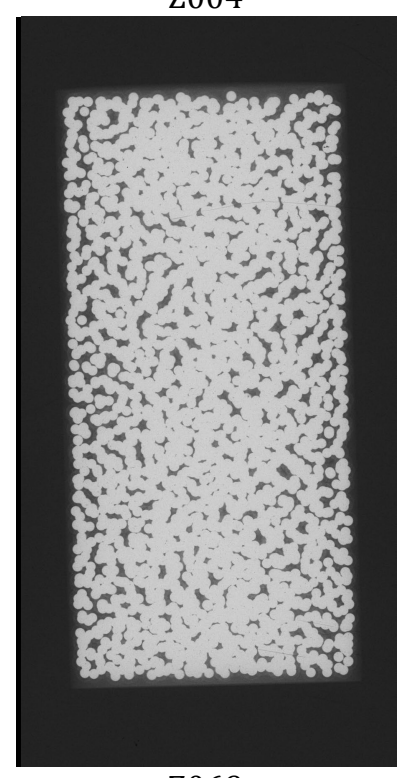

Z069

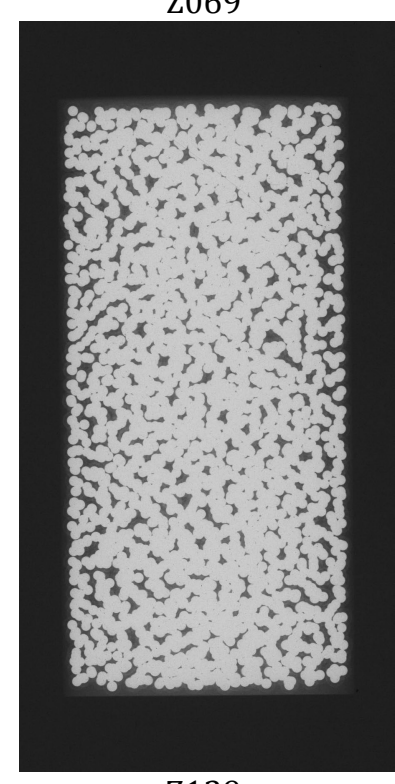

Z139

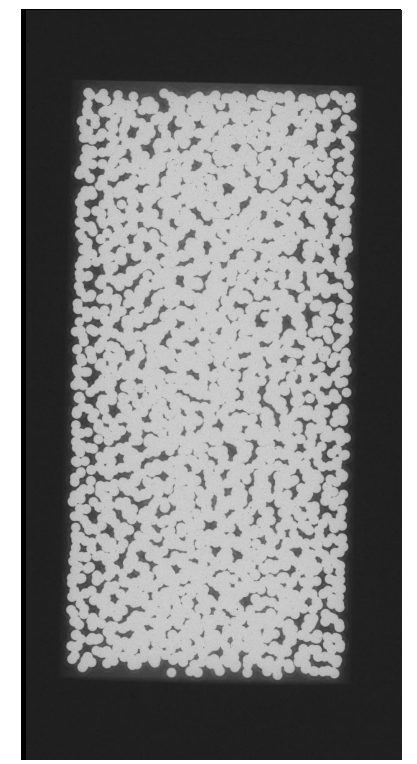

Z005

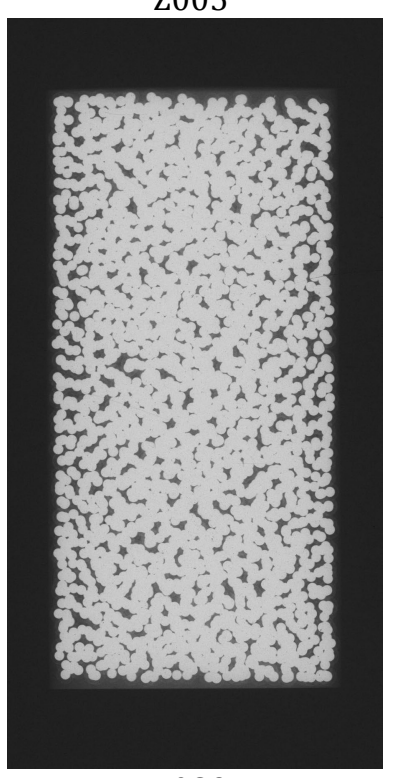

Z089

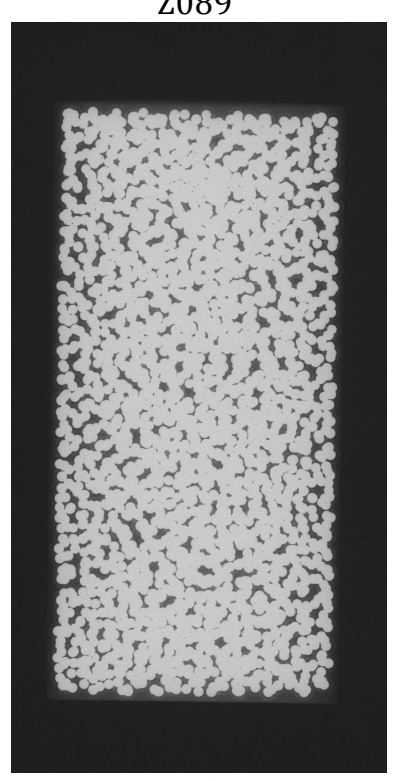

Z158

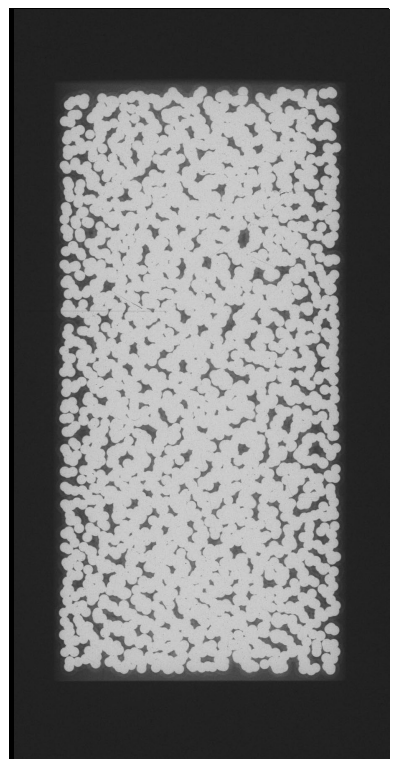

Z038

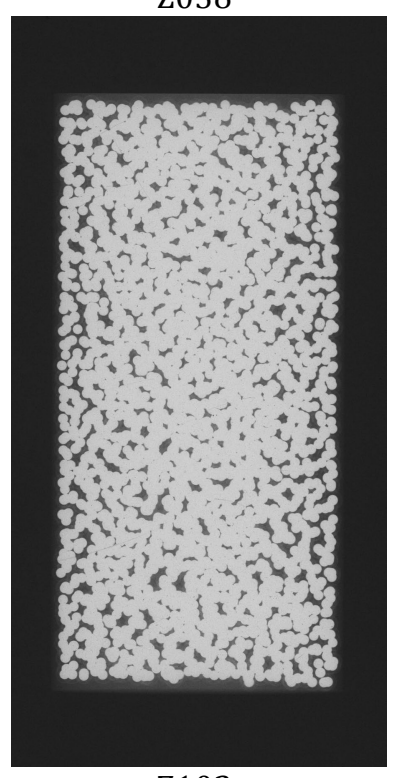

Z102

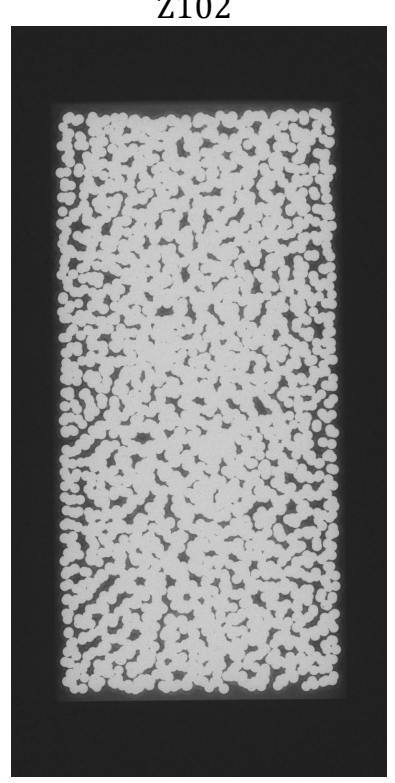

Z165 
Appendix B-4. X-ray radiographs of archive compacts from LEU11-OP2-Z.

Appendix B-4 contains x-ray radiographs of 12 archive compacts from compact lot LEU11-OP2-Z. The compacts are identified by the compact ID number, which can be traced back to the fabrication record for each compact. These compacts are representative of those that were inserted into the AGR-2 irradiation test. 
Appendix B-4. X-ray radiographs of archive compacts from LEU11-OP2-Z.

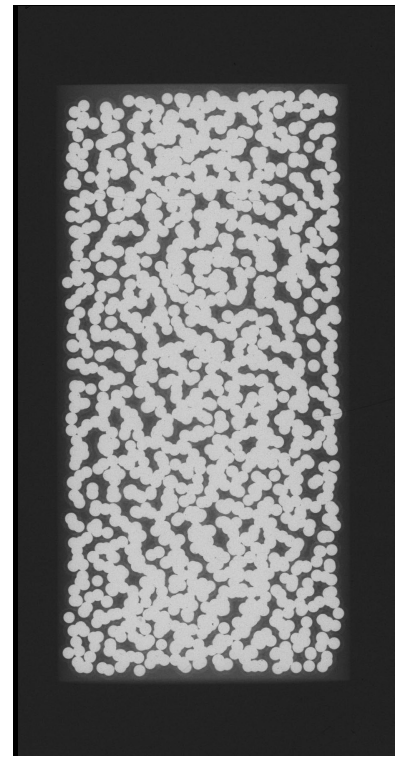

Z018

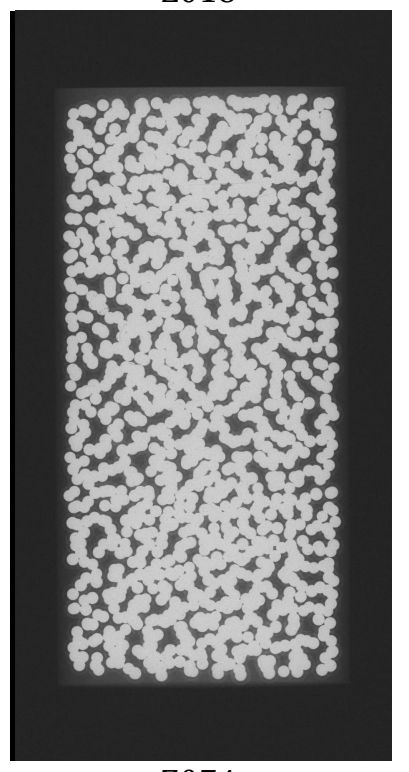

Z074

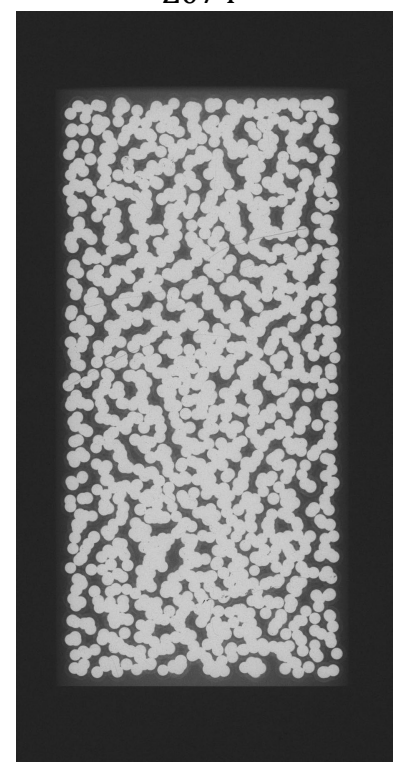

Z147

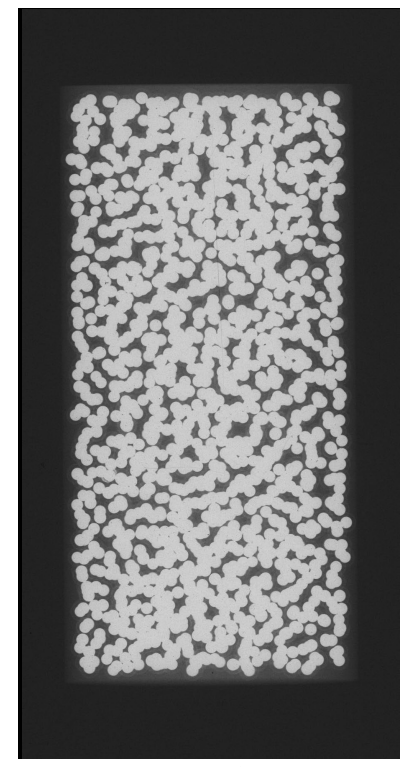

Z045

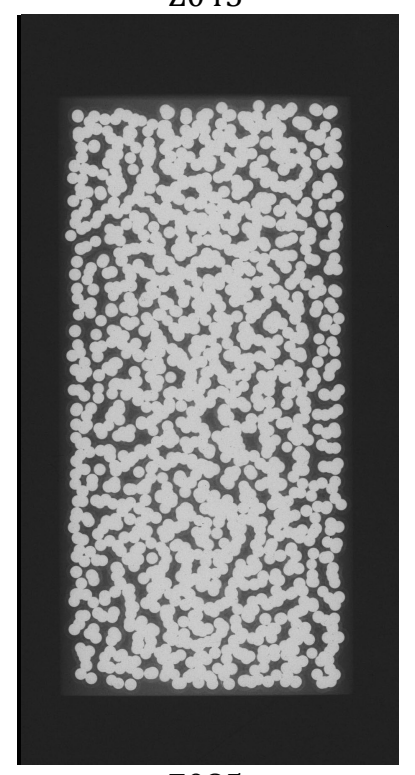

Z085

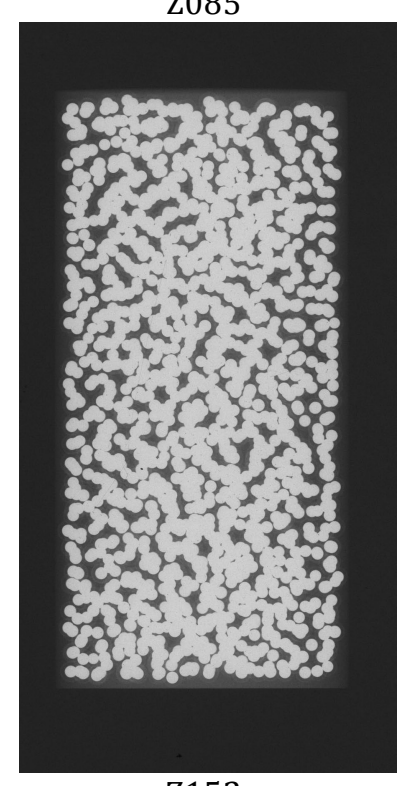

Z152

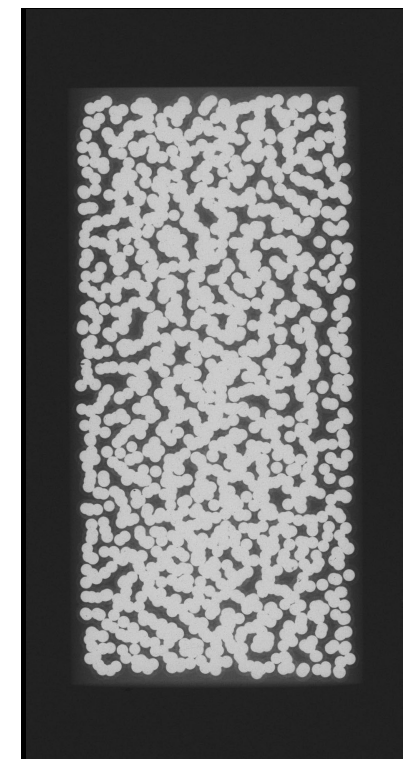

Z062

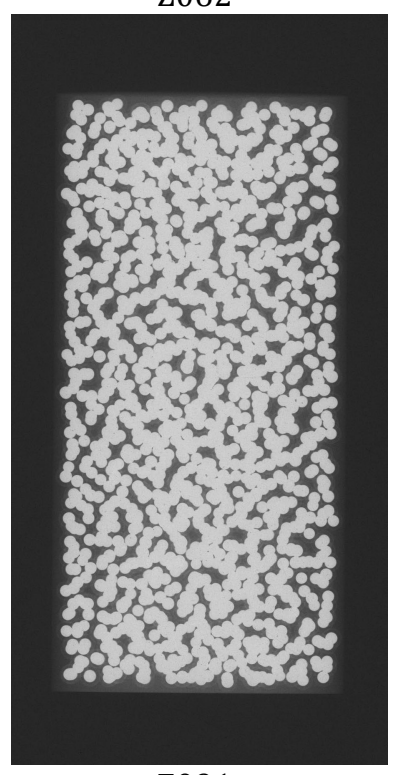

Z091

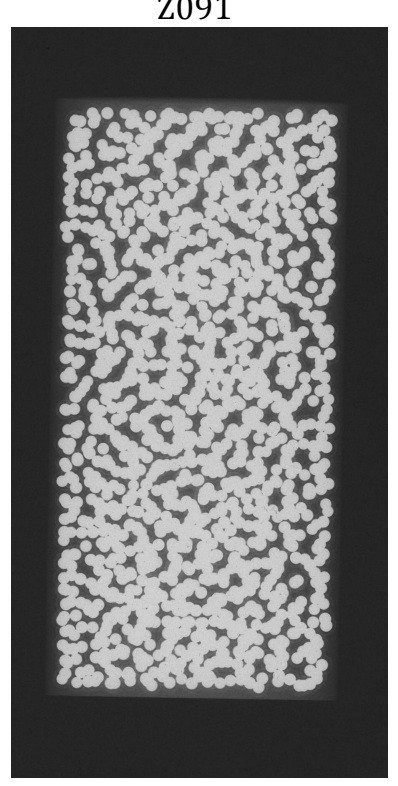

Z186

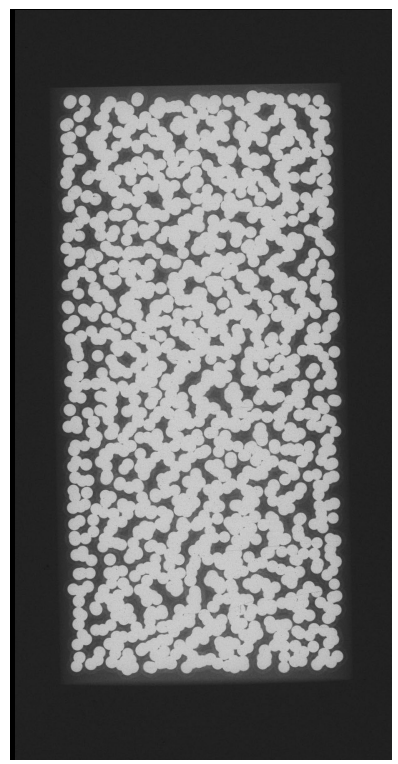

Z066

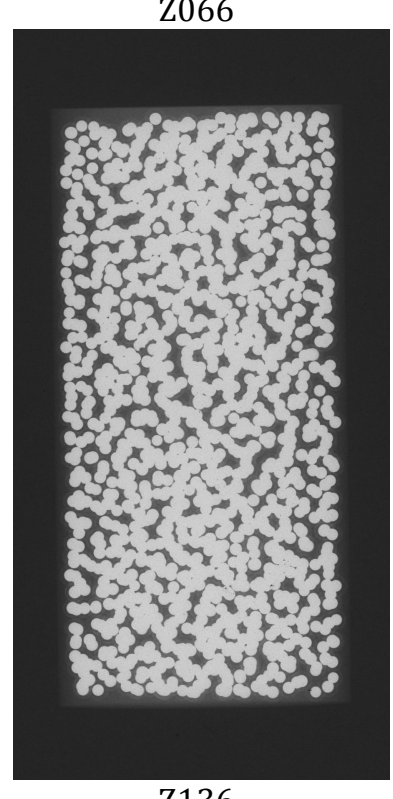

Z136

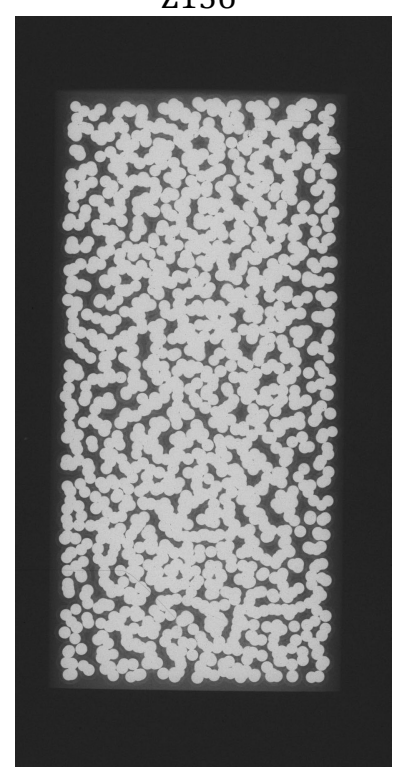

Z198 


\section{Appendix C - Optical Images of AGR-2 Fuel Compact Sections}

This appendix contains a record of the typical appearance under an optical microscope of polished sections from the AGR-2 fuel compacts. Two compacts were selected from each compact lot for sectioning. One compact was used to make two lateral sections (perpendicular to the long axis) at positions $1 / 4$ and $1 / 2$ along the compact's length. The other compact was used to make a longitudinal section (parallel to the long axis) through the middle of the compact. This appendix contains images of two lateral sections and one longitudinal section from each compact lot.

The images were obtained using a Leica DMRX microscope in bright field reflected light mode. Using a computer controlled X/Y stage, a mosaic of each section was constructed from a scanned array of images that covered the entire section. This allowed for higher resolution imaging than could be obtained in a single image at lower magnification. At the magnification chosen for making the mosaics, an 8x10 array of images was sufficient for the lateral sections, while longitudinal sections required a $15 \times 10$ array. If the mosaics are enlarged for better viewing of detail, some discontinuities may be seen at the boundaries between each individual image. These should not be mistaken as coating defects.

In addition to the mosaics, several higher magnification/higher resolution images were obtained of select areas showing examples of the particles and interparticle graphite matrix. Finally, a close-up of a region of interest (ROI) on one typical particle was obtained using the microscope's highest power objective. These close-up images provide the best detail of the individual particle layer interfaces.

Voids where particles were dislodged during sample preparation were back-filled with epoxy. These appear as dark gray circles. Fuel kernels in particles where the section passed below the particle mid-plane were also susceptible to dropping out. If a kernel came out during cutting, it was back-filled with epoxy and will appear as a dark gray spot. However, if it came out during grinding and polishing, a new void was created in the polished surface and this appears as a black spot in the image. Black spots also appear in some of the epoxy filled voids as a result of small bubbles in the epoxy. Some scratches are evident in each image and most often occurred as a result of kernels or small pieces of SiC pulled out during polishing. 
Appendix C-1. Images of polished sections of archive compacts from LEU06-OP1-Z.

Appendix C-1 contains optical microscope images of polished sections taken from compact lot LEU06-OP1-Z. The compacts are identified by the compact ID number, which can be traced back to the fabrication record for each compact. Compact lot LEU06-OP1-Z was fully characterized, but was not used in the AGR-2 irradiation test. 
Appendix C-1. Images of polished sections of archive compacts from LEU06-OP1-Z.

\section{LEU06-0P1-Z050 - Lateral Section 1}
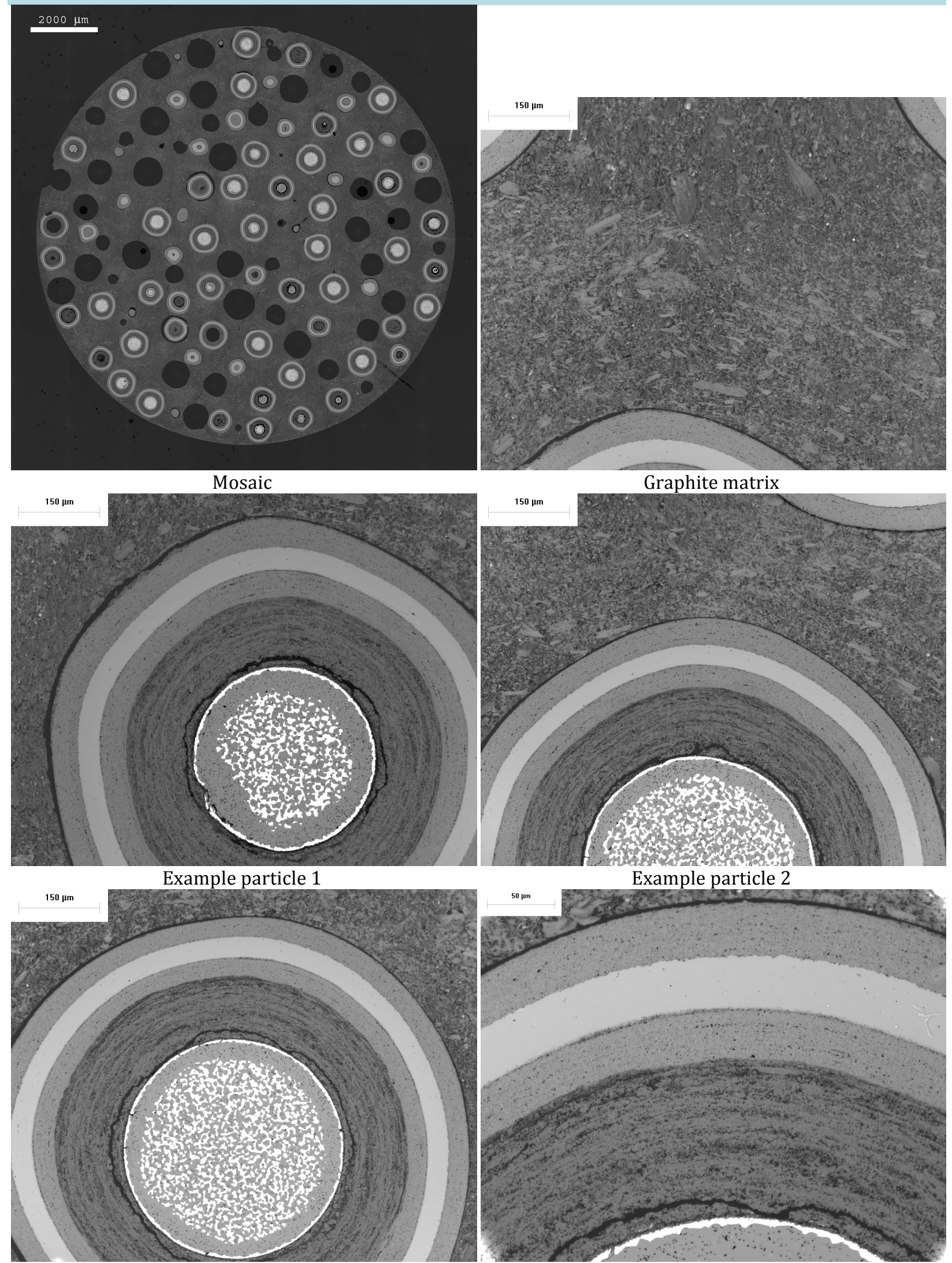

Example particle 3

Particle 3 ROI close-up (slight CCW rot.) 
Appendix C-1. Images of polished sections of archive compacts from LEU06-OP1-Z.

\section{LEU06-0P1-Z050 - Lateral Section 2}
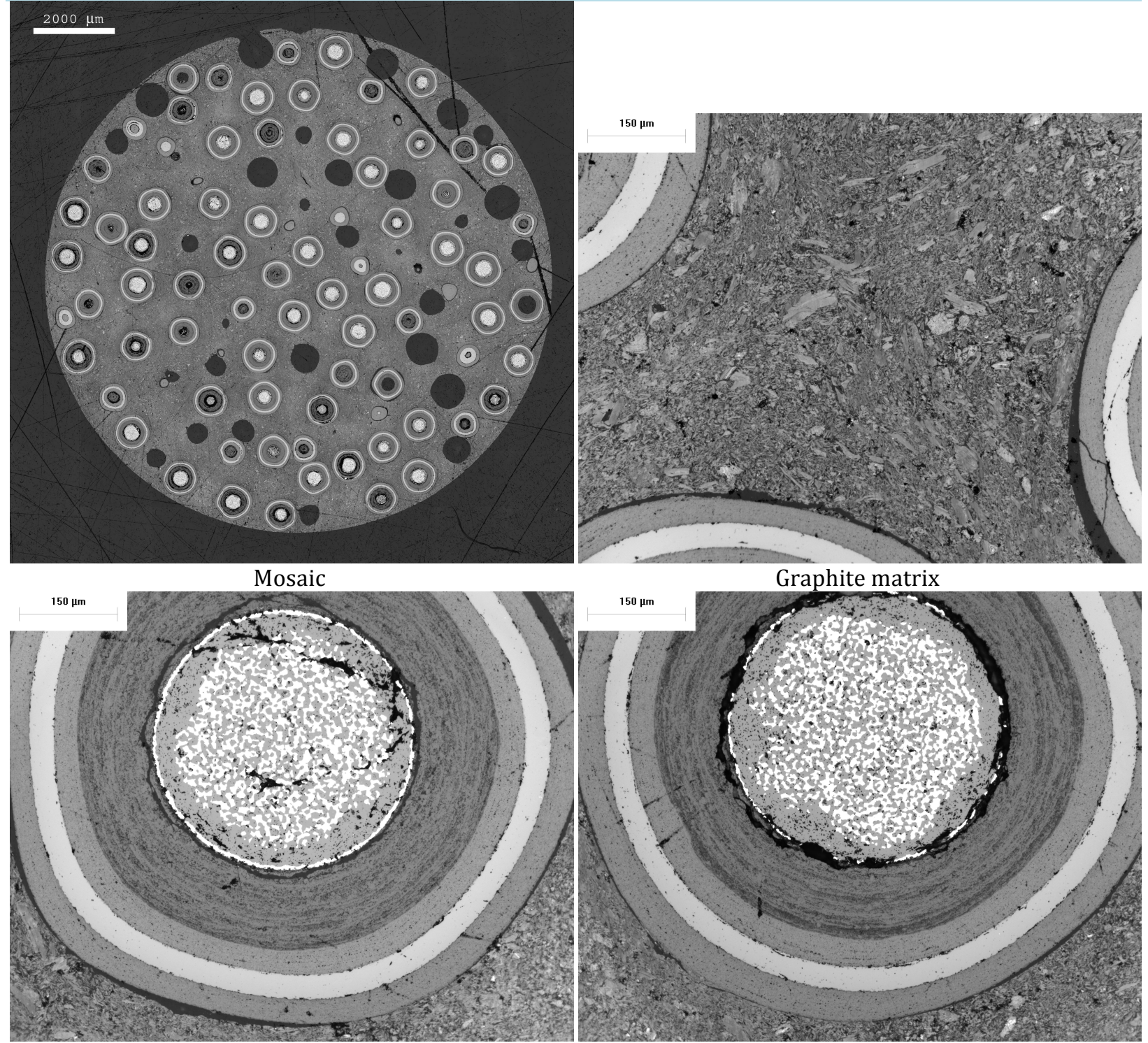

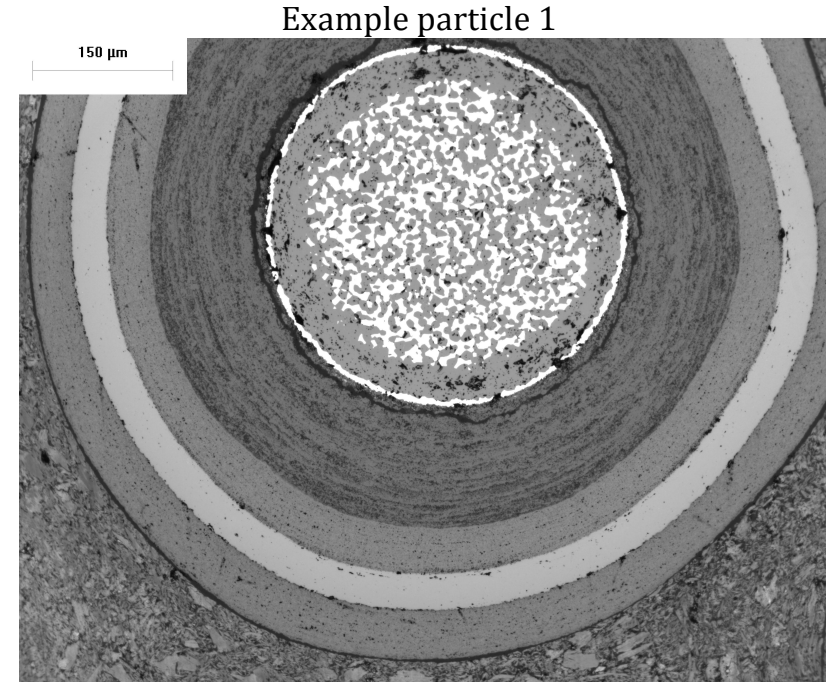

Example particle 3
Example particle 2

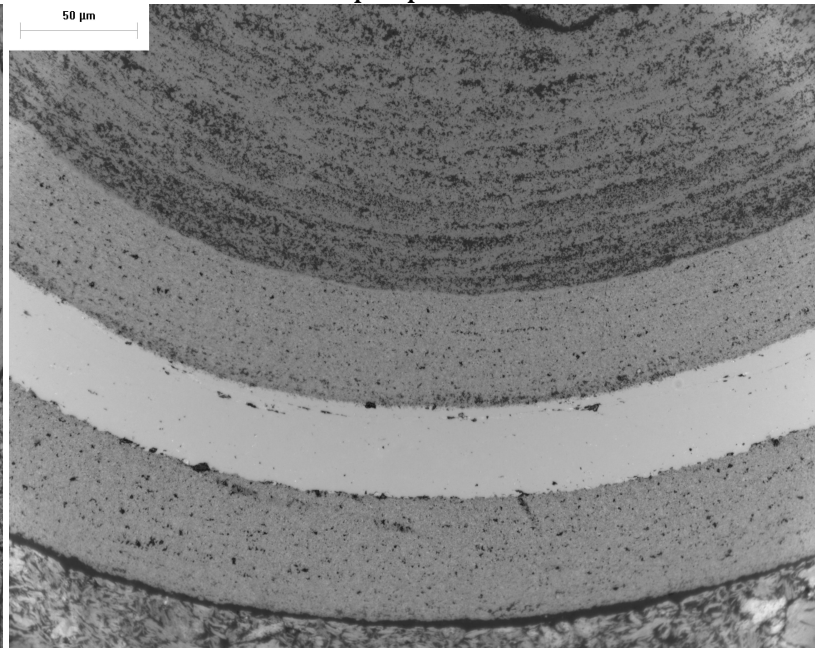

Particle 3 ROI close-up 
Appendix C-1. Images of polished sections of archive compacts from LEU06-OP1-Z.

\section{LEU06-0P1-Z042 - Longitudinal Section}

$2000 \mu$

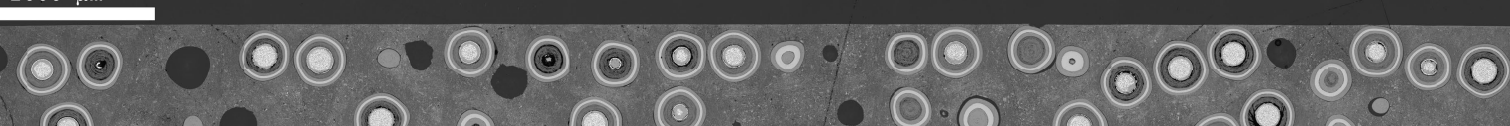

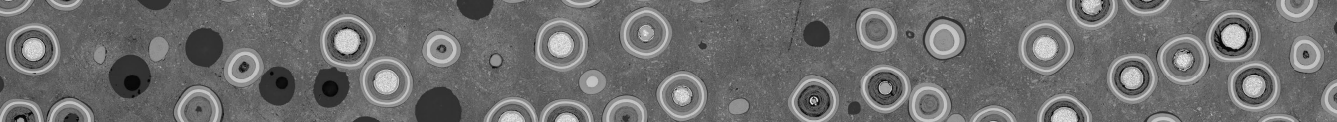

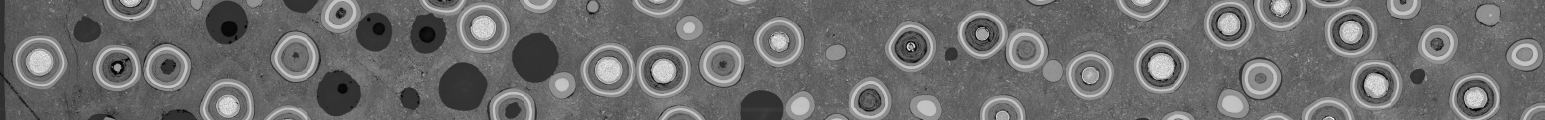

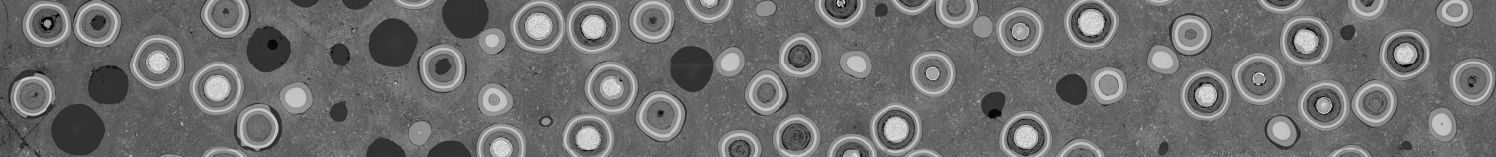

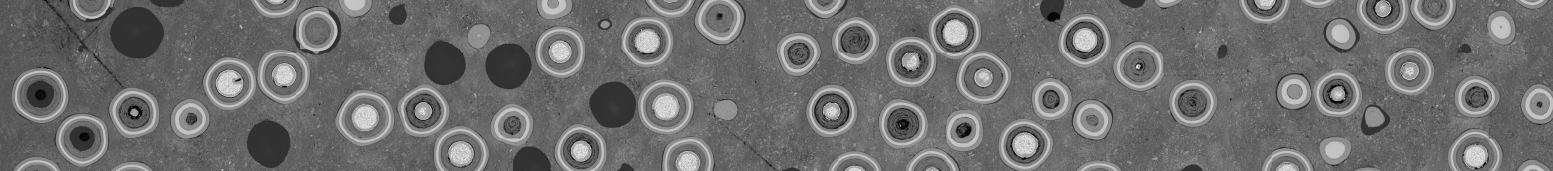

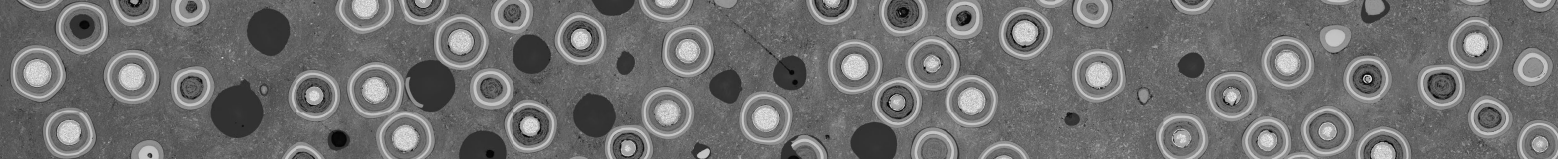

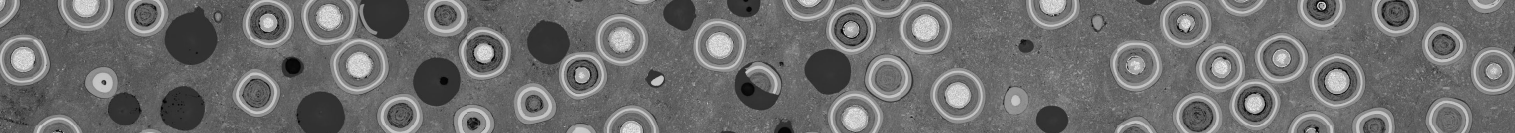

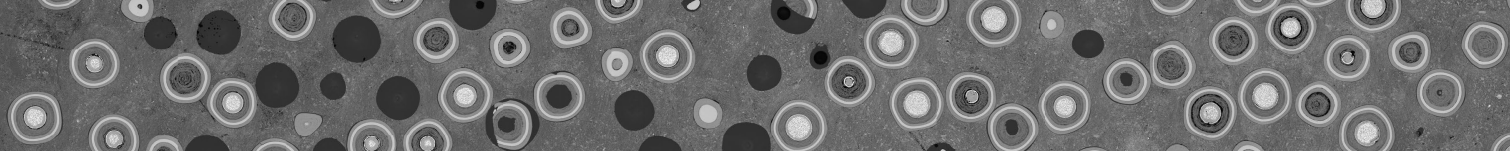

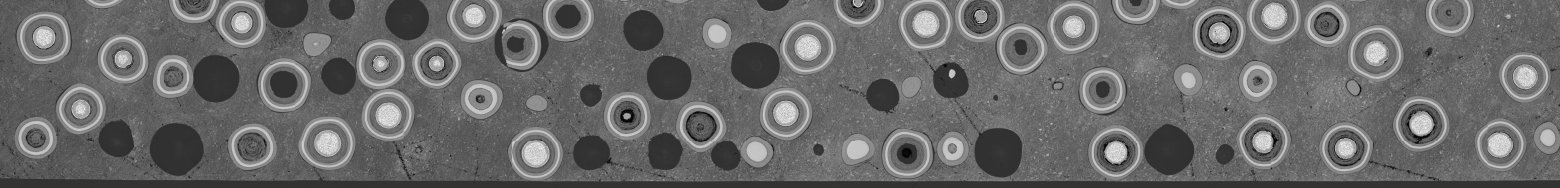

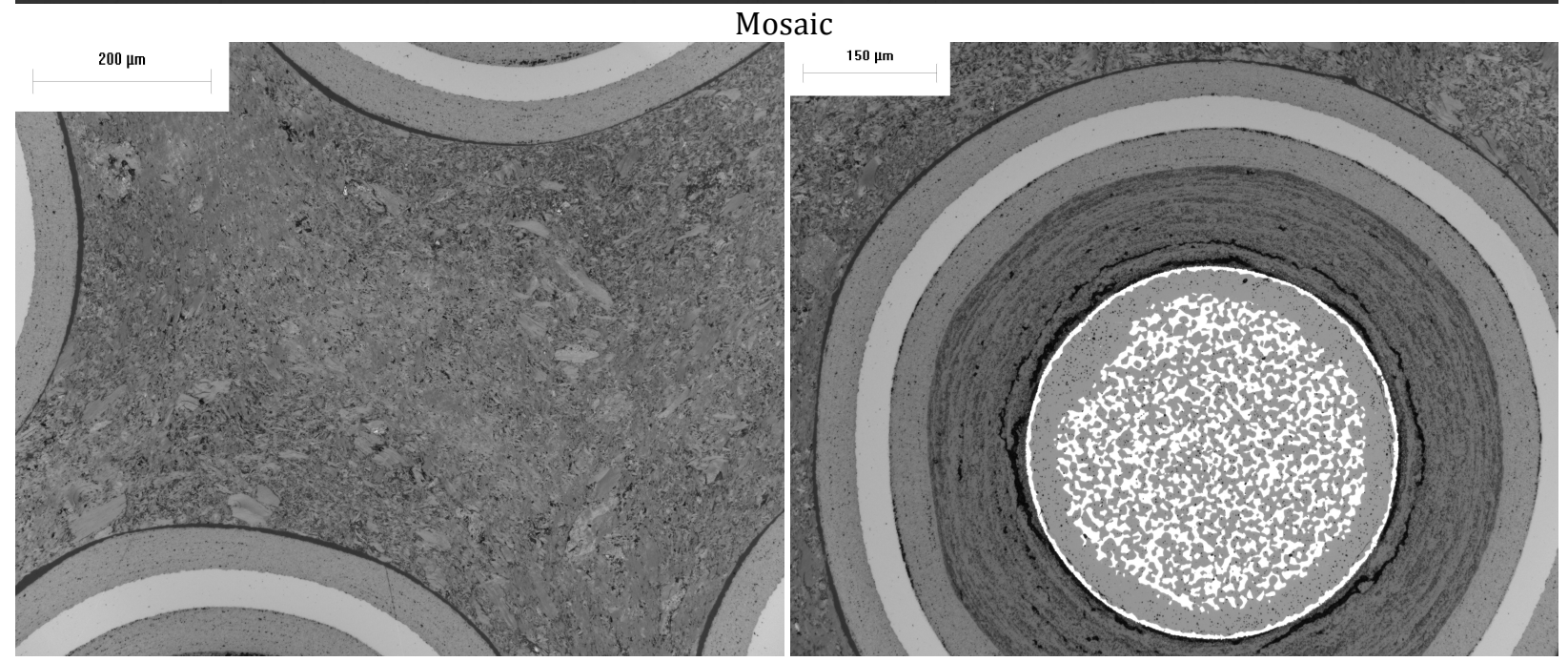

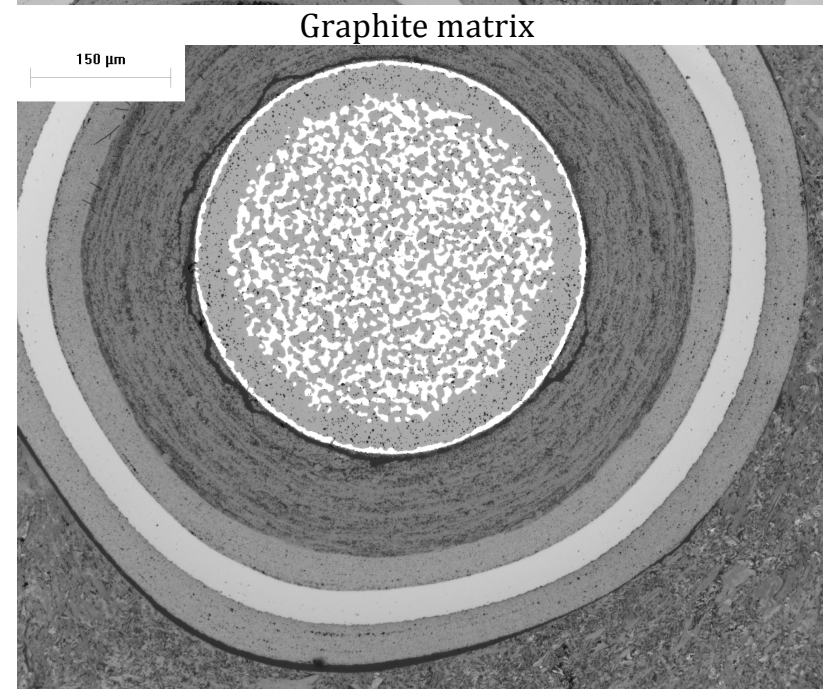

Example particle 2
Example particle 1

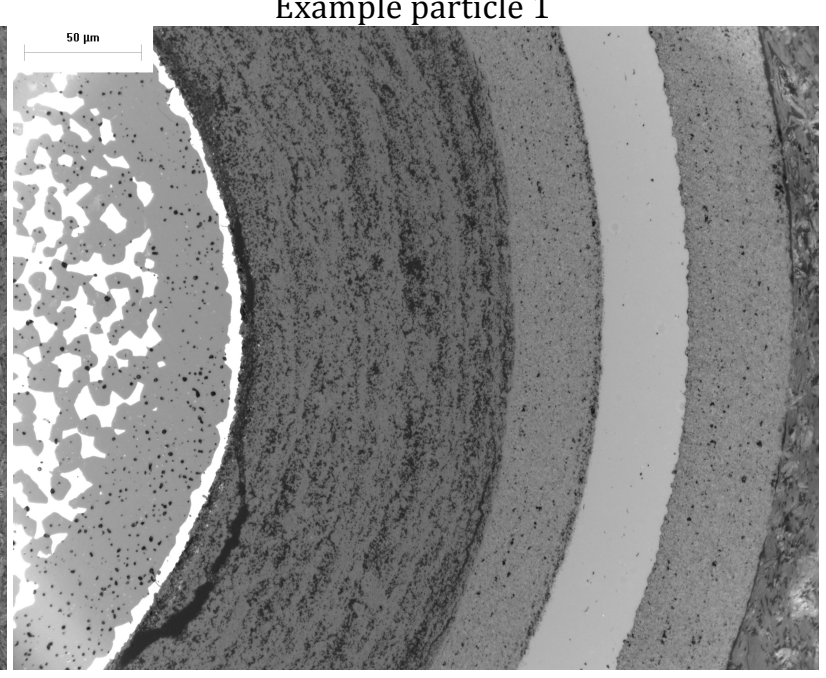

Particle 2 ROI close-up 
Appendix C-2. Images of polished sections of archive compacts from LEU07-OP1-Z.

Appendix C-2 contains microscope images of polished sections taken from compact lot LEU07-OP1-Z. The compacts are identified by the compact ID number, which can be traced back to the fabrication record for each compact. Compact lot LEU07-OP1-Z was fully characterized, but was not used in the AGR-2 irradiation test. 
Appendix C-2. Images of polished sections of archive compacts from LEU07-OP1-Z.

\section{LEU07-0P1-Z016 - Lateral Section 1}
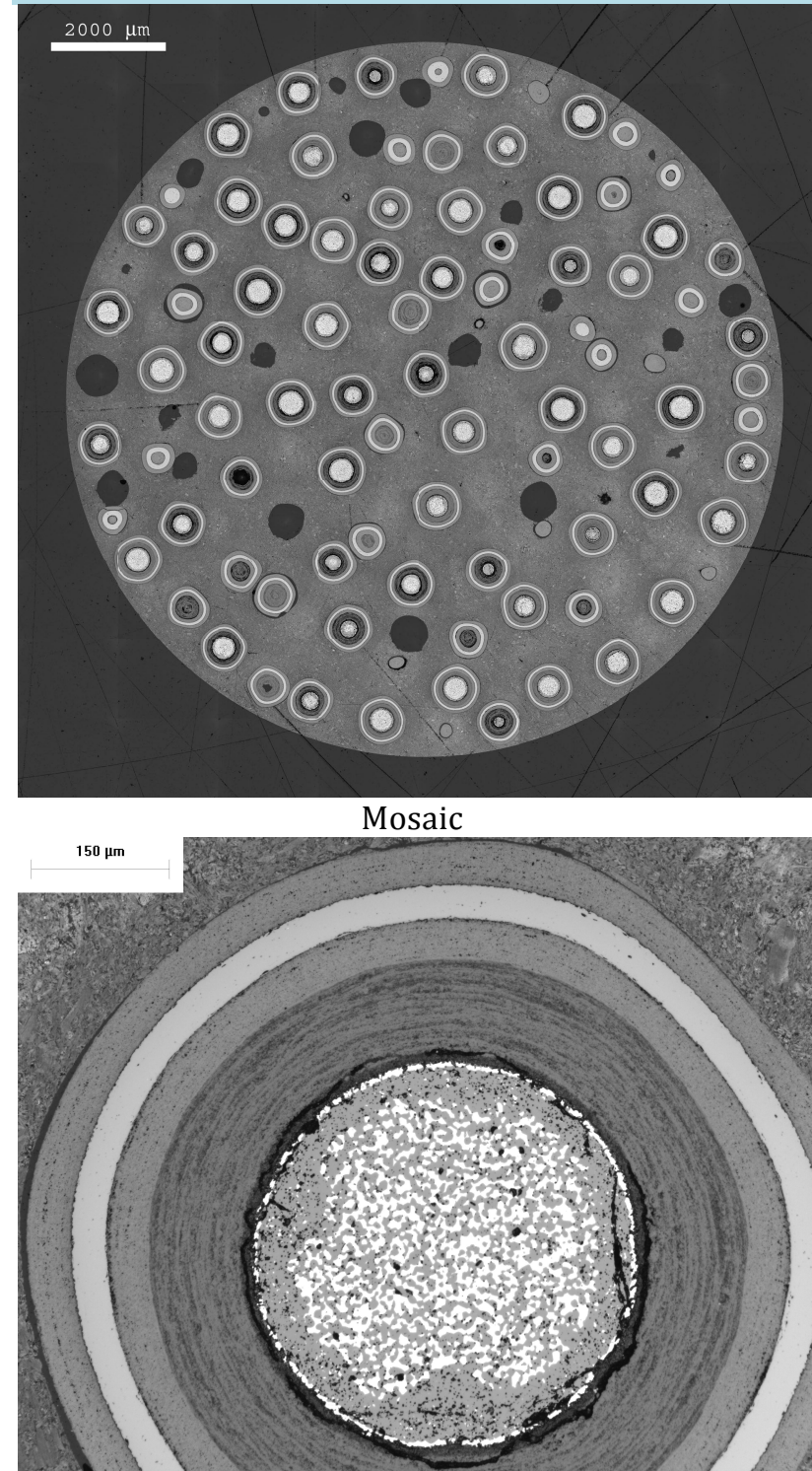

Example particle 1

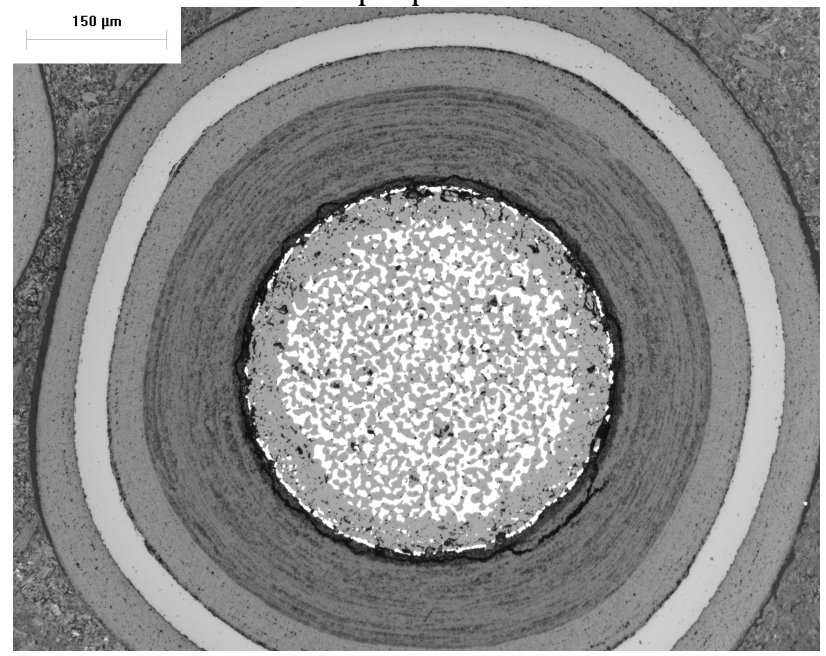

Example particle 3
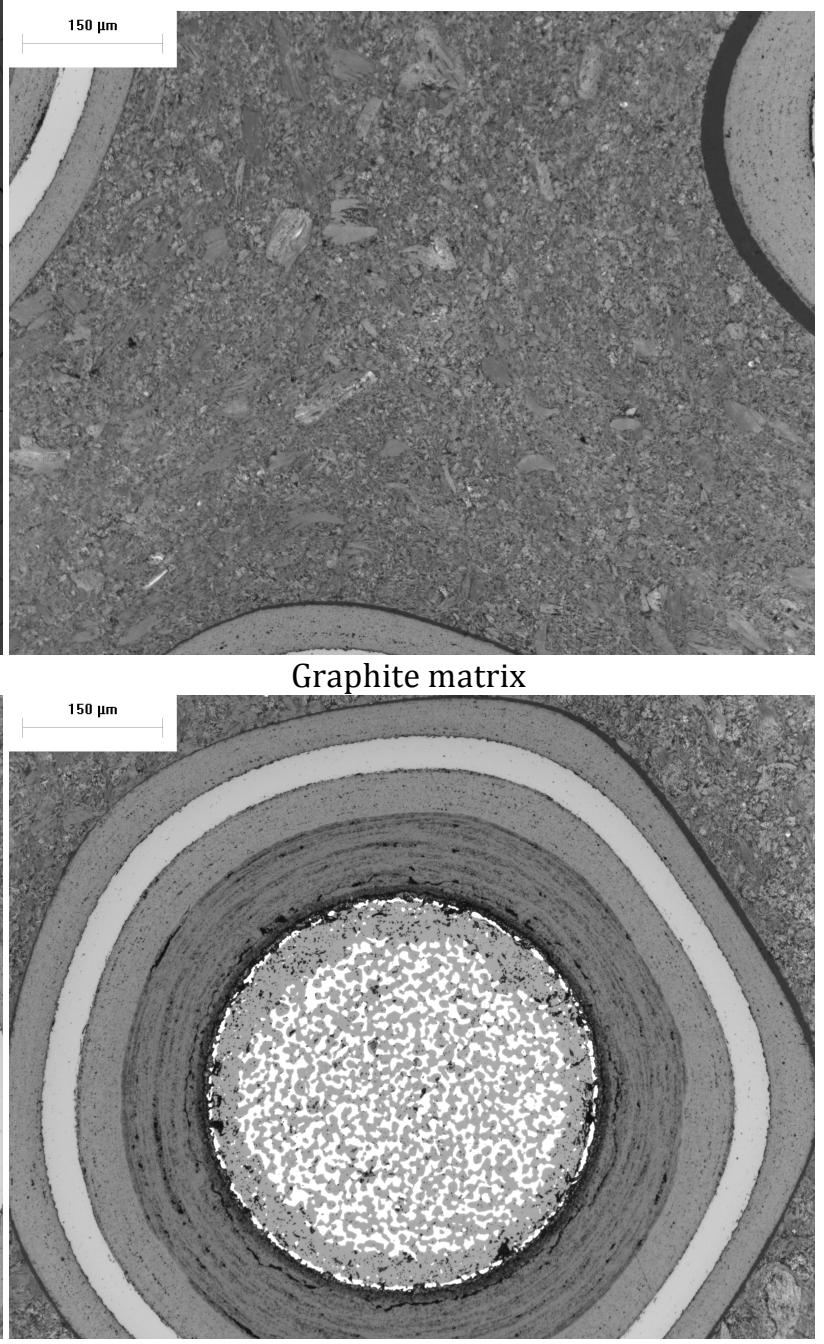

Example particle 2

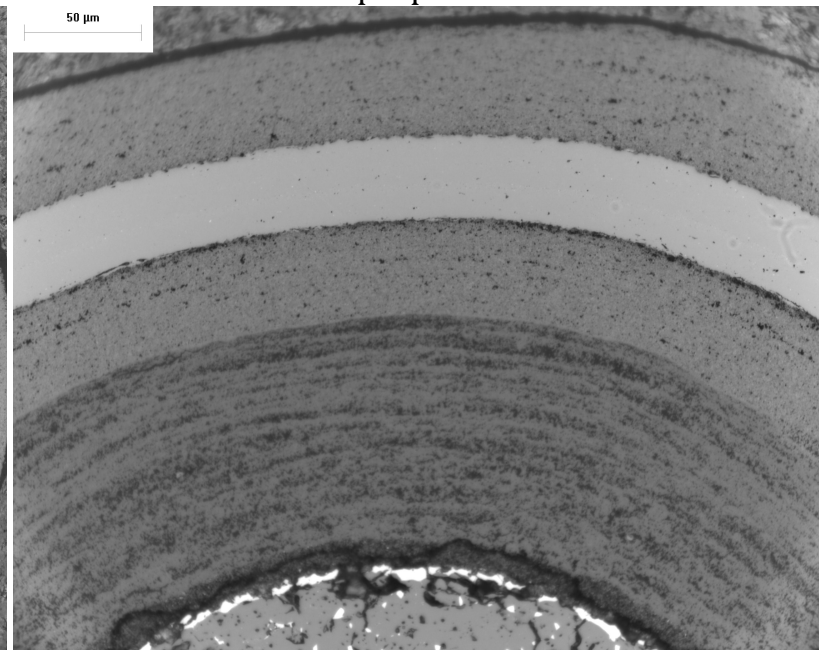

Particle 3 ROI close-up 
Appendix C-2. Images of polished sections of archive compacts from LEU07-OP1-Z.

\section{LEU07-0P1-Z016 - Lateral Section 2}
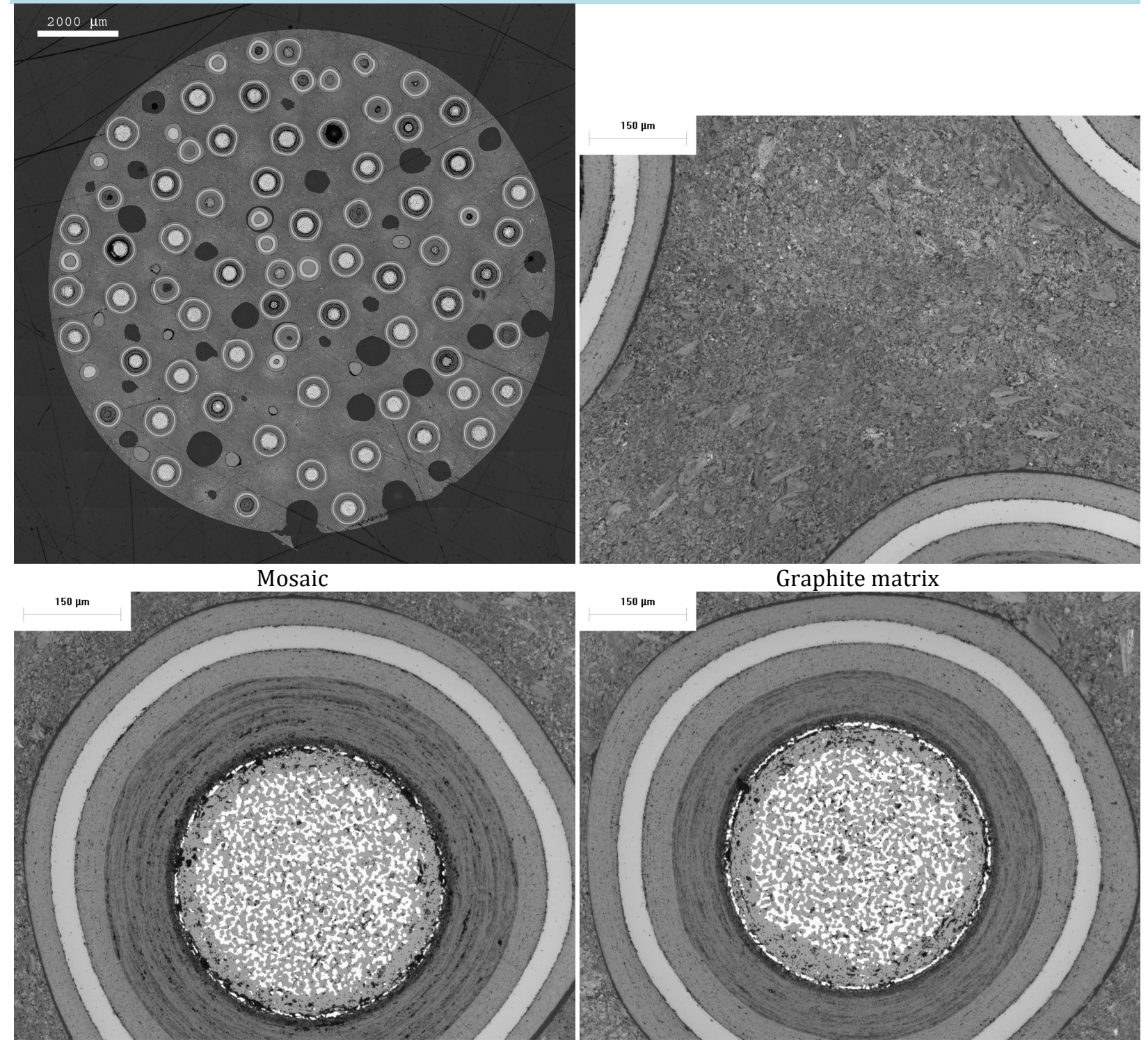

Example particle 1

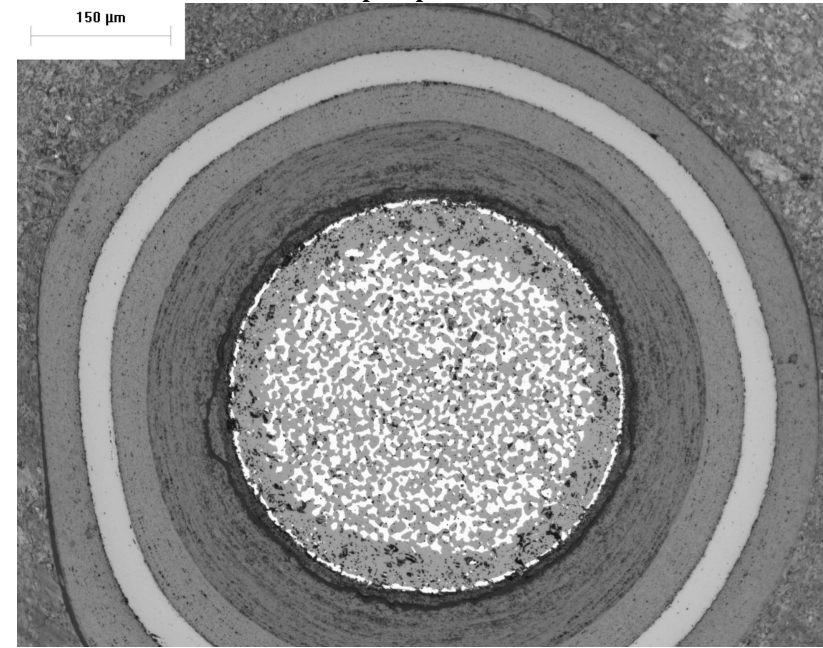

Example particle 3
Example particle 2

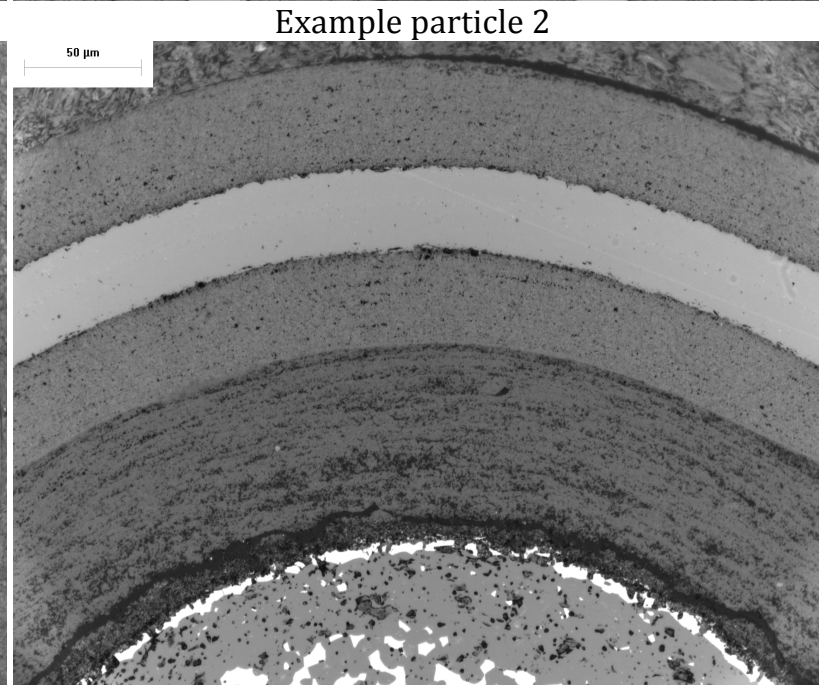

Particle 3 ROI close-up 
Appendix C-2. Images of polished sections of archive compacts from LEU07-OP1-Z.

\section{LEU07-OP1-Z036 - Longitudinal Section}
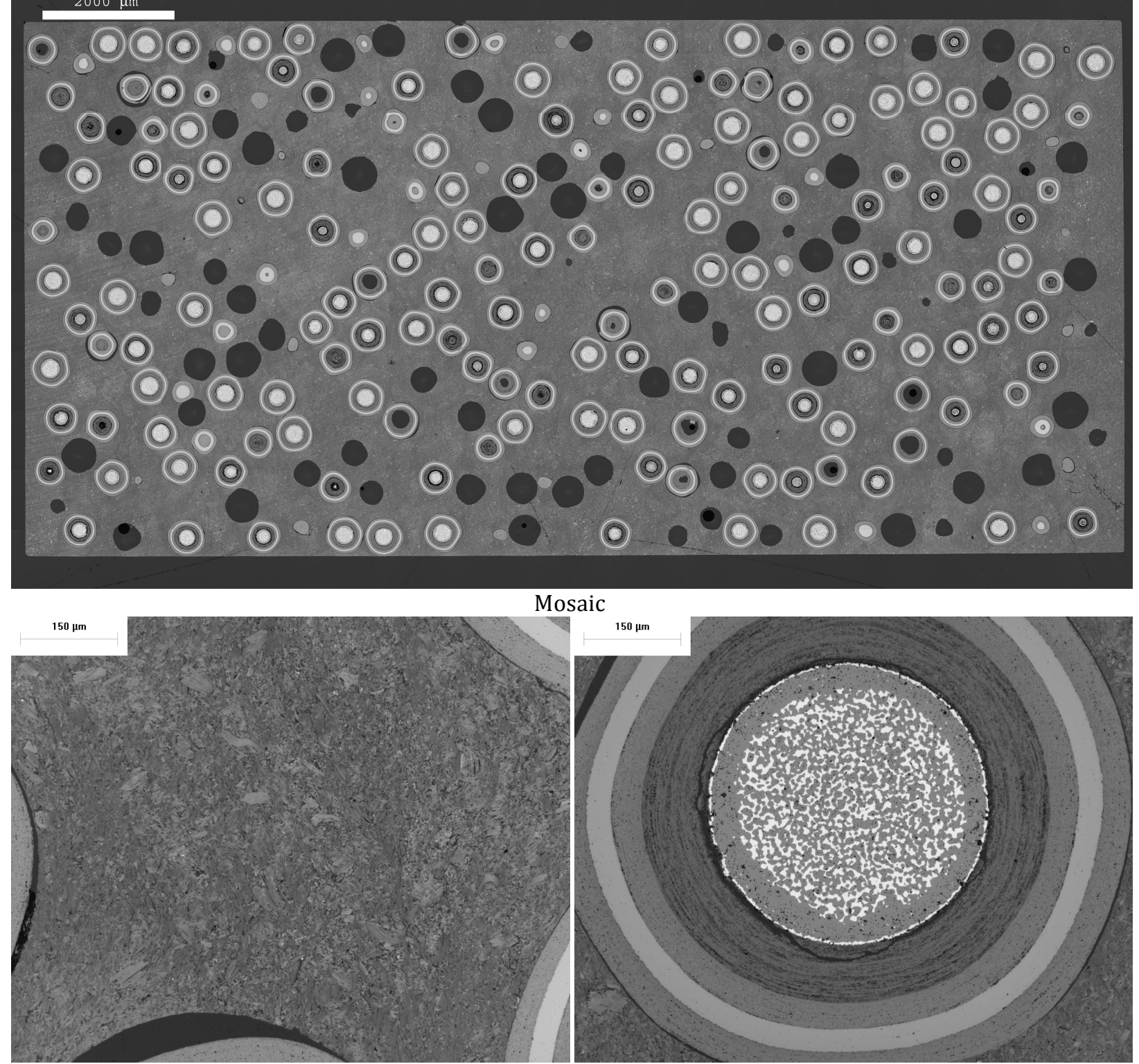

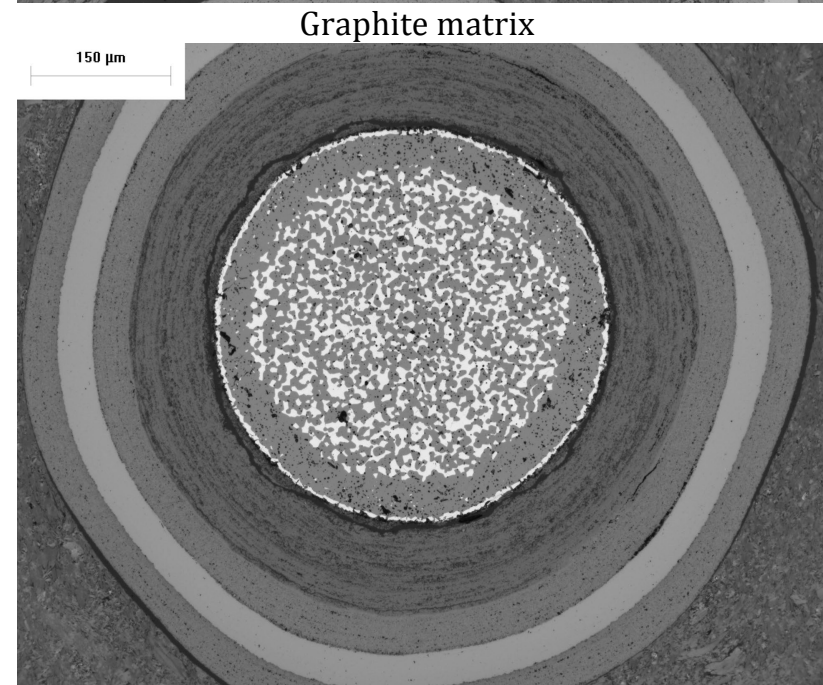

Example particle 2
Example particle 1

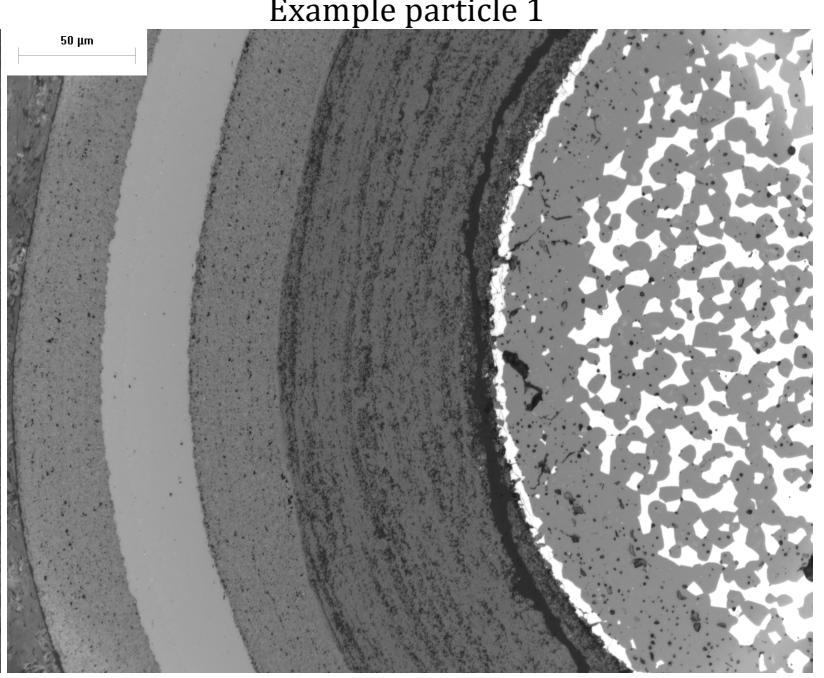

Particle 2 ROI close-up 
Appendix C-3. Images of polished sections of archive compacts from LEU09-OP2-Z.

Appendix C-3 contains microscope images of polished sections taken from compact lot LEU09-0P2-Z. The compacts are identified by the compact ID number, which can be traced back to the fabrication record for each compact. These compacts are representative of those that were inserted into the AGR-2 irradiation test. 
Appendix C-3. Images of polished sections of archive compacts from LEU09-OP2-Z.

\section{LEU09-0P2-Z004 - Lateral Section 1}
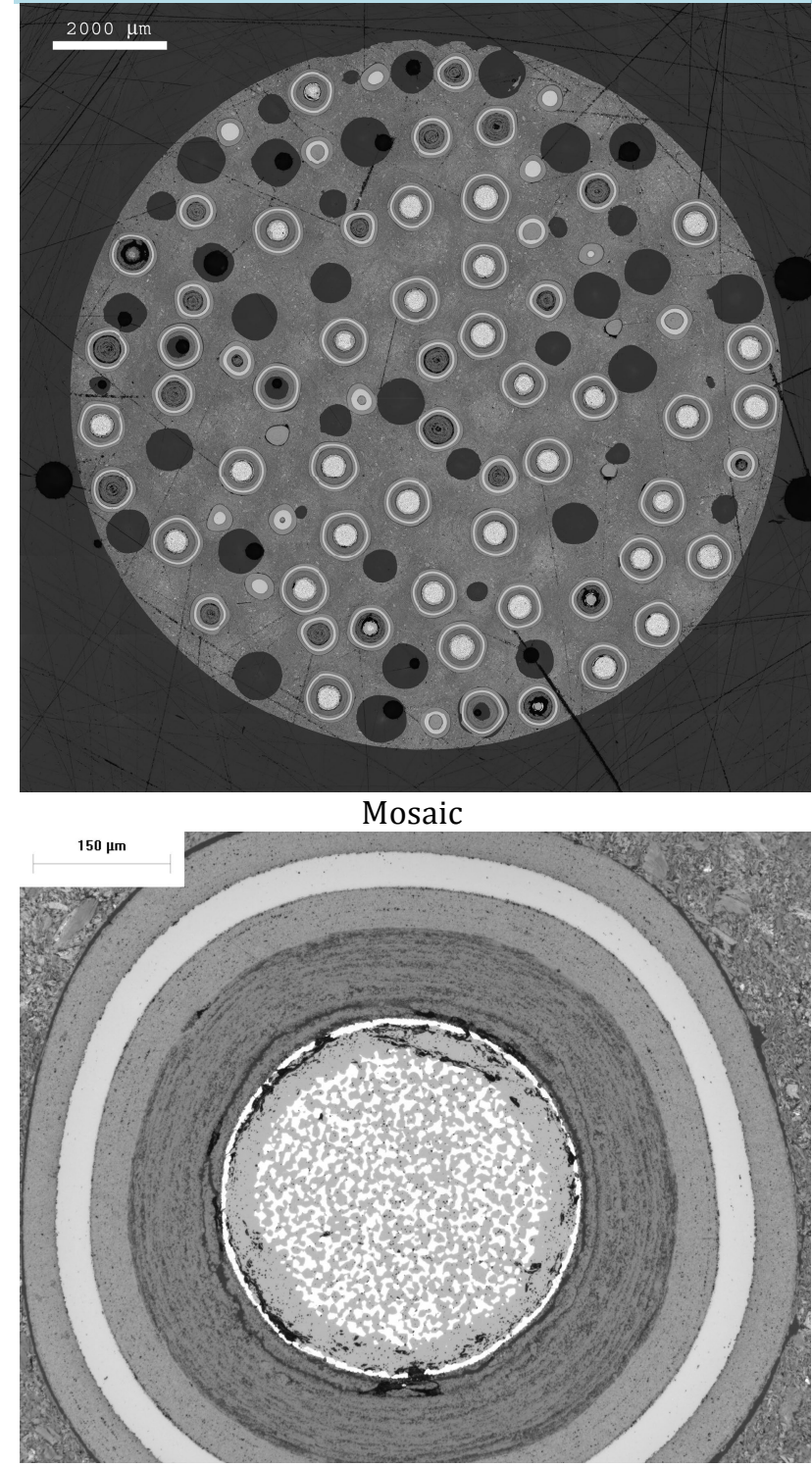

Example particle 1
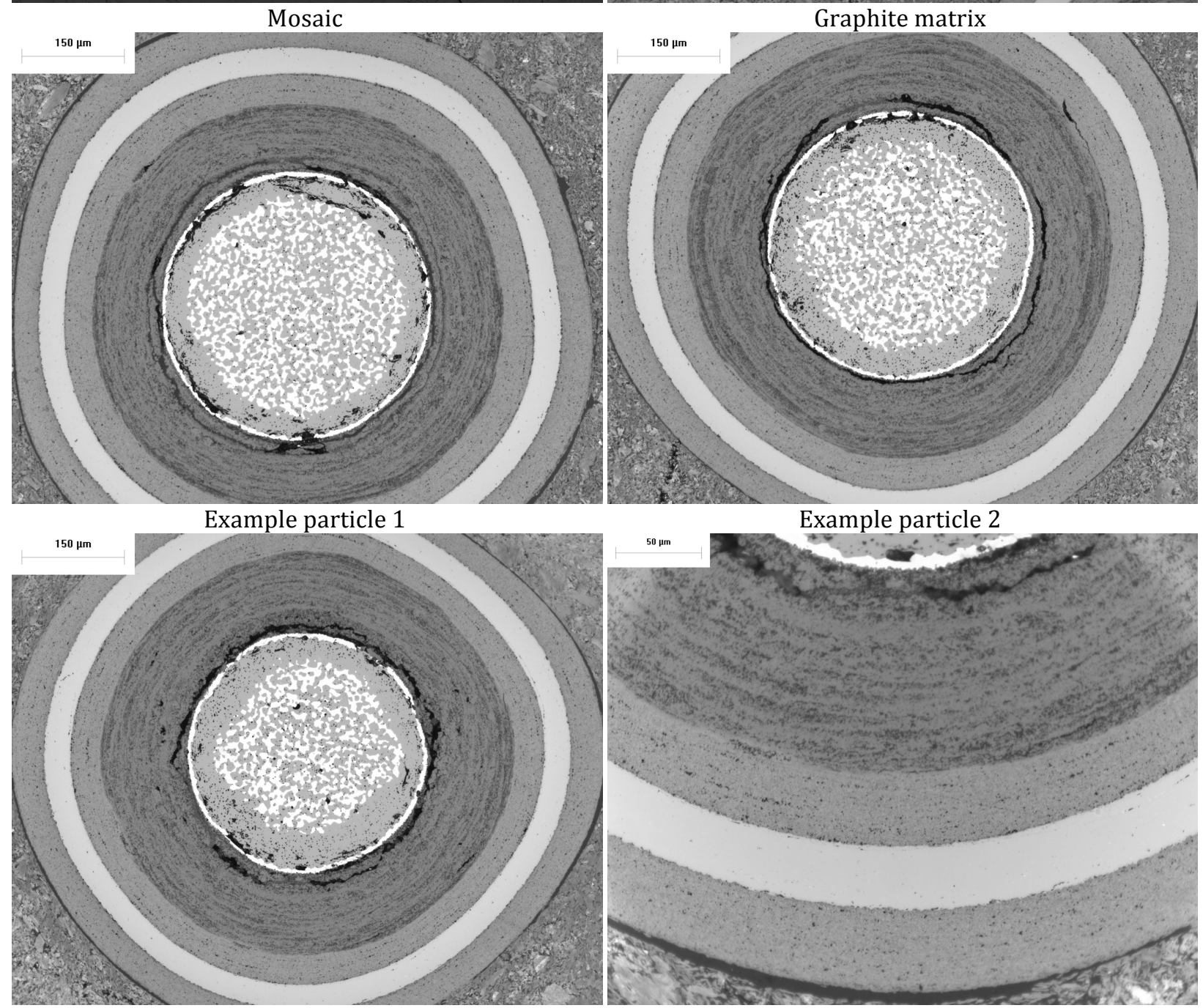

Example particle 3

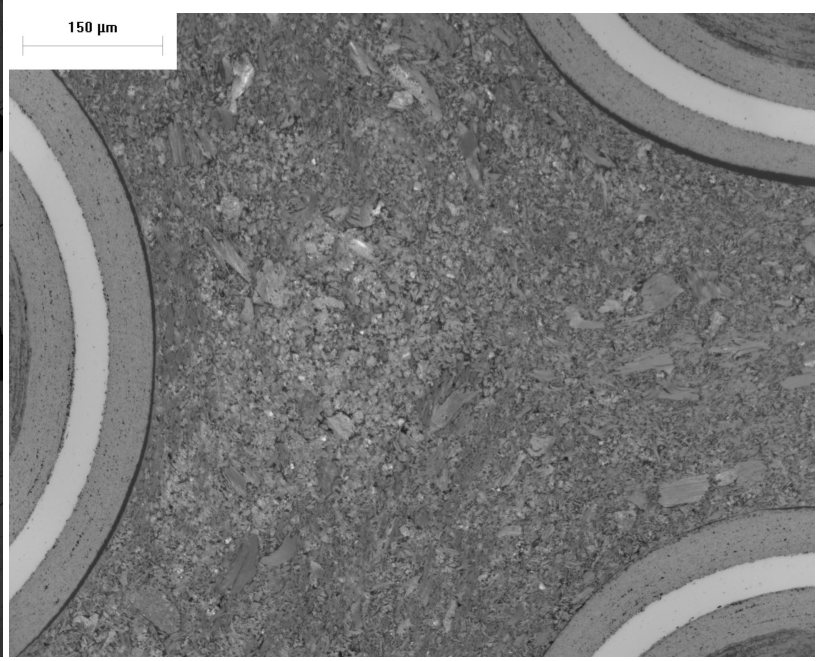

Example particle 2

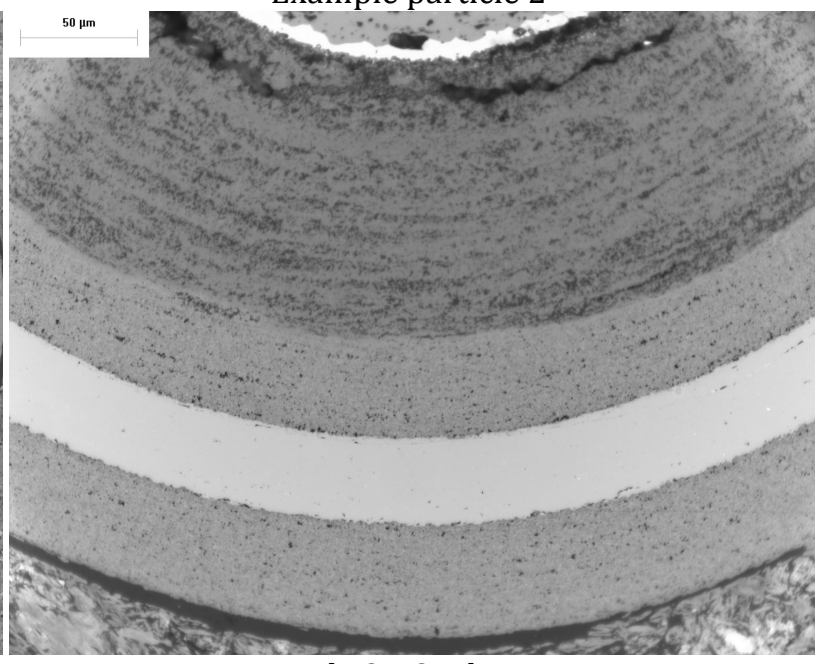

Particle 3 ROI close-up 
Appendix C-3. Images of polished sections of archive compacts from LEU09-OP2-Z.

\section{LEU09-0P2-Z004 - Lateral Section 2}
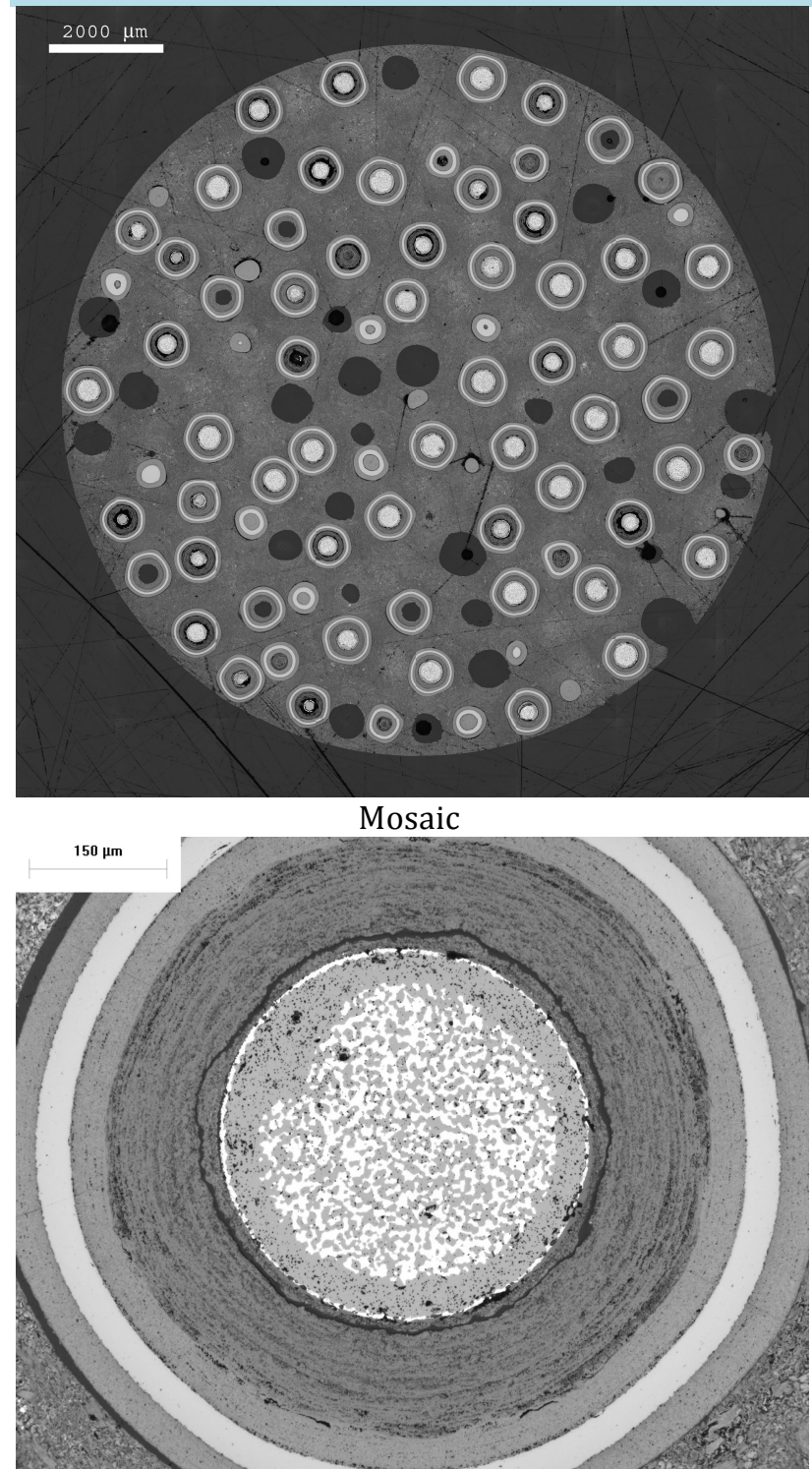

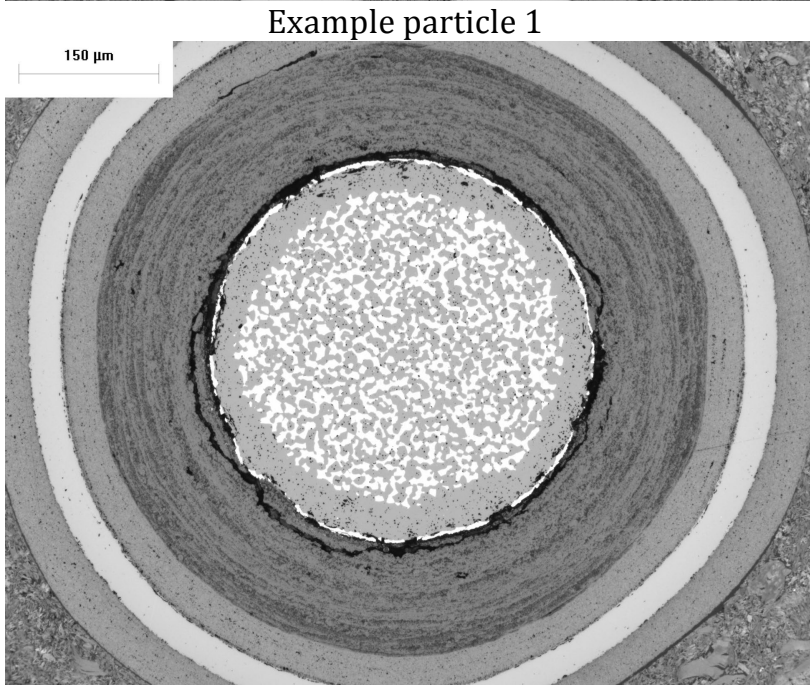

Example particle 3
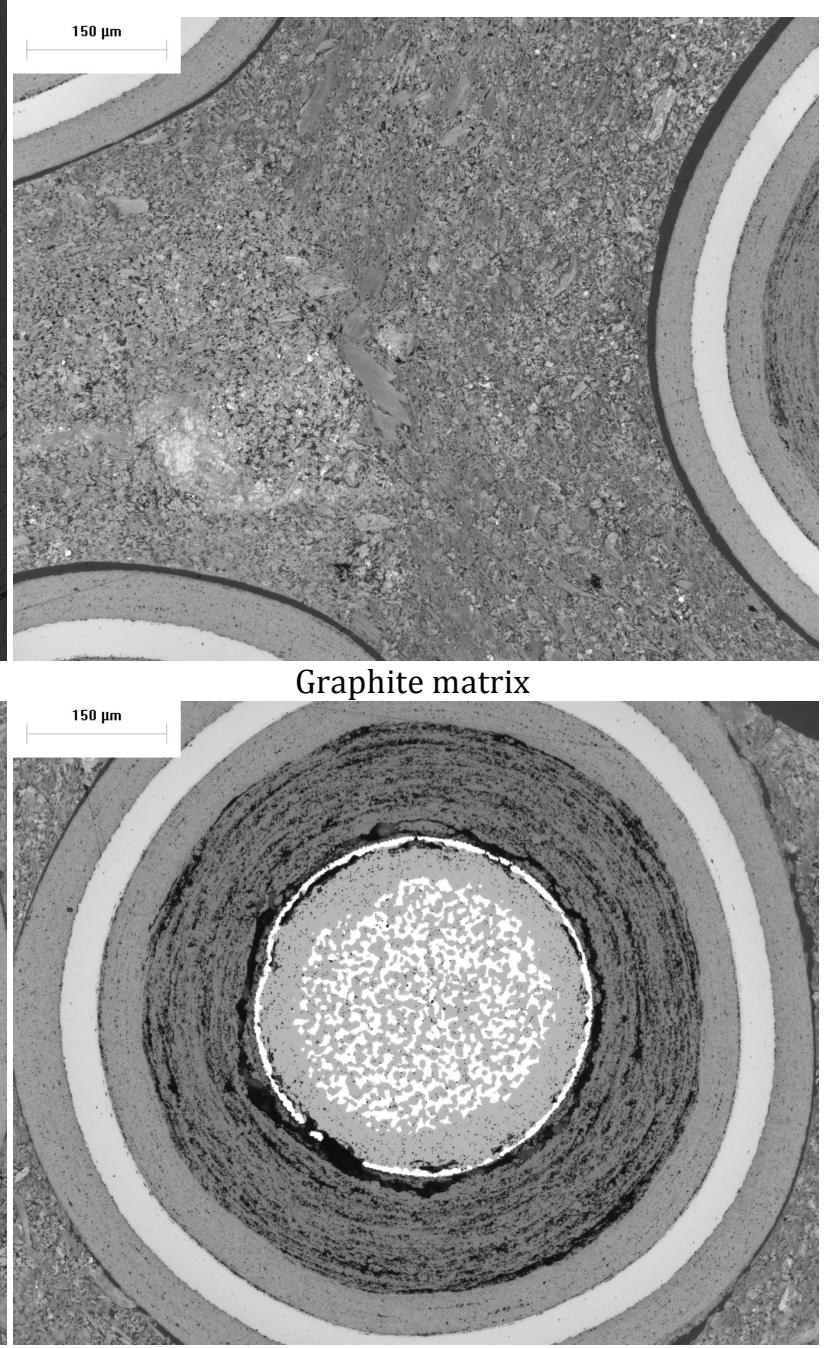

Example particle 2

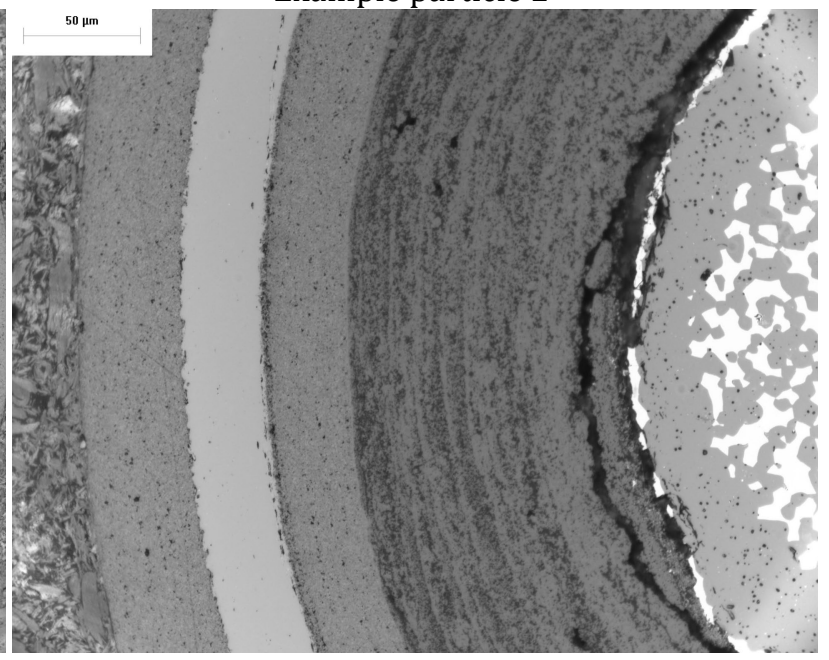

Particle 3 ROI close-up 
Appendix C-3. Images of polished sections of archive compacts from LEU09-OP2-Z.

LEU09-0P2-Z005 - Longitudinal Section
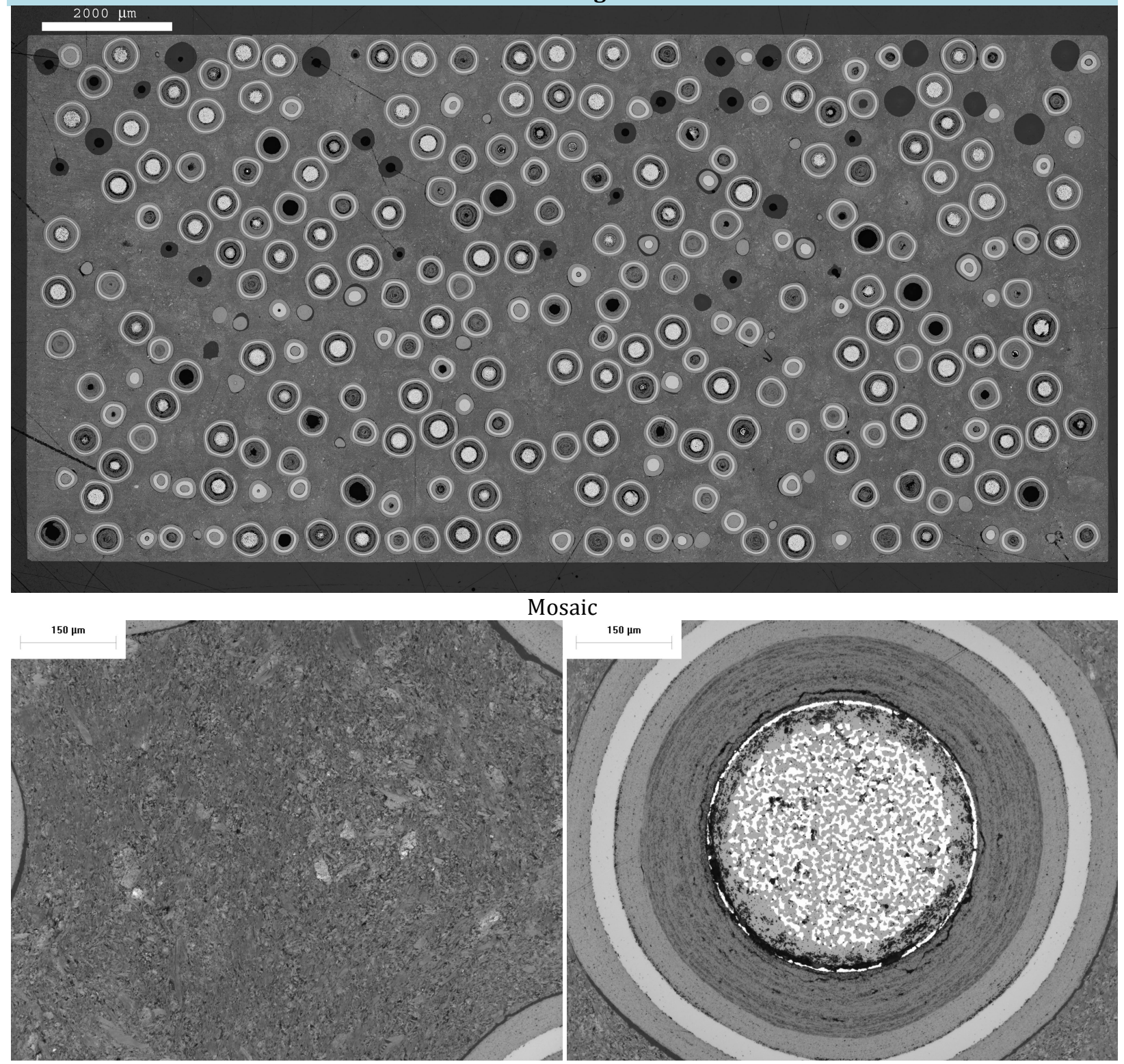

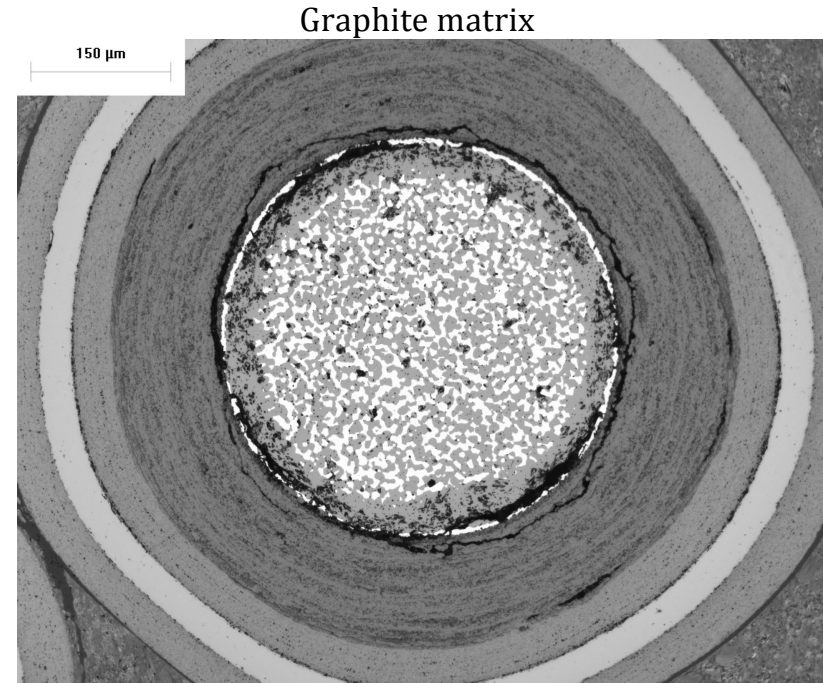

Example particle 2
Example particle 1

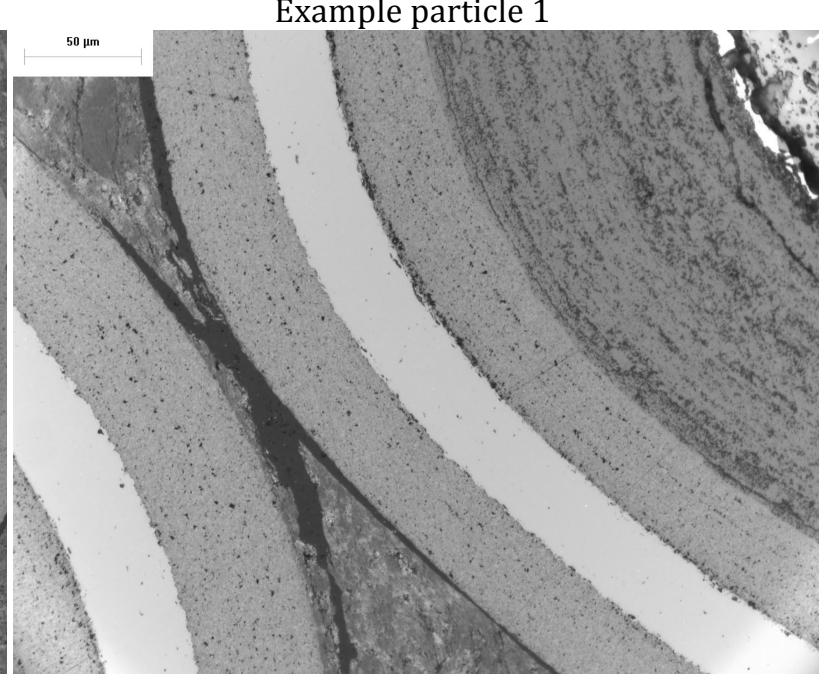

Particle 2 ROI close-up 
Appendix C-4. Images of polished sections of archive compacts from LEU11-OP2-Z.

Appendix C-4 contains microscope images of polished sections taken from compact lot LEU11-OP2-Z. The compacts are identified by the compact ID number, which can be traced back to the fabrication record for each compact. These compacts are representative of those that were inserted into the AGR-2 irradiation test. 
LEU11-0P2-Z062 - Lateral Section 1
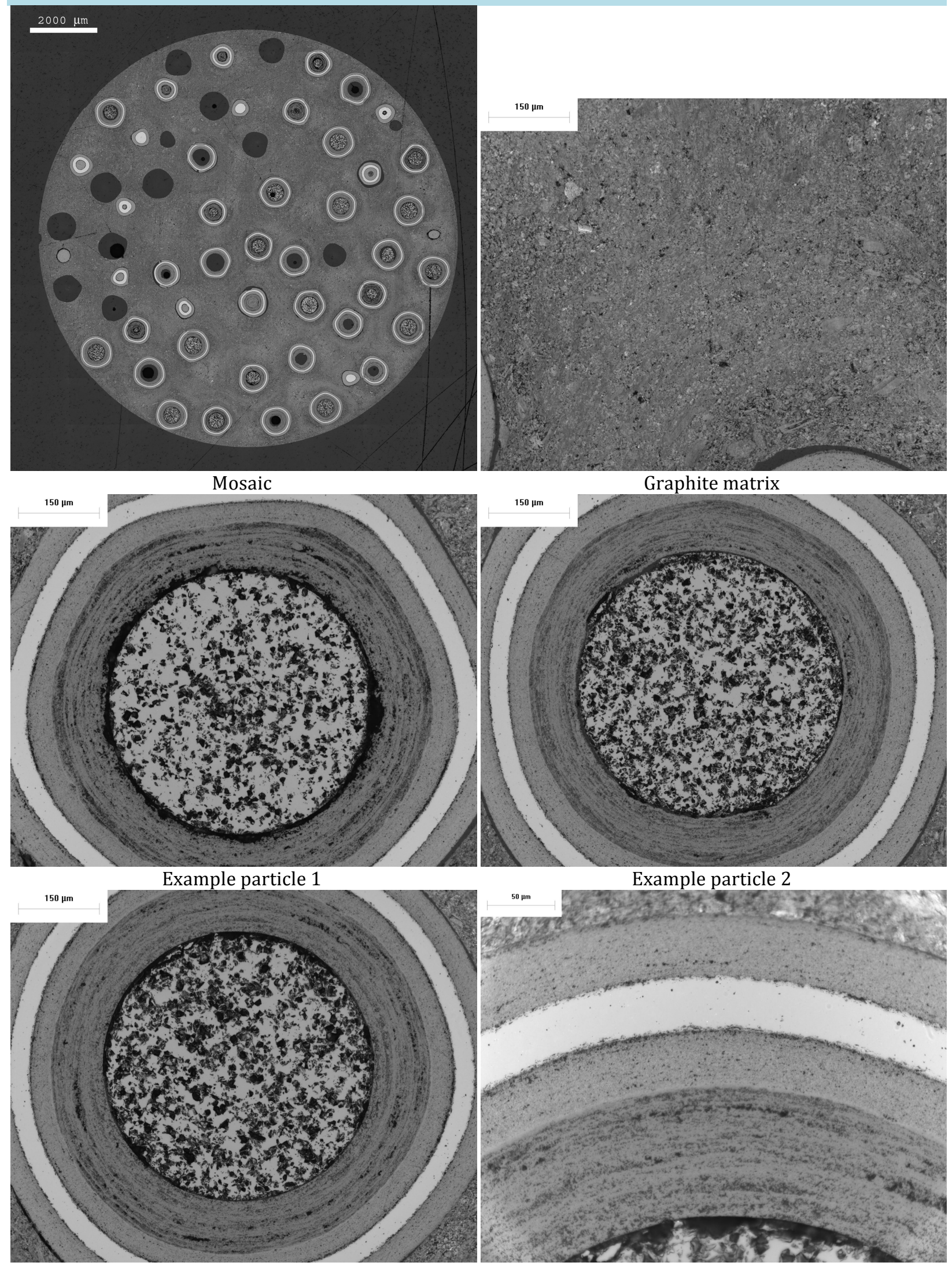

Example particle 3

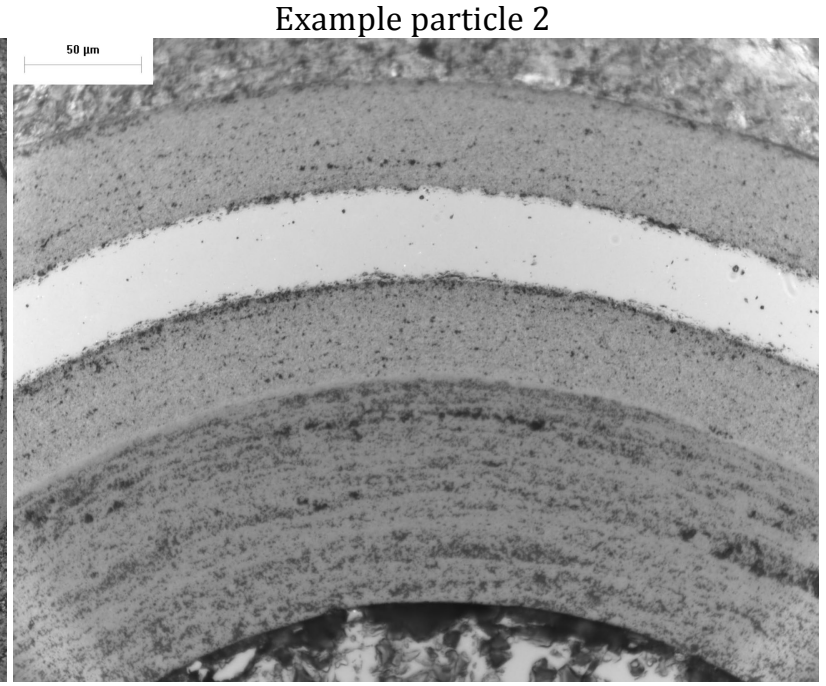

Particle 3 ROI close-up 
LEU11-0P2-Z062 - Lateral Section 2
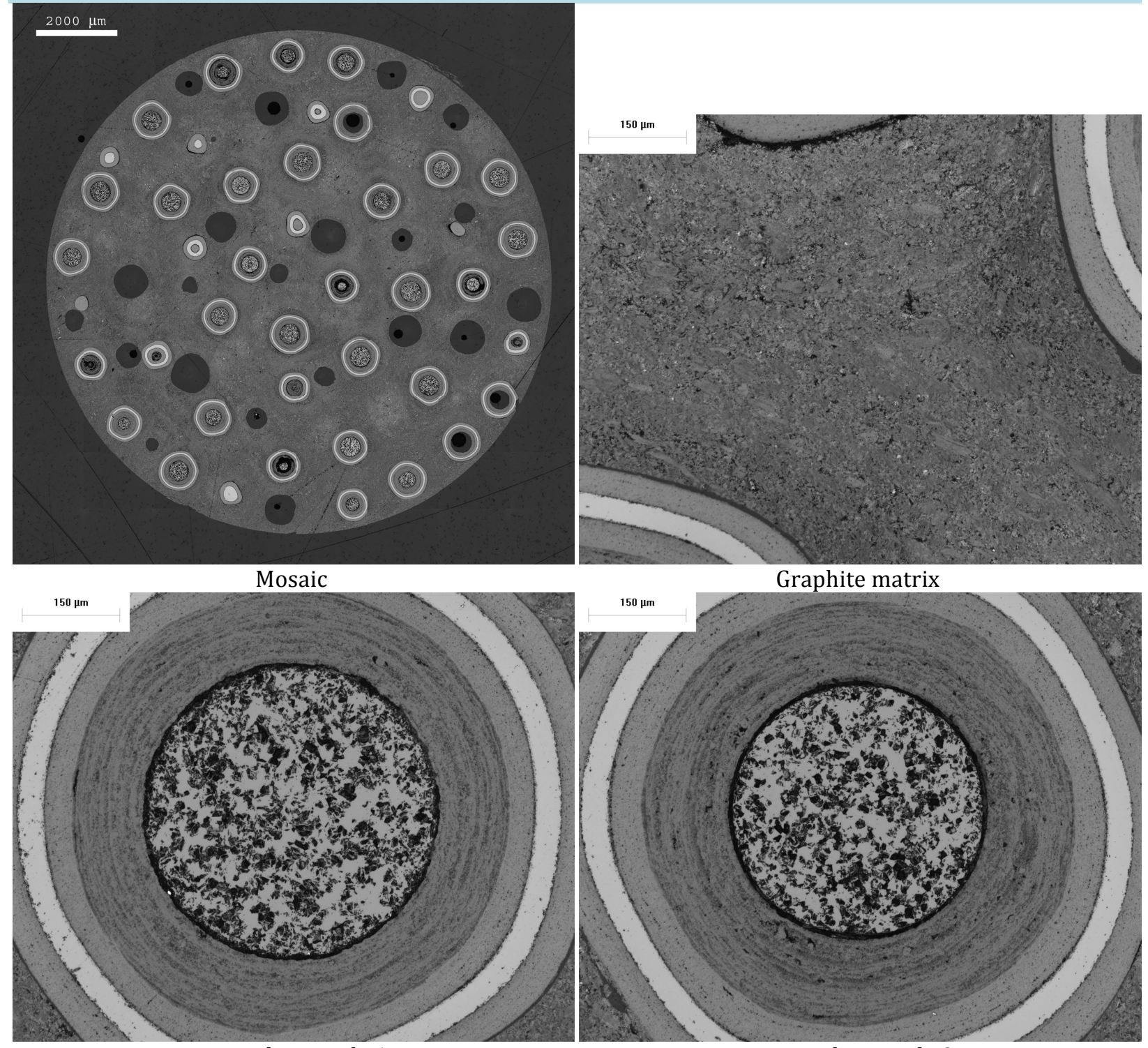

Example particle 1

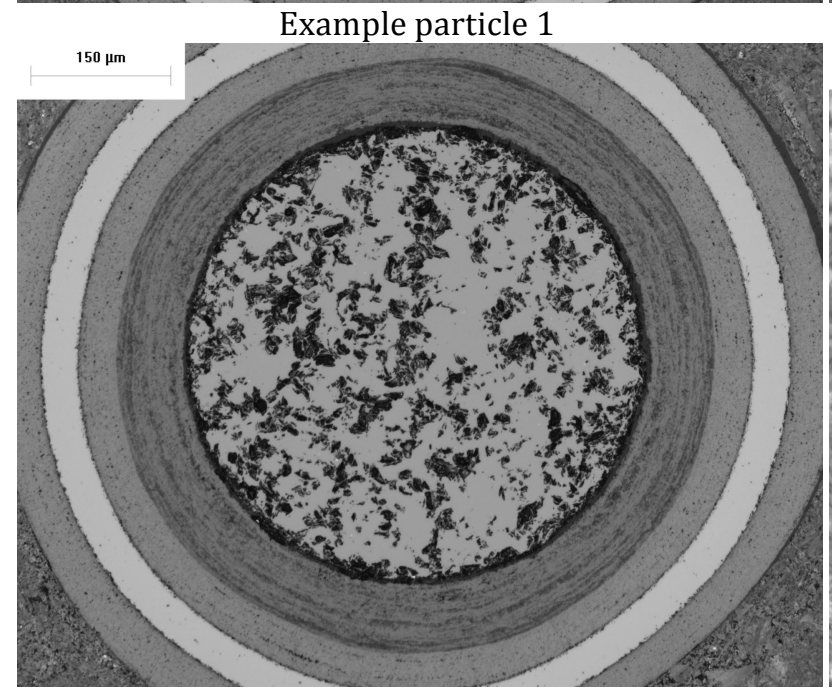

Example particle 3

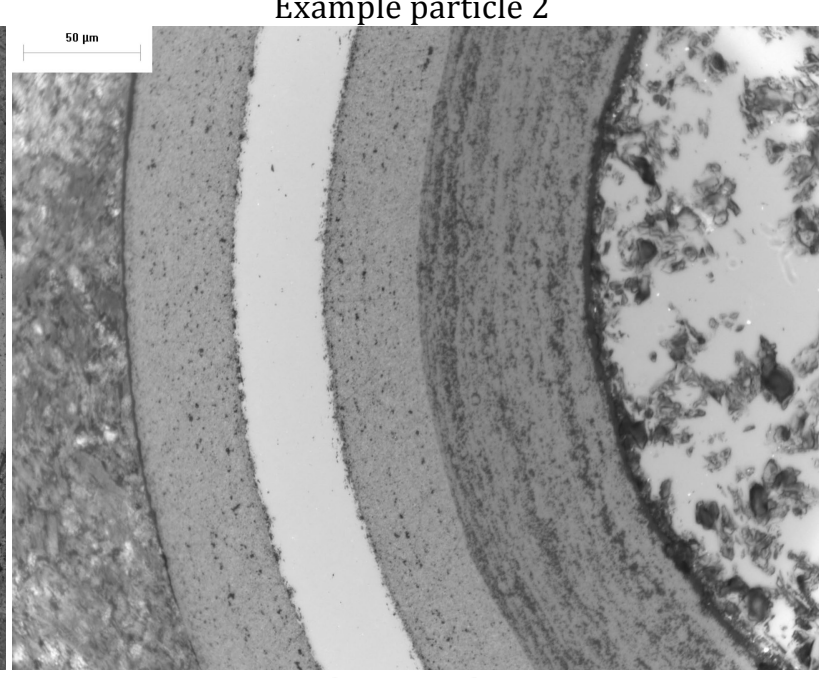

Particle 3 ROI close-up 

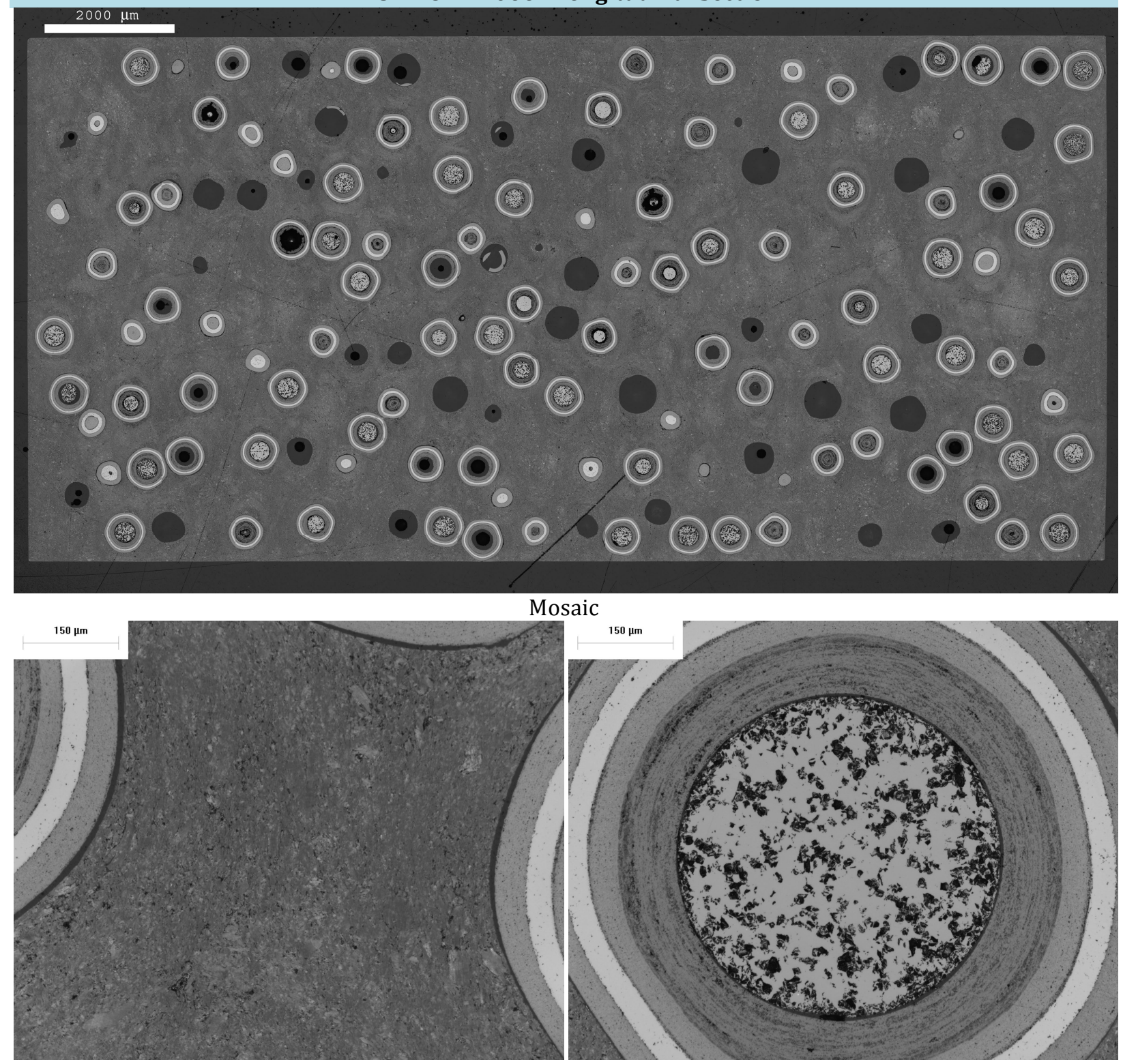

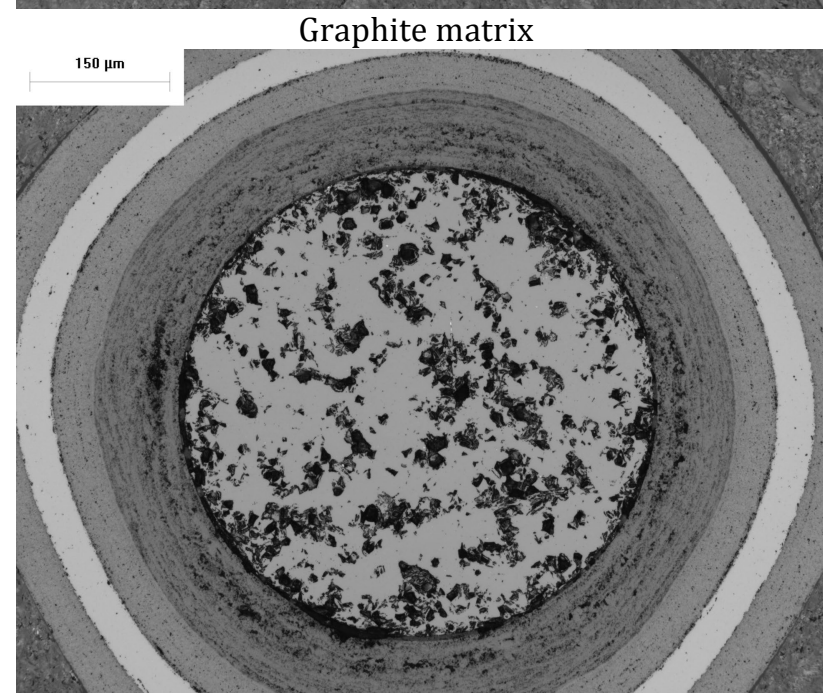

Example particle 2
Example particle 1

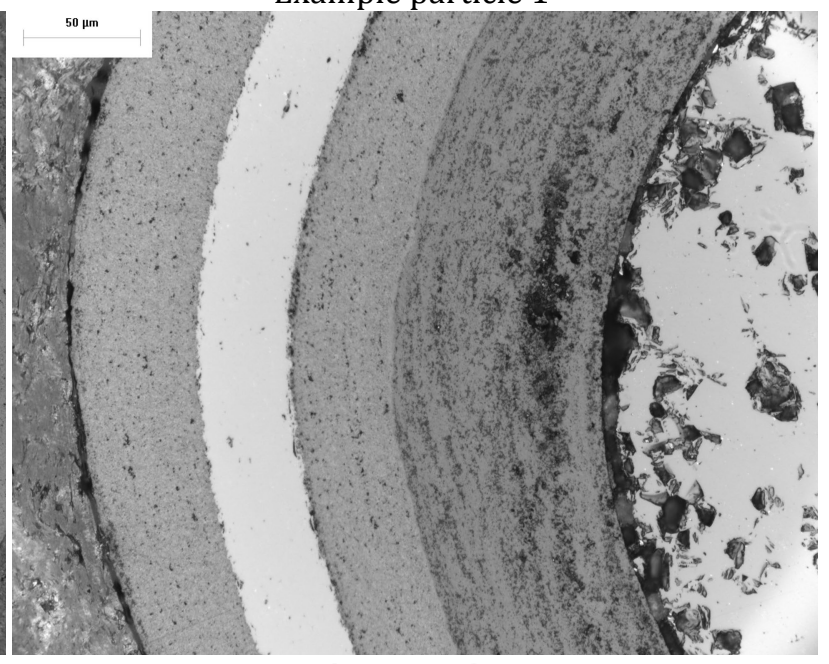

Particle 2 ROI close-up 